\title{
THERMOSYPHON FLOODING IN REDUCED GRAVITY ENVIRONMENTS
}

\author{
by \\ Marc Andrew Gibson \\ Submitted in partial fulfillment of the requirements \\ For the degree of Master of Science \\ Thesis Advisor: Dr. Joseph M. Prahl \\ Department of Mechanical and Aerospace Engineering \\ Case Western Reserve University
}

January 2013 


\section{Case Western Reserve University School of Graduate Studies}

We hereby approve the thesis of

Marc Andrew Gibson

candidate for the Master of Science degree*.

(signed) Dr. Joseph Prahl

(chair of the committee)

Dr. Yasuhiro Kamotani

Dr. Paul Barnhart

Lee Mason

(date) $11 / 19 / 2012$

*We also certify that written approval has been obtained for any proprietary material contained therein. 


\section{$\underline{\text { Table of Contents }}$}

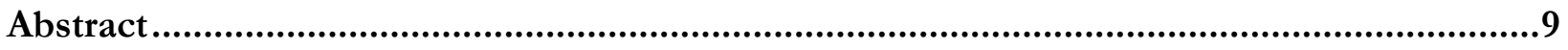

Chapter 1: Introduction ............................................................................................. 10

1.1 Heat Rejection of Nuclear Power Systems for Planetary Surface Applications............................. 10

1.2 Themosyphons, Heat Pipes, and the effects of Gravity .......................................................... 15

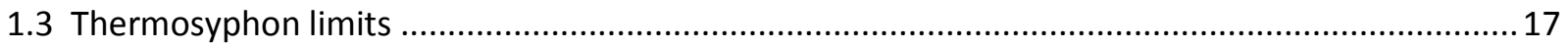

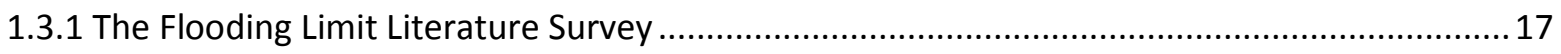

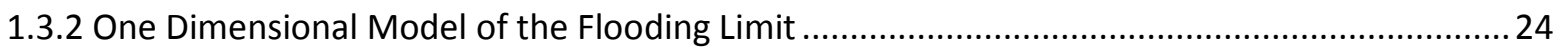

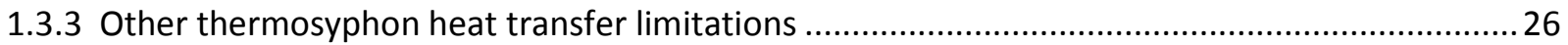

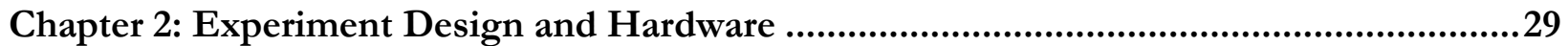

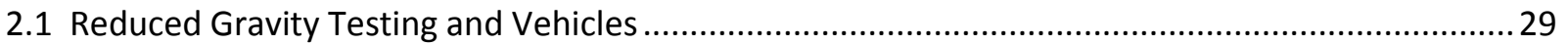

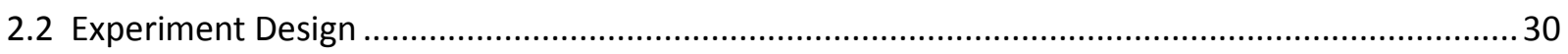

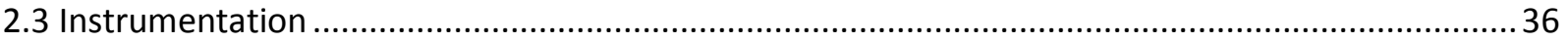

Chapter 3: Ground Testing in Earth's gravity ..................................................................39

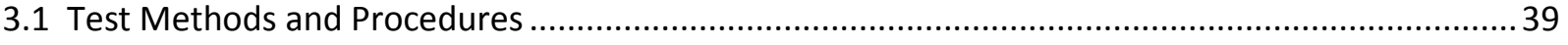

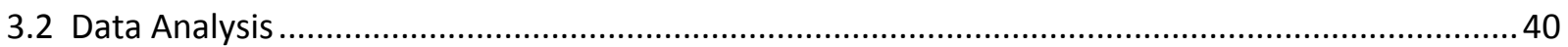

Chapter 4: Reduced Gravity Testing ......................................................................4 47

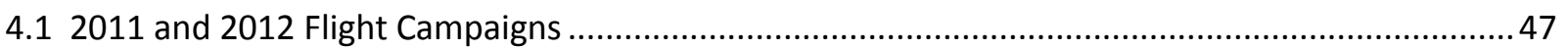

4.2 Reduced Gravity Data Analysis .................................................................................................. 51

Chapter 5: Data Correlation..........................................................................................55

5.1 Non-dimensional Analysis and Data Correlation ........................................................................ 55

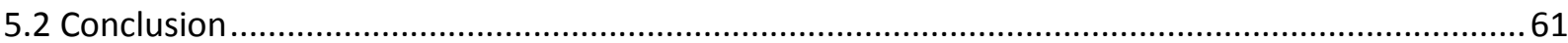

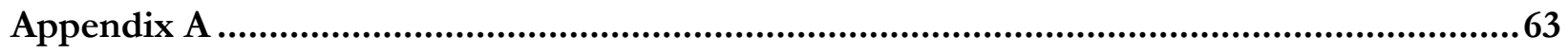

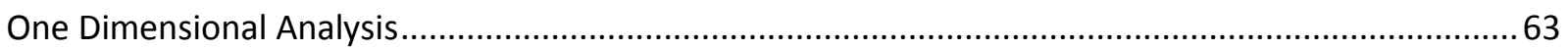

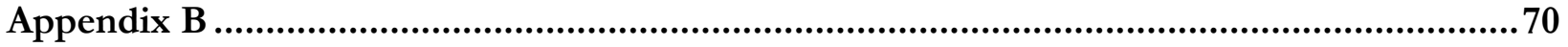

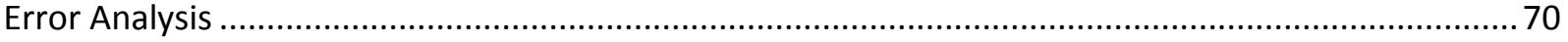

Appendix C ................................................................................................................78

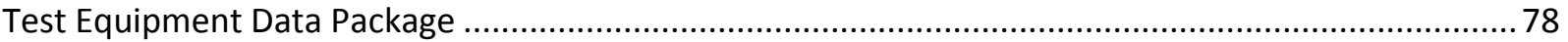




\section{$\underline{\text { List of Tables }}$}

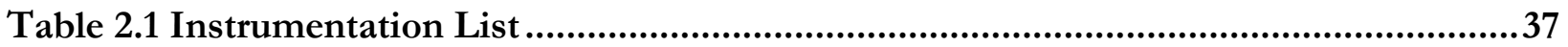

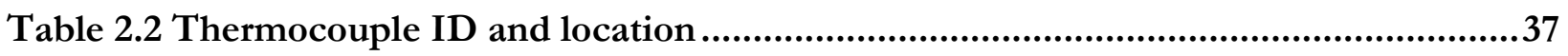

Table B.1 Lunar parabolic flight data and statistical analysis ........................................76

Table B.2 1g Laboratory data and statistical analysis .................................................77 


\section{$\underline{\text { List of Figures }}$}

Figure 1.1 Notional 40kWe Fission Surface Power System............................................. 11

Figure 1.2 Photograph and infrared image of a $1.7 \mathrm{~m} \times 2.7 \mathrm{~m}$ full scale fission surface power radiator. The IR image shows 16 thermosyphons isothermally spreading heat to the radiator

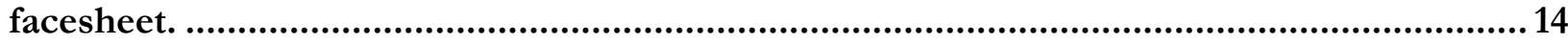

Figure 1.3 Illustration of a fully wicked heat pipe ...........................................................15

Figure 1.4 Illustration of Condenser Flooding .............................................................. 18

Figure 1.5 Faghri and Tien and Chung correlations of the thermosyphon flooding limit for

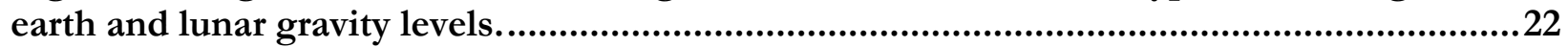

Figure 1.6 Expected thermosyphon performance of a Fission Power System on the lunar surface vs. current thermosyphon flooding models from Faghri and Tien and Chung........23

Figure 1.7 One dimensional Diagram of a thermosyphon ............................................25

Figure 1.8 Thermosyphon heat transfer limits using experiment thermosyphon geometry ..28

Figure 2.1 Thermosyphon Components ............................................................................32

Figure 2.2 Top: National Instruments PXI Data System and electrical controls; Bottom: Screen shot of flight software showing critical information and controls for all twelve

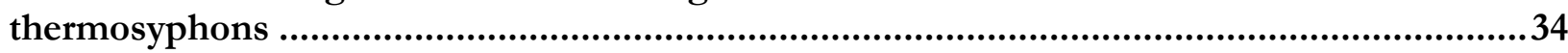

Figure 2.3 Thermosyphon flooding experiment payload...................................................35

Figure 2.4 Thermocouple Location Diagram ...........................................................38

Figure 3.1 Graphical representation of two different methods used to approach the flooding

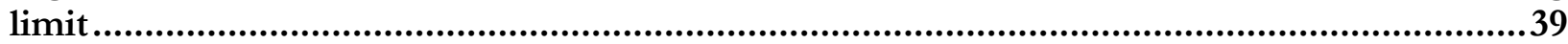

Figure 3.2 Typical 1-g flooding event using the constant power method. .......................... 41

Figure 3.3 Initial $1 \mathrm{~g}$ test data showing scattered results caused by fluid charge differences 42

Figure 3.4 Initial individual thermosyphon flooding limits showing dissimilar results during fluid charge investigation ........................................................................................43

Figure 3.5 Effect of fluid charge on thermosyphon flooding limit ......................................44

Figure 3.6 Flooding limit of correctly filled thermosyphons using $2.0 \mathrm{~g}$ of water................45

Figure 4.1 G-Force One aircraft and 2011 research teams..............................................4 47

Figure 4.2 Pre-flight test readiness review at the reduced gravity office, Ellington Field. ...49

Figure 4.3 Thermosyphon Flooding Experiment ....................................................50

Figure 4.4 Flooding event data of thermosyphon number 8 taken during Martian and lunar gravity parabolas in Sept. 2011 ...................................................................................52

Figure 4.5 "First parabola flood" depicting 3 key events. 1) Lunar gravity forces decrease mass flow, heater temperature increases, upper evaporator temperature decreases. 2) Flooding occurs and heat transfer is stalled, slope change shows increase in heater temperature rate, no sign of recovery. 3) Hyper-g forces flooded fluid back to evaporator and cools heater until next parabola. .53 
Figure 4.6 Parabolic flooding data during Lunar gravity compared to predictive models ....54

Figure 5.1 Non-dimensional parameter $q$ from the original Faghri model vs. nondimensional q test data at $1 \mathrm{~g}$, top, and Lunar gravity, bottom.

Figure 5.2 New non-dimensional Flooding Correlation " $q$ " showing gravity independence

Figure 5.3 New Thermosyphon Flooding Correlation vs. 1g Test Data ................................58

Figure 5.4 New Thermosyphon Flooding Correlation vs. Parabolic Lunar Test Data .........59

Figure 5.5 New thermosyphon flooding model, expected performance of an FPS thermosyphon on the lunar surface, and existing flooding models....................................62

Figure A.1 One dimensional Diagram of the thermosyphon ...........................................64

Figure A.2 Top: One dimensional analysis of the thermosyphon axial power limits vs. several $\delta \boldsymbol{l}$ ratios. Bottom: Non-dimensional power parameter " $\mathrm{q}$ " from the one dimensional analysis as compared to different values of $\delta \boldsymbol{l}$ and the latest flooding model.....................69

Figure B.1 Standard deviation of the $1 \mathrm{~g}$ and Lunar test data compared to the new flooding

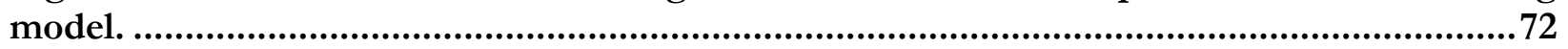

Figure B.2 3 axis accelerometer data during typical lunar gravity parabolas......................73

Figure B.3 The $95 \%$ confidence interval for the $1 \mathrm{~g}$ and lunar model .................................75 
Acknowledgements

I would like to thank, first and foremost, my wife and children for their support, understanding, and tolerance to the numerous hours spent studying. Dr. Prahl for his personal guidance and patience throughout the fluids coursework, extended office hours, and master's thesis process. Lee Mason for his support throughout the development and testing of the experiment and for providing the freedom to allow the author to conduct the research for two consecutive flight campaigns. Our experiment flight crew; Jim Sanzi, Damir Ljubanovic, and Don Jaworske for their expertise and hard work. The thermal energy conversion branch at the NASA Glenn Research Center for providing the tuition reimbursement to complete the graduate program. The Flight Opportunities Program for providing the parabolic flights and unforgettable memories. The Reduced Gravity Office for their professionalism and leadership during flight operations. 


\section{$\underline{\text { Nomenclature }}$}

\begin{tabular}{|c|c|}
\hline$h_{f g}$ & Heat of vaporization \\
\hline$A_{i}$ & Area \\
\hline$A_{v}$ & Vapor area \\
\hline$B_{o}$ & Bond number \\
\hline$C_{K}$ & Dimensionless Constant, Tien and Chung \\
\hline$C_{W}$ & Dimensionless Constant, Wallis \\
\hline$K_{c}$ & Thermal conductance $(\mathrm{W} / \mathrm{K})$ \\
\hline$j_{i}$ & Wallis velocity parameter $(\mathrm{m} / \mathrm{s})$ \\
\hline$\dot{m}$ & Mass flow rate $(\mathrm{kg} / \mathrm{s})$ \\
\hline$u_{i}$ & Velocity (m/s) \\
\hline$\mu_{i}$ & Dynamic Viscosity (Pa s) \\
\hline$v_{i}$ & Kinematic Viscosity $\left(\mathrm{m}^{\wedge} 2 / \mathrm{s}\right)$ \\
\hline$\rho_{L}$ & Density of the liquid \\
\hline$\rho_{V}$ & Density of the vapor \\
\hline$\sigma_{S}$ & Stefan Boltzmann Constant $\left(5.67 \mathrm{E}-8 \mathrm{~W} / \mathrm{m}^{\wedge} 2 \mathrm{~K}^{\wedge} 4\right)$ \\
\hline$\tau_{i}$ & Shear Stress (Pa) \\
\hline $\mathrm{C}$ & Degrees Celsius \\
\hline $\mathrm{D}$ & Thermosyphon inner diameter \\
\hline $\mathrm{DAC}$ & Data Acquisition and Control \\
\hline FOP & Flight Opportunities Program \\
\hline FPF & First Parabola Flood \\
\hline FPS & Fission Power System \\
\hline FSP & Fission Surface Power \\
\hline g & Acceleration of gravity $\left(\mathrm{m} / \mathrm{s}^{\wedge} 2\right)$, grams \\
\hline GCD & Game Changing Development \\
\hline GRC & Glenn Research Center \\
\hline $\mathrm{Hz}$ & Hertz \\
\hline JSC & Johnson Space Center \\
\hline K & Dimensionless Constant, Kutateladze and Faghri \\
\hline $\mathrm{kW}$ & Kilowatt \\
\hline $\mathrm{L}$ & Thermosyphon Length \\
\hline W & Thermosyphon Width \\
\hline 1 & Thermosyphon inner radius \\
\hline $\mathrm{m}$ & meter \\
\hline $\mathrm{N}$ & Newton \\
\hline OCT & Office of the Chief Technologist \\
\hline $\mathrm{P}$ & Pressure \\
\hline Q & Thermal Power (Watts) \\
\hline q & Dimensionless power \\
\hline $\mathrm{r}$ & Density Ratio $\rho_{v} / \rho_{l}$ \\
\hline RGE & Reduced Gravity Environment \\
\hline RGO & Reduced Gravity Office \\
\hline s & seconds \\
\hline
\end{tabular}




$\begin{array}{ll}\text { SrLV } & \text { Suborbital re-useable Launch Vehicle } \\ \text { T } & \text { Temperature } \\ \text { TC } & \text { Thermocouple } \\ \text { TEDP } & \text { Test Equipment Data Package } \\ \text { TRL } & \text { Technology Readiness Level } \\ \text { TRR } & \text { Test Readiness Review } \\ \text { V } & \text { Volts } \\ \mathrm{W} & \text { Watts } \\ \delta & \text { Liquid thickness }(\mathrm{m}) \\ \varepsilon & \text { emissivity } \\ \sigma & \text { Surface Tension }(\mathrm{N} / \mathrm{m}) \\ \sigma_{d} & \text { Standard deviation } \\ \Phi(z) & \text { Cumulative normal distribution function } \\ \mathrm{z} & \text { Statistical parameter } \\ \mathrm{N} & \text { Statistical sample size } \\ \alpha & \text { Confidence parameter } \\ \mathrm{i} & \text { Subscript used to denote individual variables for certain nomenclature }\end{array}$




\title{
Thermosyphon Flooding in Reduced Gravity Environments
}

\author{
Abstract \\ by \\ MARC ANDREW GIBSON
}

An innovative experiment to study the thermosyphon flooding limits was designed and flown on a parabolic flight campaign to achieve the Reduced Gravity Environments (RGE) needed to obtain empirical data for analysis. Current correlation models of Faghri and Tien and Chung do not agree with the data. A new model is presented that predicts the flooding limits for thermosyphons in earth's gravity and lunar gravity with a $95 \%$ confidence level of $+/-5 \mathrm{~W}$. 


\section{Chapter 1: Introduction}

\subsection{Heat Rejection of Nuclear Power Systems for Planetary Surface Applications.}

Fission Power Systems (FPS) have long been recognized as potential multi-kilowatt power solutions for lunar, Martian, and extended planetary surface missions. Current heat rejection technology associated with fission surface power systems has focused on titanium water thermosyphons embedded in carbon composite radiator panels. The thermosyphons, or wickless heat pipes, are used as a redundant and efficient way to spread the waste heat from the power conversion unit(s) over the radiator surface area where it can be rejected to space. It is well known that thermosyphon performance is reliant on gravitational forces to keep the evaporator wetted with the working fluid.

One of the performance limits that can be encountered, if not understood, is the phenomenon of condenser flooding. This occurs when the gravity forces acting on the condensed fluid cannot overcome the shear forces created by the vapor escaping the evaporator throat. When this occurs, the heat transfer process is stalled and may not re-stabilize to effective levels without corrective control actions. The flooding limit in earth's gravity environment has been studied as experimentation is readily accessible, but when the environment and gravity change relative to other planetary bodies, experimentation becomes difficult.

Fission power can provide decades of uninterrupted power, day or night, making them especially attractive where solar intensity is limited or non-existent. Typically, 30 to 40 percent of the reactor heat gets converted to electricity and the remaining 60 to 70 percent gets rejected to space through large surface area heat rejection radiators. Figure 1 provides a graphical representation of a potential 
40-kWe, 186-kWt, Moon-based Fission Surface Power (FSP) system (1) that has a total heat rejection surface area of $184 \mathrm{~m}^{2}$ with over 300 thermosyphons. Unique to surface power systems, when compared to in-space power systems, is the presence of gravity. Gravitational forces are a significant variable in fluid system design and directly impact the amount of power produced and rejected in a FSP system. A pumped water loop is used to transfer the waste heat from the cold side

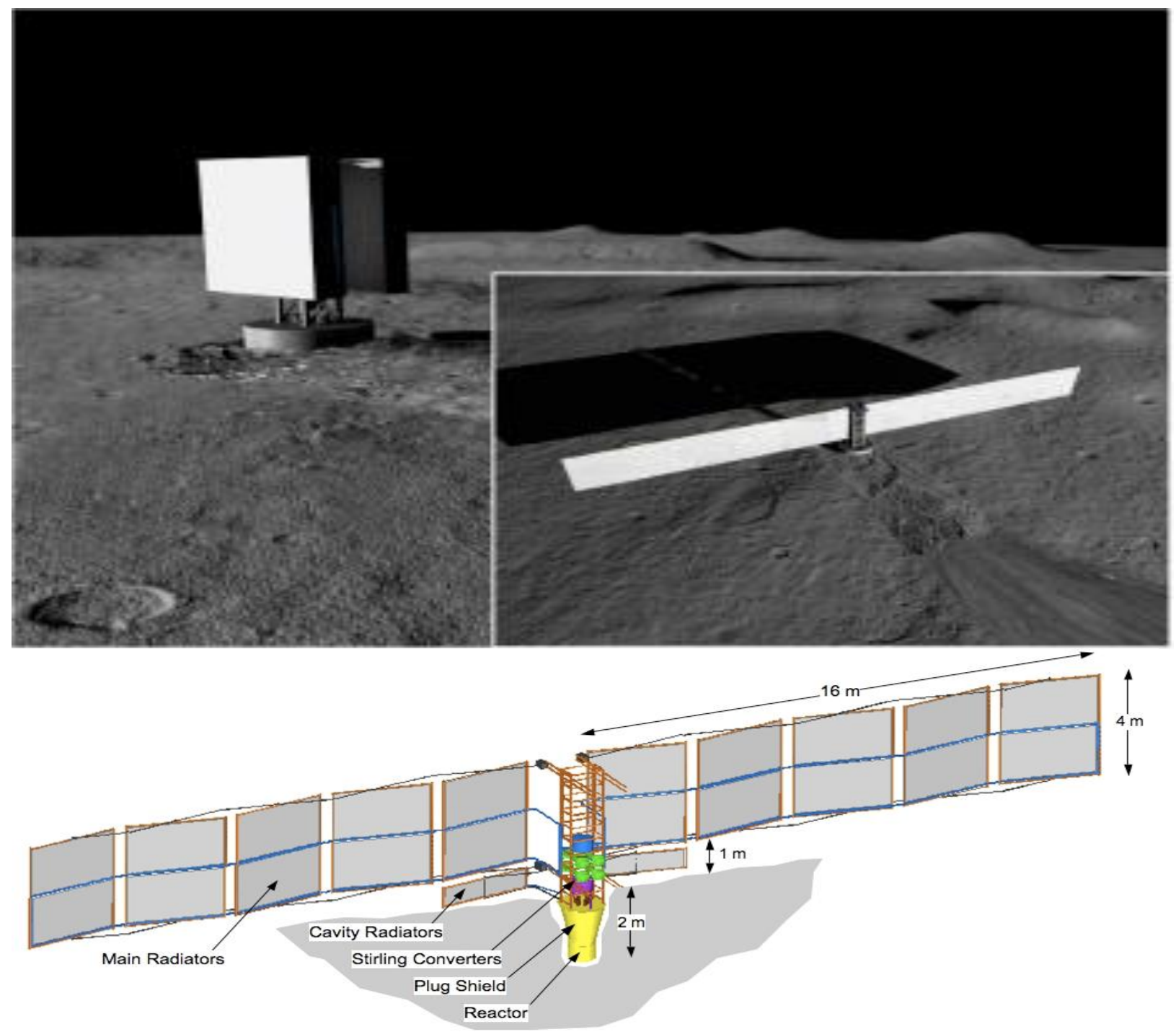

Figure 1.1 Notional 40kWe Fission Surface Power System 
of the Stirling power conversion system to a total quantity of $20(1.7 \mathrm{~m} \times 2.7 \mathrm{~m})$ radiators. The radiators are equipped with heat exchangers to transfer the heat from the pumped water to the individual thermosyphon evaporators. The closed two phase thermosyphons are separate, cylindrical pressure vessels with the sole purpose of transferring the heat from the evaporator to the condenser where an attached fin can radiate the heat to the space environment. This heat transfer is accomplished using the saturated vapor, generated in the evaporator, to create the needed pressure difference to force the vapor up the tube where it can lose its latent heat to the cooler condenser wall. The heat transport capability of the saturated vapor can travel several meters from the evaporator to the condenser making the thermal conductance of thermosyphons several thousand times better than the most conductive materials. This high thermal conductance provides a near isothermal temperature throughout the condenser and allows the heat to be spread over several square meters of radiator area. Figure 1.2 shows an Infrared image and photograph of a full scale FSP radiator with 16 embedded thermosyphons isothermally spreading heat to the radiator facesheet.

In the FSP concept, the heat rejection system must reject approximately $120-\mathrm{kWt}$ using the energy balance between the convective pumped loop and the radiation heat transfer according to the following generalized convective and radiation equations where the pumped loop convection is Qin and the radiation rejection is Qout. The thermosyphons are denoted as Qtransport and are required to transport the heat from the pumped loop to the radiator surface. It is important to note that the pumped loop and thermosyphons are two separate pressure systems using the same working fluid, de-ionized water, and $\dot{m}_{P L}$ refers to the mass flow of the Pumped Loop and $\dot{m}_{T}$ refers to the mass flow within the Thermosyphon. With these pressure systems being separate, different working fluids could be used for different applications. 


$$
\begin{aligned}
& Q_{\text {in }}=\dot{m}_{P L} C_{p}\left(T_{m i}-T_{m o}\right) \\
& Q_{\text {transport }}=\dot{m}_{T} h_{f g} \\
& Q_{\text {out }}=\sigma_{S} \varepsilon A_{R}\left(T_{R}^{4}-T_{S}^{4}\right)
\end{aligned}
$$

The thermosyphons must be able to transfer the required amount of thermal power axially down their length without encountering any heat transfer limitations of the two phase system. This research was aimed at studying the heat transfer limitations of thermosyphons in earth's gravity, as well as RGE, with the end goal of providing a model that will accurately predict where the maximum limitations occur. Because these limits have never been verified in RGE, potential inaccuracies of the current models could lead to problems in transporting the required thermal power through the thermosyphons when located on other planets. Should the heat transfer from the pumped loop to the radiative surface become decreased or stalled, the power system may not be able to deliver its required power output. 

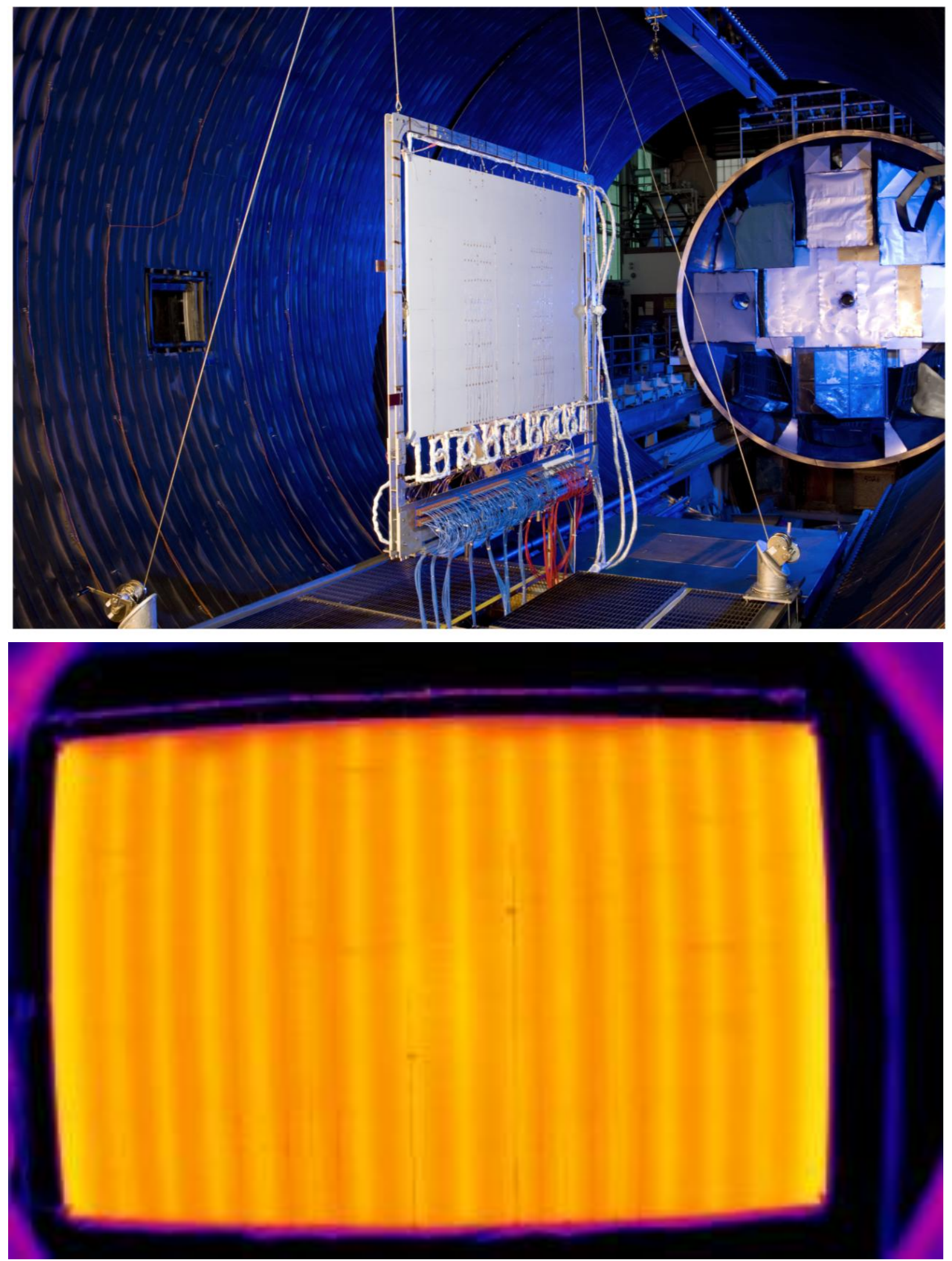

Figure 1.2 Photograph and infrared image of a $1.7 \mathrm{~m}$ x $2.7 \mathrm{~m}$ full scale fission surface power radiator. The IR image shows 16 thermosyphons isothermally spreading heat to the radiator facesheet. 


\subsection{Thermosyphons, Heat Pipes, and the effects of Gravity}

Thermosyphons are categorized as wickless heat pipes and rely on gravitational forces to pull the condensed fluid back to the evaporator, which is always positioned below the condenser. A fully wicked heat pipe uses the capillary pressure generated in the wick to pump the fluid back to the evaporator, in any position, with or without the help of gravity. Figure 1.3 illustrates the functional aspects of a fully wicked heat pipe. A thermosyphon is identical, other than there is no wick present to provide capillary forces, thus leaving gravity as the sole restoring force. When the fluid condenses to the thermosyphon wall it must overcome the same pressure force that originally pushed the vapor

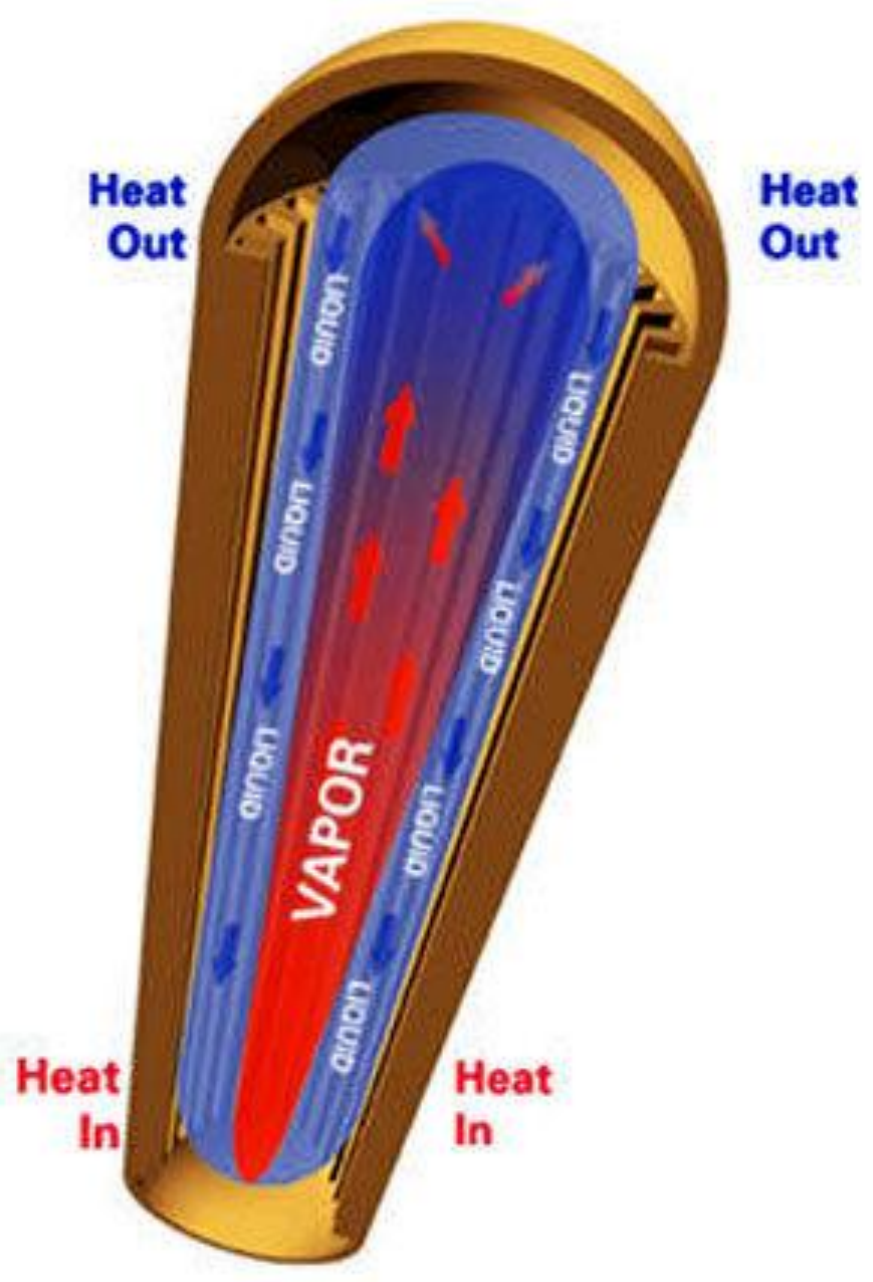

Figure 1.3 Illustration of a fully wicked heat pipe 
up the tube. In addition, the viscous forces between the two phases begins to retard the motion of the fluid returning to the evaporator as the liquid layer grows and the vapor area is reduced. In order for the fluid to overcome these forces and descend back to the evaporator to start the cycle over, gravitational forces must be present in a thermosyphon. The overall heat transport capability of heat pipes and thermosyphons is constrained by the simple expression below where Q is the overall power throughput. Later sections will show just how difficult it is to predict the mass flow rate amongst the many governing variables, one of which is gravity.

$$
Q=\dot{m} h_{f g}
$$

As gravity is reduced, the mass flow rate of the fluid returning to the evaporator decreases and ultimately reduces the heat transport capability of the device. As the mass flow decreases, the evaporator temperature increases while the condenser temperature decreases, causing a larger temperature difference across the device and thus a lower thermal conductance. The heat input at the evaporator must re-balance with the heat output at the condenser to stabilize the heat transfer. The thermal conductance of the device can be evaluated using the following equation.

$$
K_{c}=\frac{Q}{\left(T_{e}-T_{c}\right)}
$$

The thermosyphon working fluid is specifically chosen, based on its thermophysical properties, to operate in the desired temperature range, typically determined through trade studies of the total system specific power $(\mathrm{W} / \mathrm{kg})$ of the system. When gravity forces are present, such as on the surface of the moon or Mars, thermosyphons can trade better than heat pipes because they do not have a wick structure in the condenser and may ultimately have a lower mass. This trade must be taken into 
careful consideration as the additional mass of the heat pipe wick can be balanced by the increased power the wick gives the heat pipe in reduced gravity.

\subsection{Thermosyphon limits}

There are a few main heat transfer limits that will influence the amount of thermal power that can be transferred by thermosyphon. The boiling limit, viscous limit, sonic limit, and flooding limit are the most important recognized limitations that have been extensively studied and have been included for a full evaluation. It is important to evaluate each heat transfer limit to fully understand the results and determine what limit the thermosyphons reach during the experiment. The flooding limit will be extensively discussed in section 1.3.1 and 1.3.2 as it is the main focus of this research. A generalized discussion and analysis of the other limitations will also be included in section 1.3.3 to give the reader adequate background information that may influence other thermosyphon designs and applications.

\subsubsection{The Flooding Limit Literature Survey}

The flooding limit is heavily influenced by gravity forces and can stall the heat transfer process of a thermosyphon during operation. Flooding can typically occur throughout the majority of the thermosyphon temperature range making it the most often encountered heat transfer limit. The flooding limit occurs when the shear forces from the counter current flow between the vapor and liquid overpowers the gravity forces required to keep the evaporator wetted with the working fluid. This will occur near the top of the evaporator were the liquid layer is at its thickest point and the vapor is traveling through the local minimized cross sectional area at its peak velocity (Figure 1.4). 

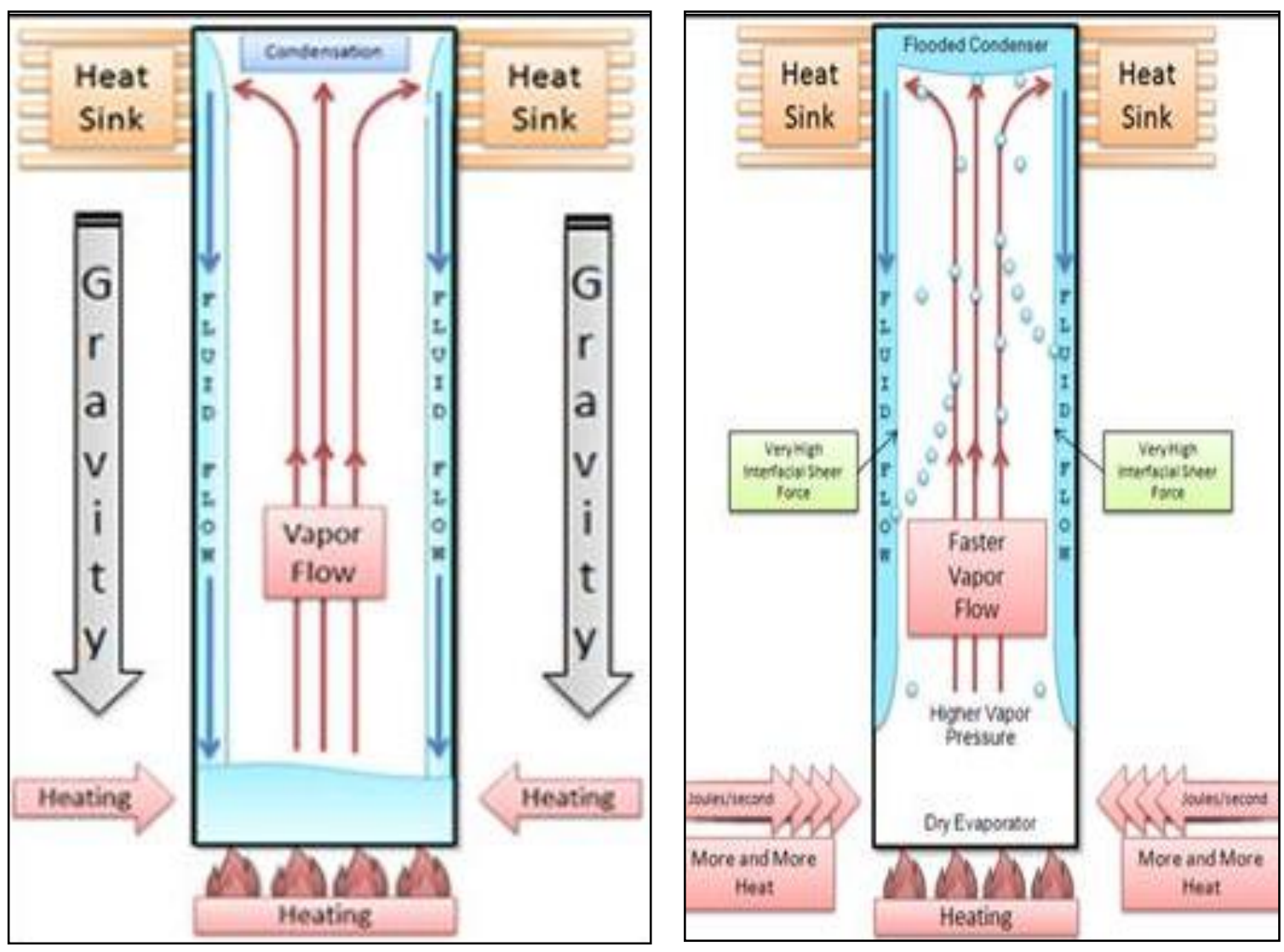

Figure 1.4 Illustration of Condenser Flooding

This creates a liquid orifice that will eventually be broken by the vapor shear force interacting with the liquid boundary. When this occurs, the fluid can form wave instabilities which can then become torn away from the liquid layer and be transported up to the condenser. This phenomenon has been called flooding because it floods the condenser with the working fluid. When wicks are present, a similar event occurs, identified as entrainment, that differs only in the fact that the capillary effect of the wick can influence the wave instability and make it harder for the vapor to rip the liquid from the wick structure. In some cases reports have indicated that this entrained fluid can be heard as the fluid particles hit the end cap. With small diameter thermosyphons, it may also be possible that the instabilities of the liquid layer near the flooding limit may cause the fluid to close off the vapor space. This would cause all the fluid in the adiabatic and condenser sections to flood the condenser 
and be held there until the pressure in the evaporator subsides, allowing the fluid to return to the condenser. In either case, flooding will cause a stall in the mass flow rate allowing the evaporator to overheat and dryout. When this happens the evaporator temperatures can rapidly increase and cause high pressure conditions inside the thermosyphon which may eventually lead to a rupture in the container wall. During experimentation, careful detection methods must be used to keep the evaporator temperature limits within manageable levels.

A literature review concerning thermosyphon flooding was examined to determine if there were existing formulas and correlations that would adequately predict the phenomenon. It was important to find a predictive model that did not require test results to form the correlation coefficients as predictions of the axial thermal power and the associated thermosyphon diameter would need to be determined beforehand. It was also important that the models be verified experimentally with water as the working fluid, and if possible with smaller diameter thermosyphons. Using these constraints, the initial research led to two models developed by Faghri et al. (2) and Tien and Chung (3).

$$
\begin{gathered}
\text { Tien and Chung } \dot{\mathrm{Q}}_{\max }=\mathrm{C}_{\mathrm{K}}^{2} \mathrm{~h}_{\mathrm{fg}} \mathrm{A}_{\mathrm{v}}\left[\mathrm{g} \sigma\left(\rho_{\mathrm{L}}-\rho_{\mathrm{V}}\right)\right]^{1 / 4}\left[\rho_{\mathrm{V}}^{-1 / 4}+\rho_{\mathrm{L}}^{-1 / 4}\right]^{-2} \\
C_{K}=\sqrt{3.2} \tanh \left(0.5 B o^{1 / 4}\right)
\end{gathered}
$$

$$
\begin{gathered}
\text { Faghri: } \quad \dot{Q}_{\max }=K h_{f g} A_{v}\left[g \sigma\left(\rho_{L}-\rho_{V}\right)\right]^{1 / 4}\left[\rho_{V}^{-1 / 4}+\rho_{L}^{-1 / 4}\right]^{-2} \\
K=\left[\frac{\rho_{L}}{\rho_{V}}\right]^{0.14} \tanh ^{2} B_{O}^{1 / 4}=R \tanh ^{2} B_{O}^{1 / 4} \\
B_{o}=D\left[\frac{g\left(\rho_{L}-\rho_{V}\right)}{\sigma}\right]^{\frac{1}{2}}
\end{gathered}
$$


The variable $\dot{Q}_{\max }$ denotes the flooding limit in Watts and depicts the maximum axial heat transfer that can be transported down the length of the thermosyphon. Both sets of equations originate from the work of Wallis (4) and Kutateladze (5) with slight variations between Faghri's variable K and Tien's variable $\mathrm{Ck}$. The non-dimensional forms of these equations are analyzed in chapter 5.

The Wallis correlation used a balance between inertia and hydrostatic forces of open two-phase systems to determine the available axial thermal power in countercurrent flow. The empirically dimensionless constants $m$ and $C w$ are functions of the fluid properties with reported values typically between 0.7 and 1.0. The values $\mathrm{j}_{1}$ and $j_{v}$ are the liquid and vapor volumetric flow rates divided by the vapor area of the thermosyphon.

$$
\begin{gathered}
\left(j_{v}^{*}\right)^{1 / 2}+m\left(j_{\ell}^{*}\right)^{1 / 2}=C_{w} \quad(i=\ell, v) \\
j_{i}^{*}=j_{i} \rho_{i}^{1 / 2}\left[g D\left(\rho_{\ell}-\rho_{v}\right)\right]^{-1 / 2} \\
j_{\ell}=\frac{\dot{m}_{\ell}}{\rho_{\ell} A} \quad j_{v}=\frac{\dot{m}_{v}}{\rho_{v} A}
\end{gathered}
$$

Wallis determined that flooding would occur when $j_{l}=1$ and $j_{v}=0$. In the case of a closed thermosyphon system, $\dot{m}_{l}=\dot{m}_{v}={ }^{q} / h_{f g}$ where $\mathrm{q}$ is the heat flux in $\mathrm{W} / \mathrm{m}^{2}$ and Av is the cross sectional area of the vapor passage. The Wallis correlation for flooding is: 


$$
\text { Wallis } Q=\frac{A_{v} C_{w}^{2} h_{f g} \sqrt{g D\left(\rho_{l}-\rho_{v}\right) \rho_{v}}}{\left[1+\left(\rho_{v} / \rho_{l}\right)^{1 / 4}\right]^{2}}
$$

The Kutateladze number $K_{i}$ is a balance between the dynamic head, surface tension, and gravitational force. The Kutateladze correlation assumes:

$$
\begin{gathered}
\left(K_{v}\right)^{1 / 2}+\left(K_{l}\right)^{1 / 2}=C_{K} \\
K_{i}=j_{i} \rho_{i}^{1 / 2}\left[g \sigma\left(\rho_{\ell}-\rho_{v}\right)\right]^{-1 / 4}
\end{gathered}
$$

Tien and Chung combined the Wallis and Kutateladze correlations assuming that $j_{l}=0$ and $\mathrm{Ck}=$ $\sqrt{3.2}$ based on letting $\mathrm{D}$ equal the critical wavelength of the Taylor Instability. The hyperbolic tangent in Tien and Chung's equation comes from the experimental results of Wallis and Makkenchery (6) in which the Kutateladze number decreases to the dimensionless diameter, or Bond number, giving $\mathrm{Cw}$ as seen in equation (1.11). The Tien and Chung correlation was shown to be accurate within $15 \%$ based on water as the working fluid but was not as accurate for other fluids.

Faghri took note of the fact that the flooding limit with other fluids needed a new dimensionless group as a ratio of the density of the fluid over the density of the vapor. Faghri recombined the correlations to predict the flooding phenomenon per equation (1.08).

Both Faghri's and Tien and Chung's correlations used the Bond number which is believed to be important as the diameter decreases below $0.5 \mathrm{in} .(12.7 \mathrm{~mm})$. The Bond number takes into account the density of the liquid and vapor as well as the surface tension, acceleration of gravity, and the 
diameter of the thermosyphon. Other sources were investigated but many had limited or no correlations with water, had limited or no test results using small diameter thermosyphons, or had equation variables that could only be determined after testing. Figure 1.5 shows the flooding limit using the Faghri and Tien correlations for both earth's gravity and lunar gravity. The graph shows just how different each correlation is when predicting the flooding limit of a thermosyphon. It is also evident that lunar gravity will have a major effect on the total axial thermal power that the

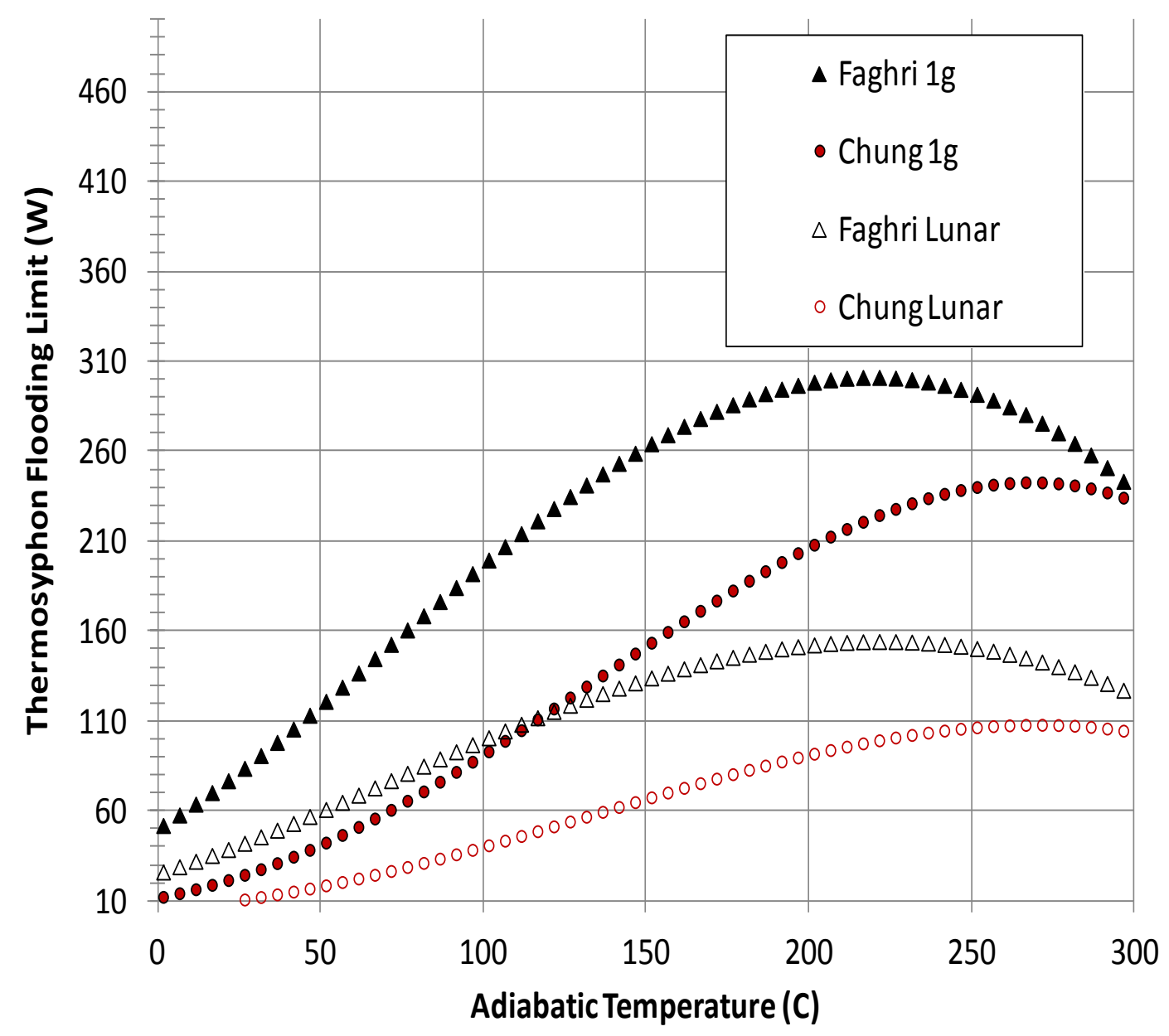

Figure 1.5 Faghri and Tien and Chung correlations of the thermosyphon flooding limit for earth and lunar gravity levels. 
thermosyphon can carry. The geometry inputs for figure 1.5 are based on using the actual dimensions of the experimental thermosyphons as described in chapter 2.

Figure 1.6 reinforces the necessity for this research by showing the expected performance of a fission surface power thermosyphon for a lunar application when compared to the Faghri and Tien and Chung models. The thermosyphon will flood if the required axial thermal power lies above the flooding curve. According to the Faghri model, the thermosyphons will not flood on the surface of the moon seeing as the expected performance points (green triangles) lay below the red curve. According to the Tien and Chung model, the thermosyphon would flood well before reaching its

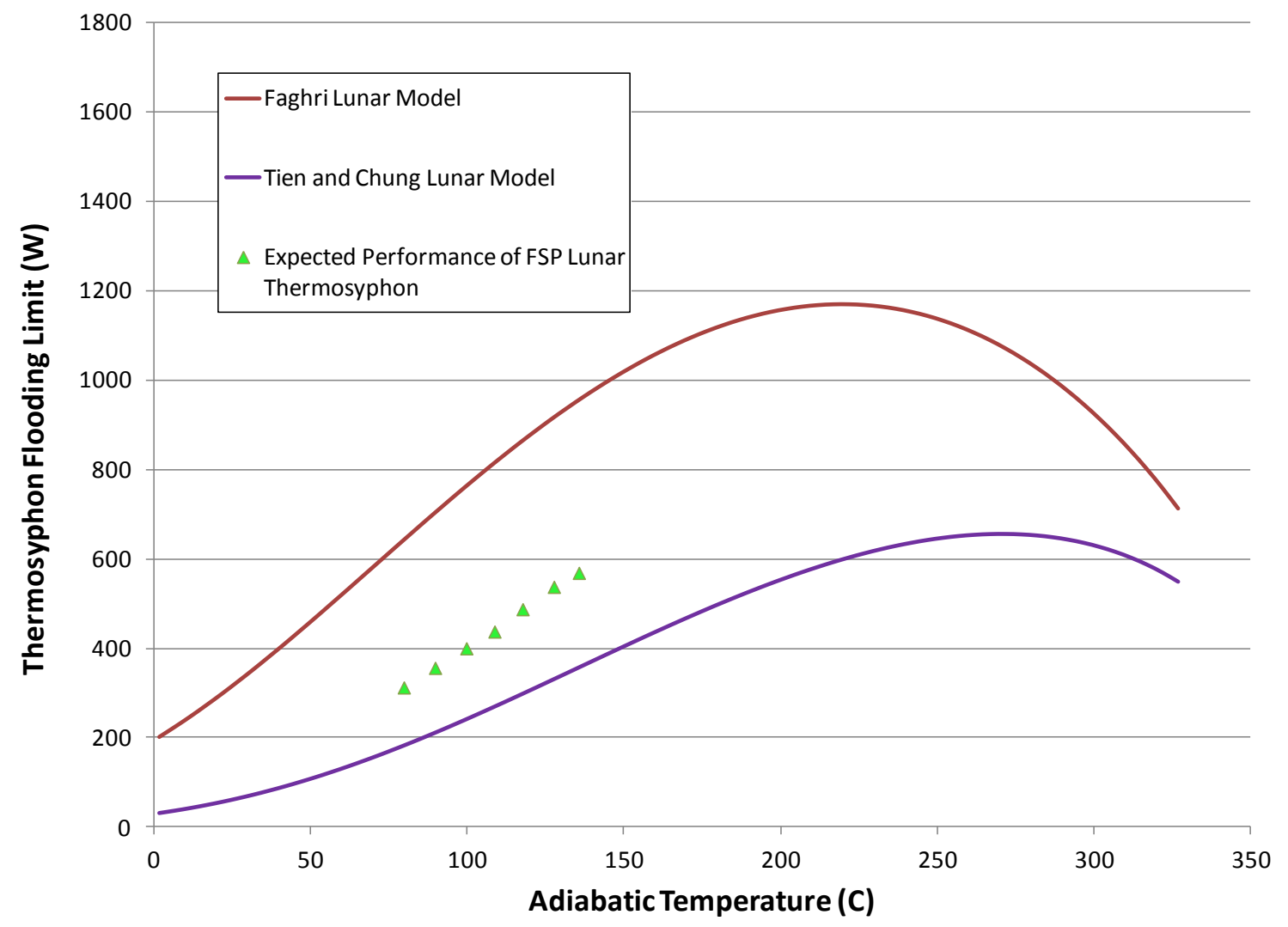

Figure 1.6 Expected thermosyphon performance of a Fission Power System on the lunar surface vs. current thermosyphon flooding models from Faghri and Tien and Chung. 
expected thermal performance, as the points lie above the purple curve. The fact that these models don't agree after numerous $1 \mathrm{~g}$ test experiments and that no experiments have been performed in RGE makes the level of uncertainty, of when a thermosyphon reaches its heat transfer limit, extremely high. Which model would a thermal engineer choose to effectively analyze the thermal performance of a thermosyphon radiator for a lunar power system, and most importantly, keep the thermosyphons from reaching any heat transfer limitations?

\subsubsection{One Dimensional Model of the Flooding Limit}

A one dimensional, laminar, incompressible model was evaluated to understand the fluid dynamics of the system. Figure 1.7 illustrates the velocity profiles, dimensional variables, and the associated Cartesian coordinate systems for the liquid and gas inside a thermosyphon. The fluid flow is a balance of the pressures associated with the liquid layer. As always, the impeding viscous forces of the liquid produce a retarding pressure that hinders the flow of the liquid layer from returning to the evaporator. Likewise, the pressure that drives the vapor up the tube will also inhibit the liquid from returning to the evaporator. The gravity component is the only pressure assisting the liquid back to the evaporator. A detailed look at the resulting equations used in this section can be found in Appendix A.

The analysis provided an expression relating the maximum axial heat transfer in a thermosyphon as a function of the liquid layer thickness compared to the thermosyphon radius $\left(\frac{\delta}{l}\right)$.

$$
Q_{\max }=\frac{2 w h_{f g} \rho_{f} g l^{3}}{3 v_{f}}\left(\frac{\delta}{l}\right)^{3}\left[1+\frac{3}{2} \frac{v_{g}}{v_{f}}\left(\frac{\delta}{l}\right)^{2}\left(1-\frac{\delta}{3 l}\right)\left(1-\frac{\delta}{l}\right)^{-3}\right]^{-1}
$$




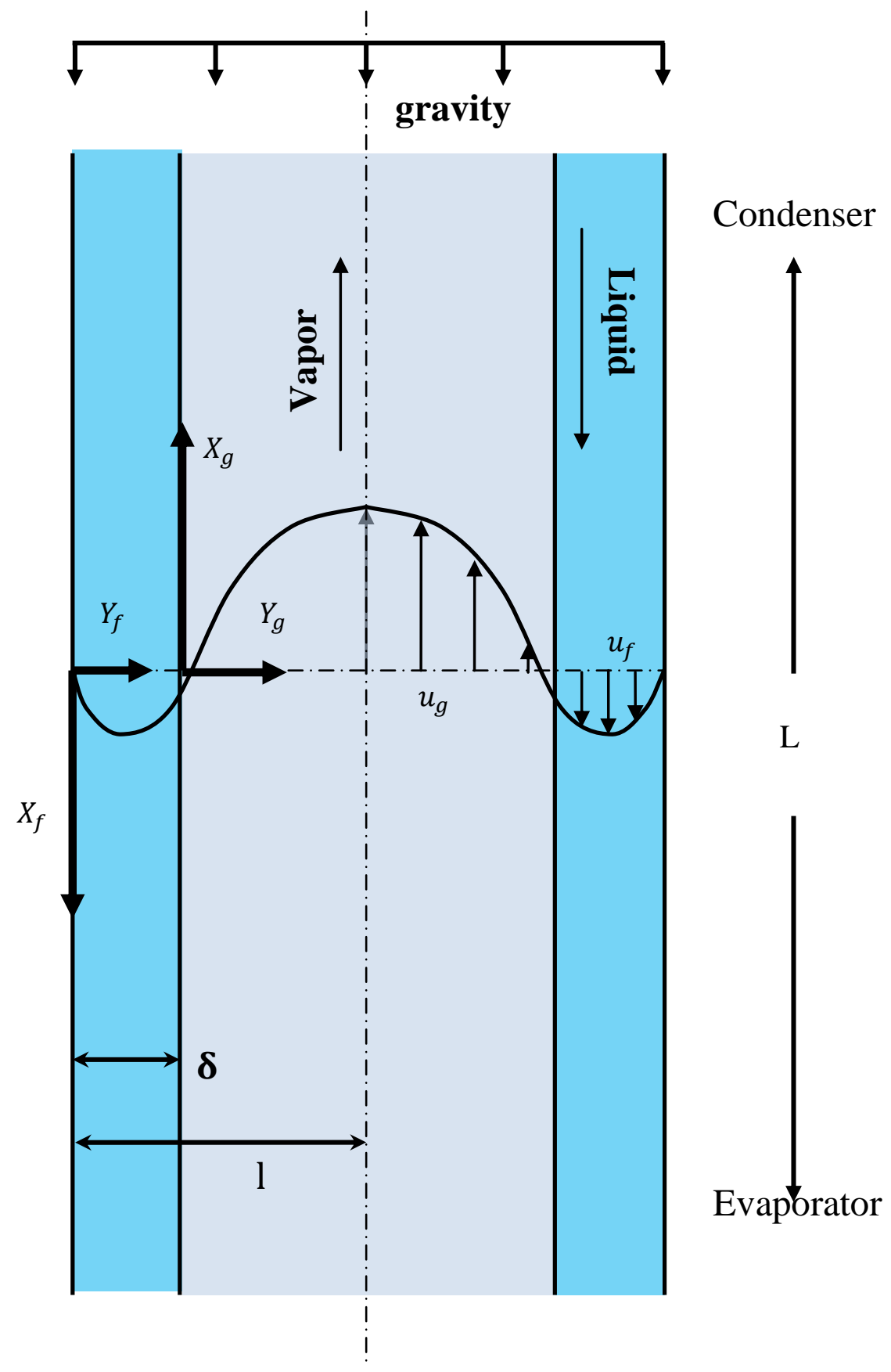

Figure 1.7 One dimensional Diagram of a thermosyphon 
The equation was also put into the dimensionless power parameter "q" which is used in chapter 5. Both dimensional and non-dimensional equations are graphically analyzed and discussed in Appendix A.

$$
q=\frac{Q_{\max }}{h_{f g} \rho_{g} A_{v} \sqrt{g D}}=\frac{l \sqrt{g D} \rho_{f}}{3 v_{f} \rho_{g}}\left(\frac{\delta}{l}\right)^{3}\left[1+\frac{3}{2} \frac{v_{g}}{v_{f}}\left(\frac{\delta}{l}\right)^{2}\left(1-\frac{\delta}{3 l}\right)\left(1-\frac{\delta}{l}\right)^{-3}\right]^{-1}
$$

\subsubsection{Other thermosyphon heat transfer limitations}

Boiling Limit- The boiling limit can be reached with thermosyphons that have large fill volumes and high radial heat fluxes. As with any boiling limitations, the high flux heat transfer leads to nucleate boiling followed by film boiling which overcomes the ability of the fluid to reach the heated surface. This causes the evaporator to overheat, producing a positive feedback mechanism with no chance of recovery without dramatically decreasing the evaporator heat flux. As discussed in the previous section, the reduction in gravity decreases the mass flow in the thermosyphon which ultimately reduces the amount of cooling that can take place over the evaporator. This, in turn, makes the boiling limitation reliant on the gravity forces. Equation 1.19 correlates the maximum power that can be transferred radially from the thermosyphon evaporator (7).

$$
Q_{\max }=0.16 A_{v} h_{f g} \sqrt{\rho_{v}}\left[g \sigma\left(\rho_{l}-\rho_{v}\right)\right]^{0.25}\left[1-\exp \left\{\left(\frac{-d}{L_{e}}\right)\left(\frac{\rho_{l}}{\rho_{v}}\right)^{0.13}\right\}\right]
$$

Sonic Limit- The sonic limit becomes important during the early stages of heat up when large pressure differences can be encountered between the evaporator and condenser sections that can 
cause choked flow at the exit of the evaporator. When the vapor Mach number is increased beyond 0.3 the vapor is compressed enough that the fluid dynamics must be evaluated using compressible flow models. The sonic limitation does not stall the heat transfer process but only limits it until the pressures differences can be decreased as the vapor temperatures increase and become less dense. The Following equation is a generalized correlation for establishing the sonic limit of a thermosyphon or heat pipe (8).

$$
Q=0.474 A_{v} h_{f g}\left(\rho_{v} P_{v}\right)^{\frac{1}{2}}
$$

Viscous Limit- This limit is dominated by the viscous forces of the vapor during the lower temperature startup of a thermosyphon. The limit is set based on the fact that the condenser pressure cannot be lower than 0 and therefore sets the amount of pressure drop available at the condenser end. At low temperatures the vapor is just slightly above the vapor pressure and cannot overcome the viscous forces associated with driving the vapor to the condenser end. As the temperatures and pressures build, the flow will no longer be limited by the viscous flow as the inertial forces begin to dominate the fluid dynamics. This transition from viscous limiting flow to sonic limiting flow becomes less critical as the temperatures rise and other limits become more prevalent. Equation 1.21 can be used to evaluate the viscous limits of thermosyphons (9).

$$
\mathrm{Q}=\frac{\mathrm{r}_{\mathrm{v}}{ }^{2} \mathrm{~h}_{\mathrm{fg}} \mathrm{A}_{\mathrm{v}} \rho_{\mathrm{v}} \mathrm{P}_{\mathrm{v}}}{16 \mu_{\mathrm{v}} \mathrm{l}_{\mathrm{eff}}}
$$

A graphic representation of the combined limits is shown in figure 1.8. The viscous and sonic limits only come into play during low temperature operation and quickly increase as the temperature of the vapor increases and the density decreases. The flooding limit and boiling limit are both dependent 
on gravity forces and are shown for both earth and lunar gravity levels. It should be noted that the boiling limit is typically determined through experimentation as many manufacturing variables make it hard to predict using analytical models. This is due to the surface conditions affecting the nucleation sites and wetting characteristics of the fluid with the inner wall of the container.

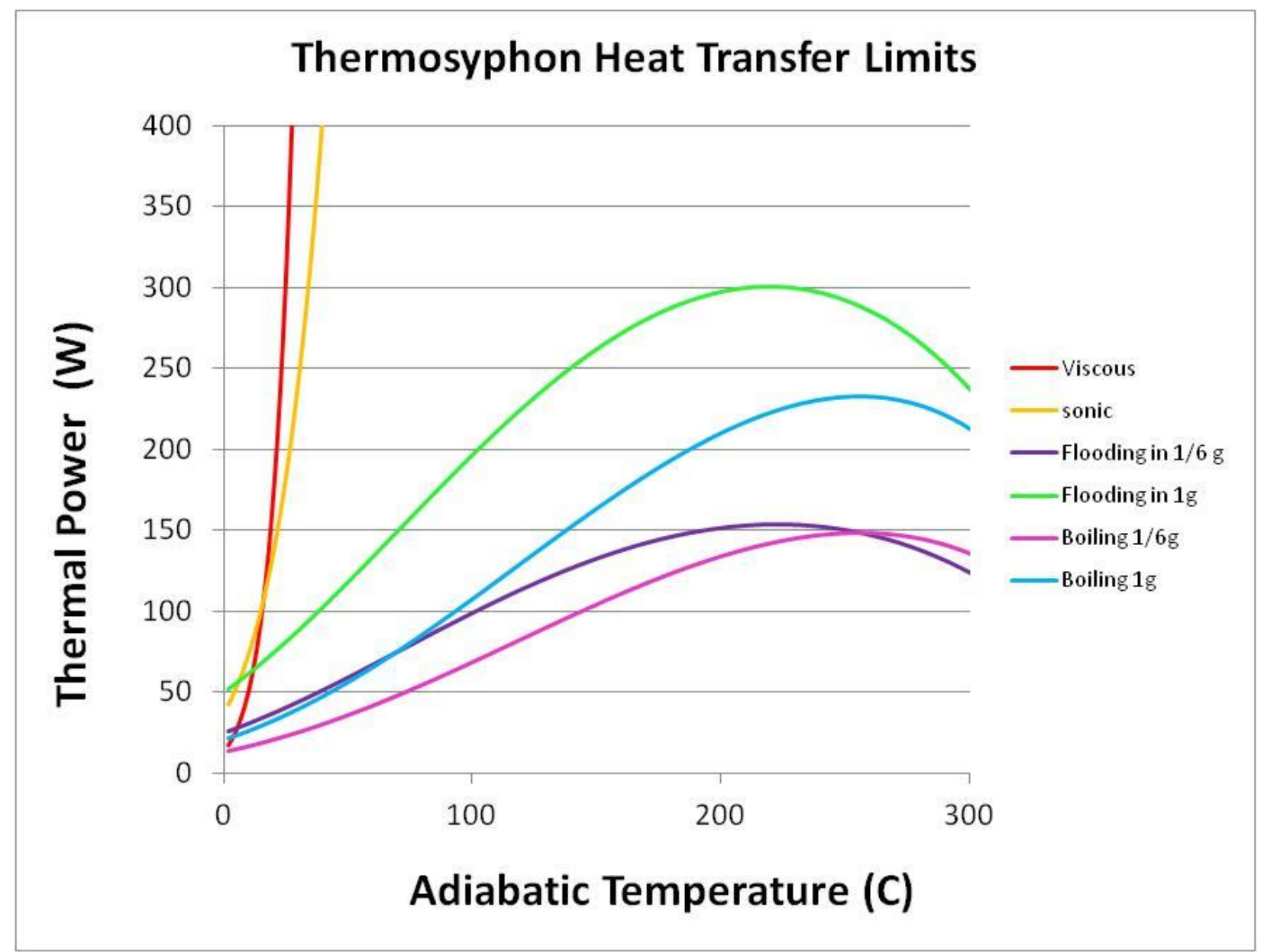

Figure 1.8 Thermosyphon heat transfer limits using experiment thermosyphon geometry 


\section{Chapter 2: Experiment Design and Hardware}

\subsection{Reduced Gravity Testing and Vehicles}

NASA has established numerous methods to study Reduced Gravity Environments (RGE) in an effort to provide research opportunities for developing gravity influenced technologies at an affordable cost. The current Flight Opportunities Program, or FOP, is run through NASA's Office of the Chief Technologist (OCT) under the Game Changing Development (GCD) program. The FOP sends out solicitations for proposals and awards flights to the technologies that align with the current OCT technology roadmap. The FOP has established a number of Suborbital Re-useable Launch Vehicles (SrLV) which are chosen depending on the research payload and RGE requirements. This fleet of vehicles currently includes conventional aircraft, sounding rockets, and other suborbital launch vehicles to provide parabolic and suborbital flight platforms that can provide a wide range of RGE for various levels of research.

Initially, research flight requirements start with the desired time at the specific gravity level needed to perform the research. The FOP has a diverse set of flight vehicles to allow several options when considering the total research objectives. After careful examination, the FOP determines which vehicle best suits the payload objectives and can award the flight. Using this approach, FOP provided a parabolic flight campaign to conduct this research with the Zero G Corporation using a Boeing 727 named G-Force One, based on the need for lunar and Martian gravity and the size of the experiment. 


\subsection{Experiment Design}

In order to fly the experiment on G-Force One, a number of requirements had to be met to ensure safe operations while in flight. The experiment would be strictly investigated during internal and external Test Readiness Reviews (TRR) for safe operations of both mechanical and electrical systems before being allowed to fly. The Test Equipment Data Package listed in Appendix C gives specific details of the experiment under the FOP guidelines and operational procedures. These safety requirements typically drive the engineering constraints for the experiment and would ultimately limit the size and power of the experiment. Within these constraints, the experiment would need to successfully determine the heat transfer limits of the thermosyphons and would require innovative techniques to design the experiment and acquire the needed data.

The NASA Glenn Research Center has a long history of parabolic flights and microgravity research which helped acquire a flight chassis to house the experiment. The chassis had already been structurally proven through other parabolic flights and would become the geometric constraints of the system with dimensions 24 -in. X 24-in. X 42-in..

Next, the electrical system and thermosyphon design would have to be specified to meet the aircraft's strict electrical requirements. It was imperative that the experiment be designed to meet the requirements of the $1 \mathrm{~g}$ laboratory testing as well as the parabolic flight testing, to minimize any error associated with the hardware. For the flight, a baseline of $2 \mathrm{~kW}$ at $115 \mathrm{~V}$ was used as the maximum

electrical constraint for the experiment based on the aircraft's available power. For laboratory $1 \mathrm{~g}$ testing, the experiment would have to provide almost three times that power to simultaneously achieve the heat transfer limits of all twelve thermosyphons. 
The next consideration was to determine the number and size of thermosyphons to meet the electrical constraints while still being able to reach the desired flooding limit. Knowing that the flooding limit was going to be extremely difficult to obtain in parabolic flight, it was determined that 12 thermosyphons, if possible, would be a good balance between getting multiple chances at capturing the flooding event while keeping in mind the electrical constraints. Using 12 thermosyphons, each heater would have a total of $165 \mathrm{~W}$ of supply power while in reduced gravity.

Faghri's Equation (1.08) was used for early predictions as it represented the more conservative approach to staying within the aircraft electrical budget. The diameter of the thermosyphon would be estimated by graphically evaluating the flooding limit of $165 \mathrm{~W}$ and a lunar gravity value of 1.622 $\mathrm{m} / \mathrm{s}^{\wedge} 2$. Both lunar and Martian gravity environments were analyzed but the lesser lunar gravity was chosen as the desired target because it would allow a wider range of data for the intended correlation, as well as require less heater power. The decision to test mostly in lunar gravity, as opposed to half lunar and half Martian, was due to the fact that during the parabolic flights only a limited number of parabolas are dedicated to reduced gravity and the experiment needed as much time as possible to pass through a flooding event.

After careful examination, the final decision was to design the experiment with a total of 12 thermosyphons made from 0.25 by 0.035 in. $(6.35$ by $0.889 \mathrm{~mm})$ wall titanium tube using water as the working fluid. The total thermosyphon length of 24 in. $(60 \mathrm{~cm})$ was built with a $2.5 \mathrm{in} .(6.35 \mathrm{~cm})$ evaporator, a 2.5 in. $(6.35 \mathrm{~cm})$ adiabatic section, and a 19 in. $(45.7 \mathrm{~cm})$ condenser, providing a length to diameter (L/D) ratio of 130, similar to the thermosyphons designed for the fission surface power system in Fig. 1. Two wraps of 100 -mesh titanium screen were used in the evaporator section to increase fluid flow during nucleation and prevent dryout. The condenser was designed to be air 
cooled, using a finned aluminum tube that would enhance heat transfer and allow the internal fluid temperature to be altered via a variable speed fan. Combination of these components would allow testing over a wide range of expected heat transfer limitations that would provide new data for the research community.

Extreme caution was used at the higher temperatures due to the pressure increase of the saturated vapor within each thermosyphon. Each thermosyphon would require proof pressure testing as well as extended temperature testing to adequately prove they would not rupture during any portion of the experiment. Photos of the thermosyphon components are shown in figure 2.1.
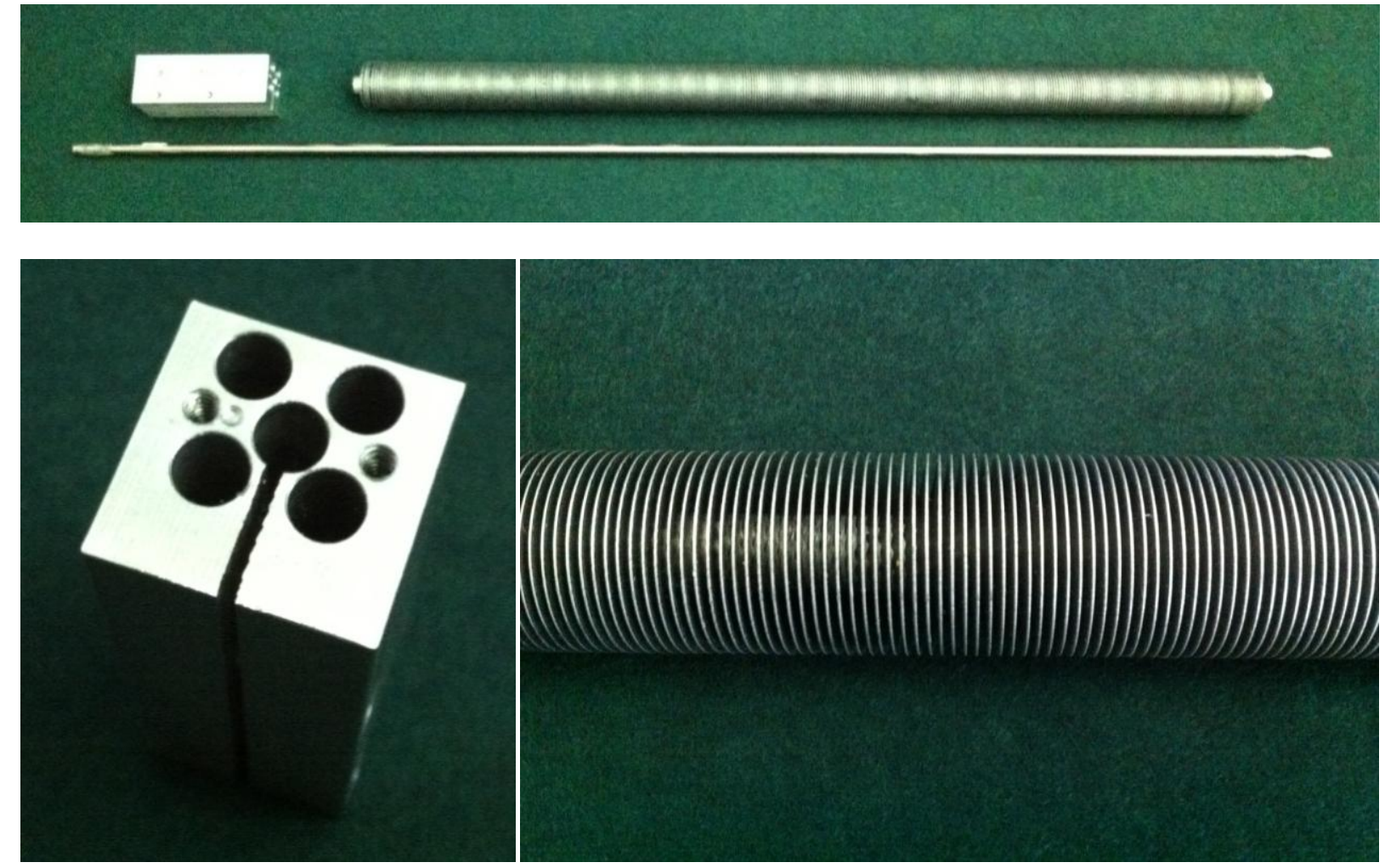

Figure 2.1 Thermosyphon Components 
When reaching any of the heat transfer limits, it is known that the heater temperatures will rapidly increase based on the associated power level. This drove the most important control system decision which required that the heater power interlock have double redundancy to protect the heater from running away during the experiment. The control system relied on several thermocouples to provide the necessary information to appropriately shut down the heaters should the operator miss the runaway event.

The data acquisition and control (DAC) system was accomplished using a National Instruments PXI chassis and real-time controller with customized Labview programming to provide the system logic and user interface functions. The end product used a laptop computer that was linked to the PXI controller inside the flight rack and let the operator view and collect data signals, control the heater power, view alarms, and record notes. Several revisions of the DAC system were implemented to establish a streamline process that allowed quick communication and control needed during parabolic maneuvers. Pictures of the experiment hardware can be seen in Figures 2.2 and 2.3. More detail relating to each individual component can be seen in the TEDP in Appendix C. 

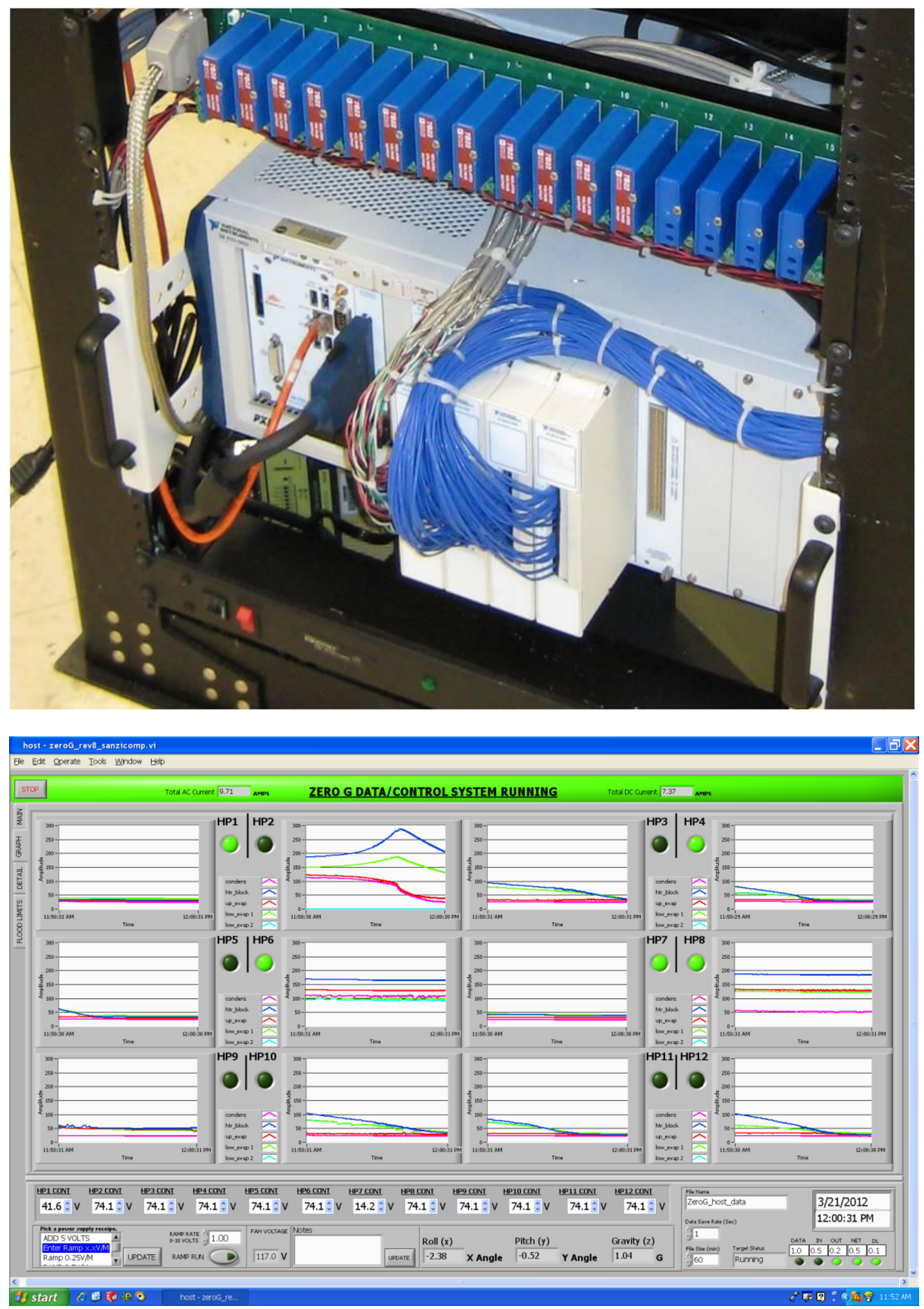

Figure 2.2 Top: National Instruments PXI Data System and electrical controls; Bottom: Screen shot of flight software showing critical information and controls for all twelve thermosyphons 


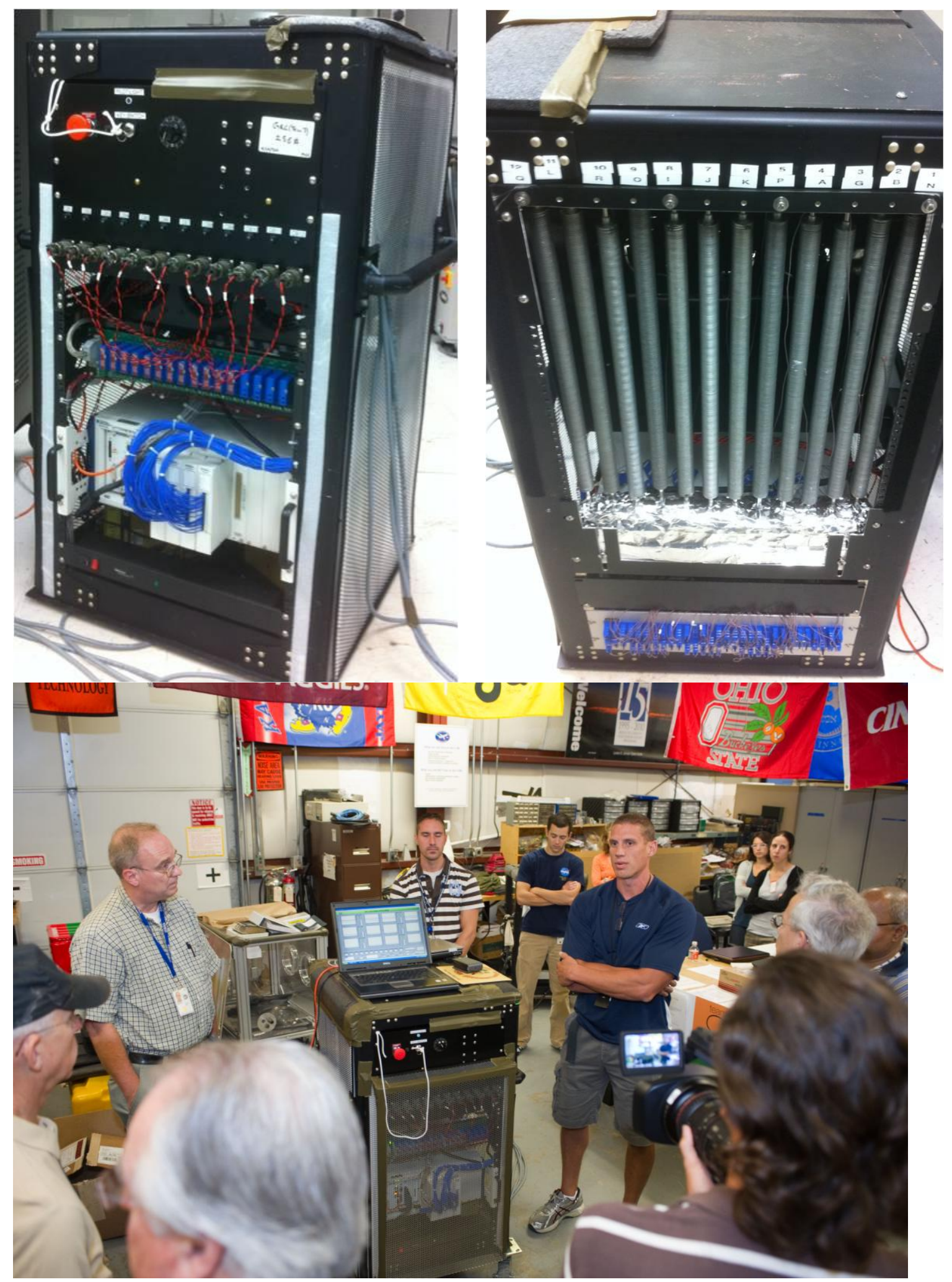

Figure 2.3 Thermosyphon flooding experiment payload 


\subsection{Instrumentation}

Tables 2.1 and 2.2 and figure 2.4 provide all the needed information for the experiment instrumentation. The data was collected at one hertz and provided the necessary information to analyze the flooding limit of the thermosyphons. Thermocouples one and two, located at the lower evaporator, were used as a flooding event marker. The screen wick extended from the top of the evaporator at $z=3.5$ down to $z=0$ and provided the capillary pressure necessary to bring the fluid stored in the lower evaporator up to the heated section during increased thermal power periods. This one inch section of tube acted as a fluid reservoir and allowed water to be inserted into the flow when additional mass was needed. With this design, the two lower evaporator thermocouples could gauge the amount fluid in the lower evaporator. When there was water present in the lower evaporator the temperatures were cooler. When the thermosyphon needed additional mass flow, the water in the lower evaporator would be pumped into the evaporator to begin the two phase thermodynamic process which could be seen as an increase in temperature at the lower evaporator temperatures. Prior to evaporator dryout, the temperatures in both lower evaporator thermocouples would increase, providing a trigger for the expected heater dryout. These thermocouples provided a good indication of what was happening in the evaporator and could be used to identify the differences between dryout and flooding.

The upper evaporator and condenser thermocouples were used in conjunction with the evaporator thermocouples to help identify the heat transfer limits. As the thermosyphon approached a limit, the difference in evaporator and condenser thermocouples would increase as the fluid mass flow was degraded. This difference caused a significant decrease in the thermal conductance and signaled a stalling event in the heat transfer process. All of these triggering events were seen as slope changes 
on the DAC time history graphs. All twelve thermosyphons could be monitored at once with the DAC software and helped the test operators identify the flooding events as they unfolded.

\begin{tabular}{|l|l|}
\hline $\begin{array}{l}\text { Instrumentation } \\
\text { Sample Rate: } 1 \mathrm{~Hz}\end{array}$ & Qty \\
\hline $\begin{array}{l}\text { Type T Thermocouples (see } \\
\text { figure xx) }\end{array}$ & 60 \\
\hline Voltage Meter & 13 \\
\hline Current Meter & 15 \\
\hline 3 Axis Accelerometer & 1 \\
\hline
\end{tabular}

Table 2.1 Instrumentation List

\begin{tabular}{|c|c|c|}
\hline $\begin{array}{c}\text { TC } \\
\text { Number }\end{array}$ & $\begin{array}{c}\text { TC } \\
\text { Name }\end{array}$ & $\begin{array}{c}\text { TC Location } \\
(z, \text { inches })\end{array}$ \\
\hline 1 & $\begin{array}{c}\text { Lower } \\
\text { Evaporator_1 }\end{array}$ & 0.375 \\
\hline 2 & $\begin{array}{c}\text { Lower } \\
\text { Evaporator_2 }\end{array}$ & 0.625 \\
\hline 3 & Heater Block & 2.25 \\
\hline 4 & $\begin{array}{c}\text { Upper } \\
\text { Evaporator }\end{array}$ & 4.5 \\
\hline 5 & Condenser & 23 \\
\hline
\end{tabular}

Table 2.2 Thermocouple ID and location 


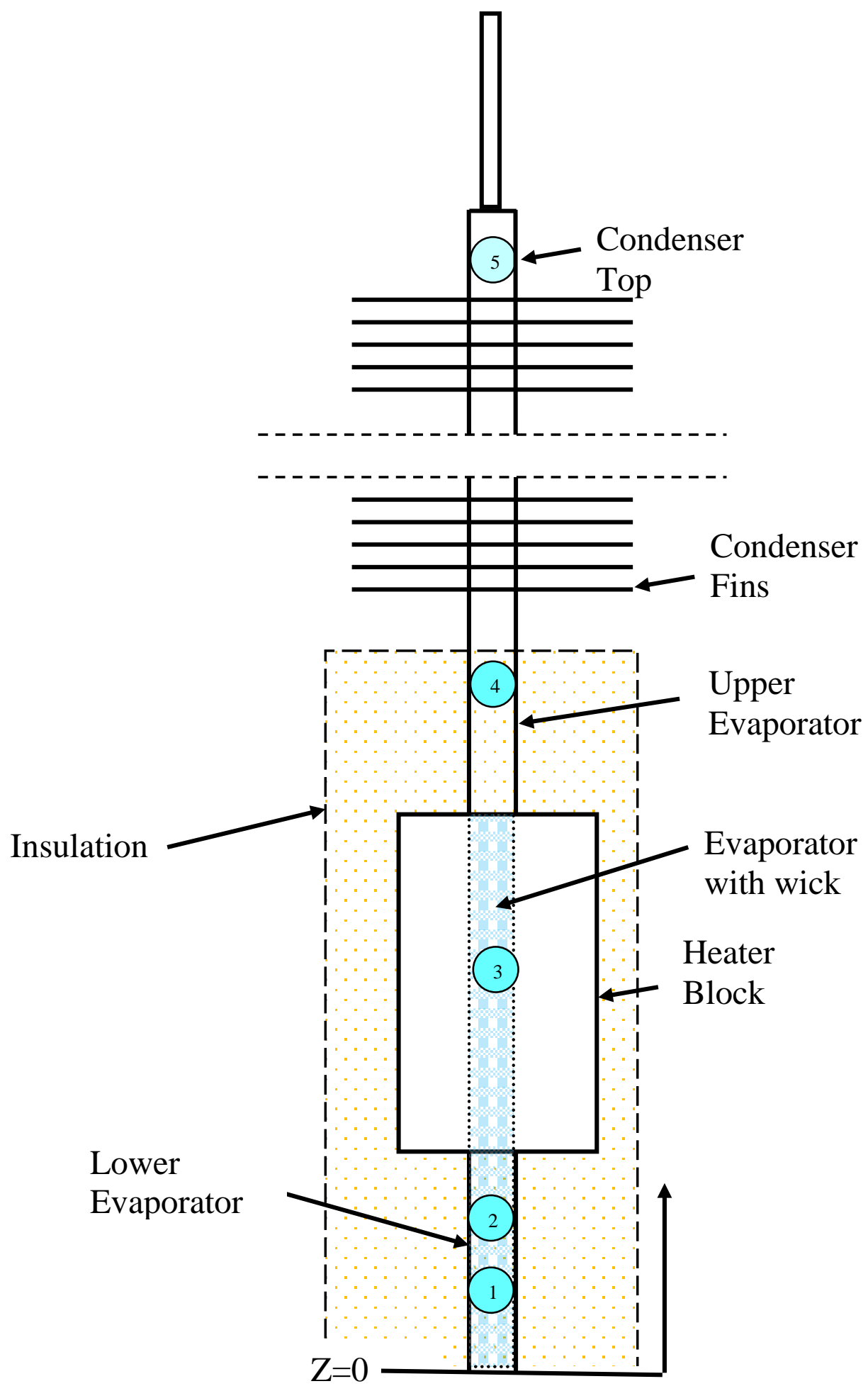

Figure 2.4 Thermocouple Location Diagram 


\section{Chapter 3: Ground Testing in Earth's gravity}

\subsection{Test Methods and Procedures}

Testing was conducted in the laboratory well before any flight testing took place to address the functionality of the experiment and determine how the sensors would be used to detect the flooding limit. The thermosyphons were taken to their flooding limit using several procedures, which were eventually down selected into the most appropriate for parabolic flight. Figure 3.1 provides a

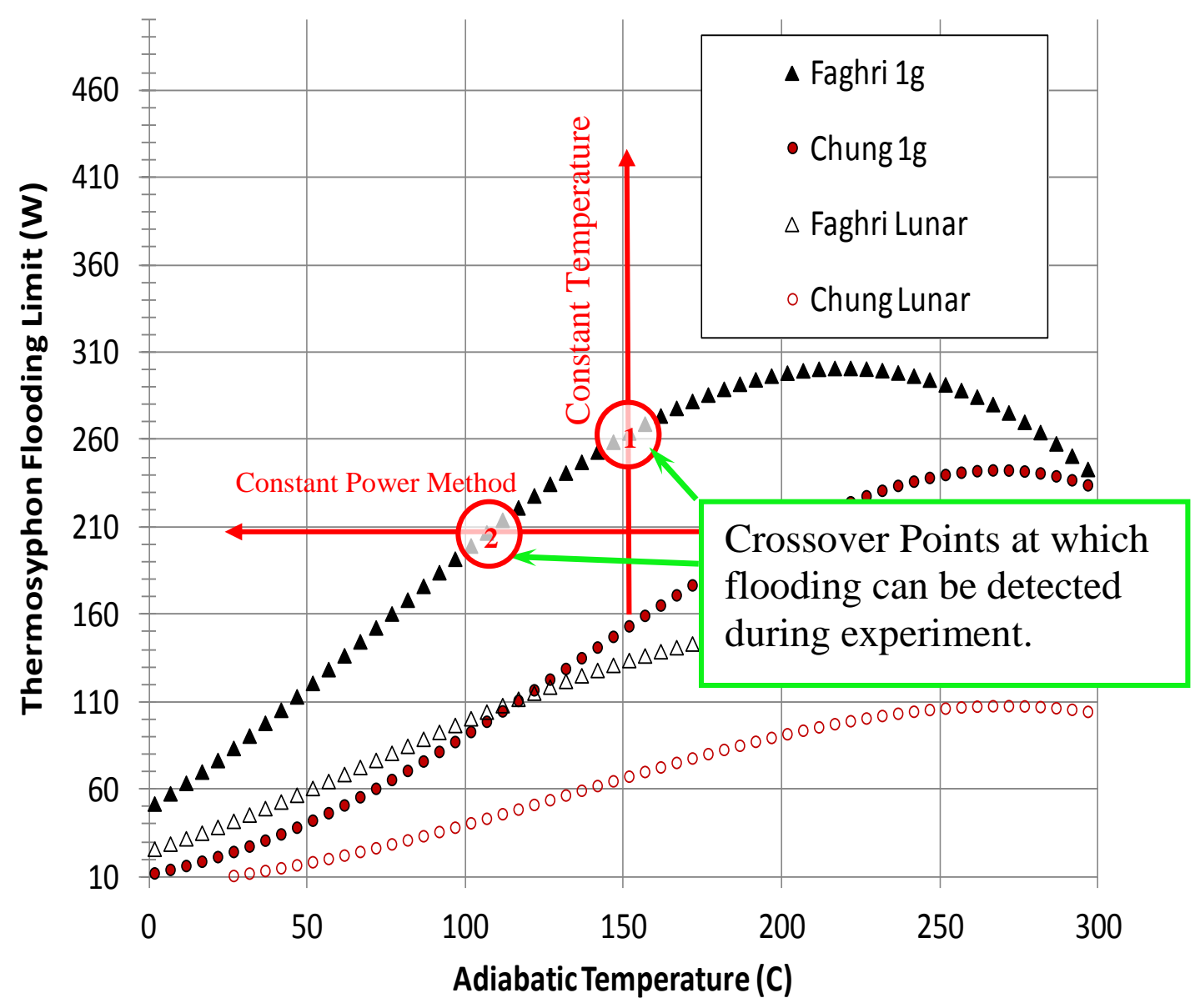

Figure 3.1 Graphical representation of two different methods used to approach the flooding limit 
graphical representation of the two selected methods for determining the flooding limit during experimentation. These separate methods were used to approach the flooding limit to determine if either method provided different results. During the constant temperature procedure, the heaters were taken up in temperature using a voltage ramping function that would vary the heater voltage at $1 \mathrm{~V} / \mathrm{min}$. Using the variable speed fans, the operator adjusted the airflow across the finned condenser to control the adiabatic temperature of the thermosyphon. Using this strategy, the power increases as the adiabatic temperature stays constant, and eventually the thermosyphon passes through the flooding limit. This can be seen graphically by the "Constant Temperature" arrow and crossover point 1 in Fig. 3.1. Another method that was incorporated into the test procedures was to keep the power constant and increase the airflow, thus cooling the adiabatic temperature and ultimately passing through the flood limit from a different angle. As the adiabatic temperature decreases, the flooding limit will eventually be crossed at point 2 following the "Constant Power" arrow in Fig. 3.1. Both methods produced similar results and would be used for parabolic flight.

\subsection{Data Analysis}

When flooding occurs, the heat transfer process is stalled causing an increase in the heater temperature and a decrease in the condenser temperature. This can be seen in the thermocouple data as a change in slope and is easily visible during testing. An example of a 1 -g flooding event can be seen in Fig. 3.2 and depicts the change in slope of both the heater and condenser temperatures. During the laboratory and parabolic testing, 12 thermosyphons would be monitored visually to detect if a flooding event had occurred and would initiate shutdown of the individual heaters. Using this philosophy, all thermosyphons were set and ramped at exactly the same settings, providing a total of 12 flooding data points during an ideal test run. This procedure was used to gather multiple 


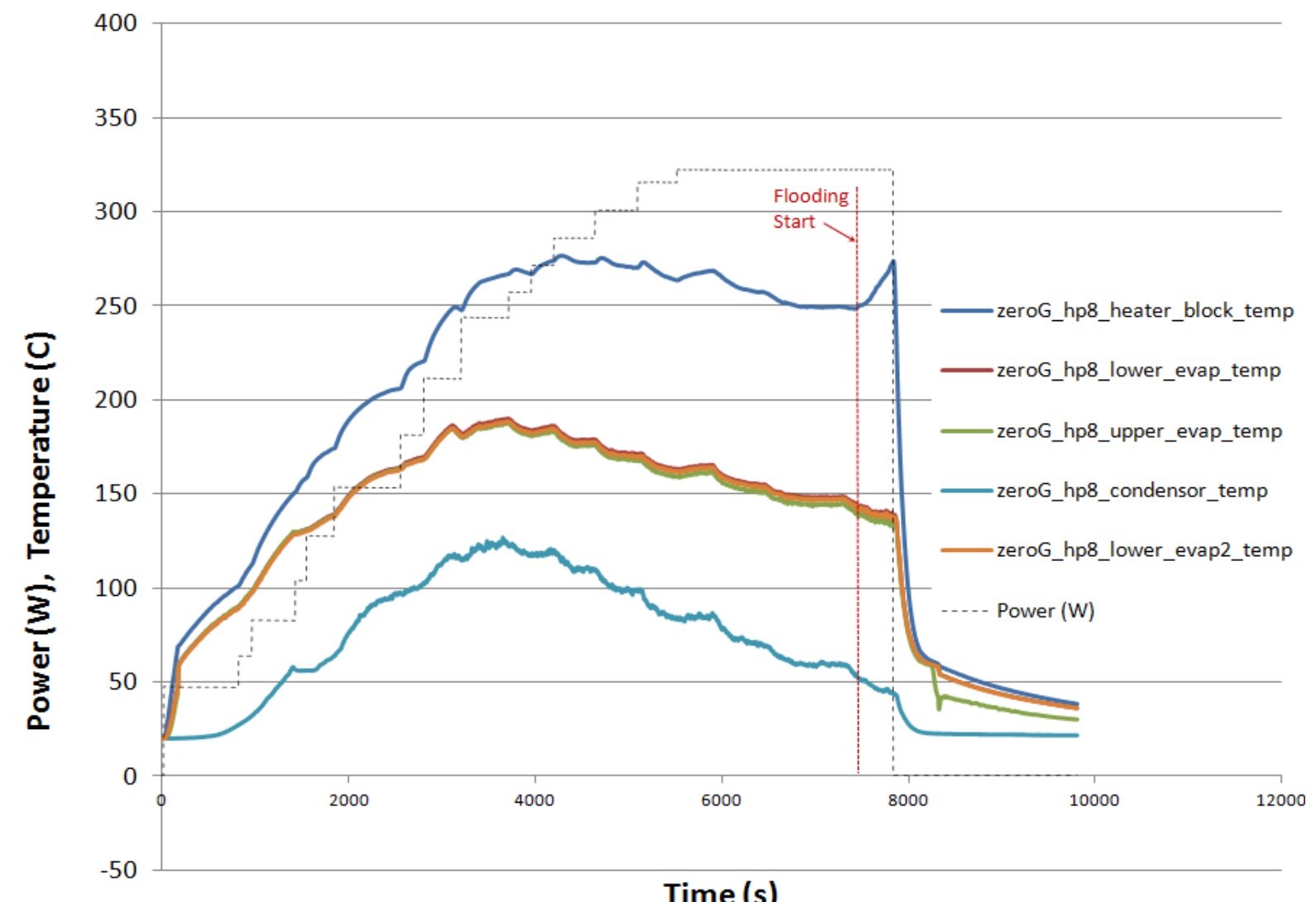

Figure 3.2 Typical 1-g flooding event using the constant power method.

flooding points over a large temperature range providing the needed data to compare to Eqs. (1.06) and (1.08).

Results from Initial $1 \mathrm{~g}$ laboratory testing are compared to the models from Faghri and Tien and Chung in figure 3.3. The combined flooding limits of all twelve thermosyphons in numerous test runs show significant data scatter. This made it difficult to determine, with any accuracy, exactly where the flooding limit was and how to best define it. This triggered an investigation to try and understand exactly what was causing the data dispersion. One idea that had surfaced throughout initial $1 \mathrm{~g}$ testing was the exact amount of working fluid in each thermosyphon and how it affected 


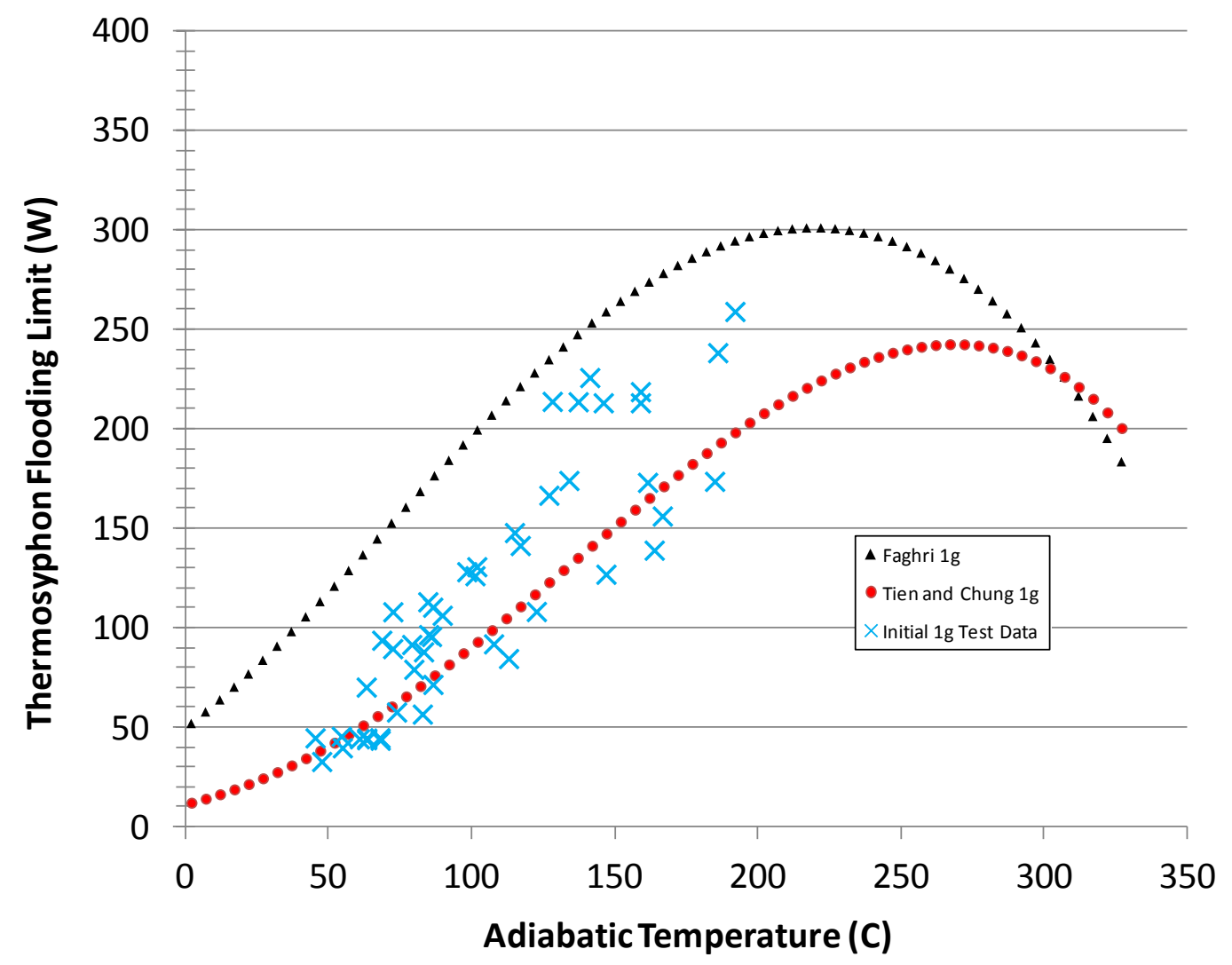

Figure 3.3 Initial $1 \mathrm{~g}$ test data showing scattered results caused by fluid charge differences

the test results. Of the initial 12 thermosyphons, 3 were tested individually to their flooding limits and are reported in Fig. 3.4. It was thought that these differences were due to the amount of working fluid, but to determine this, the thermosyphons would have to be cut open. The investigation would have to wait as preparations were already underway for the 2011 flight campaign. After the September 2011 flight campaign, the thermosyphons were all weighed and cut open so that the water could be completely evaporated through the open end. After completing the dryout process the assemblies were reweighed to determine the fill charge. The thermosyphons had fluid charges ranging from 0.76 grams to 2.5 grams and could be related to the performance of the individual units with number 6 having 0.76 grams of fluid, 8 with 2.5 grams, and 12 with 2.1 grams. 


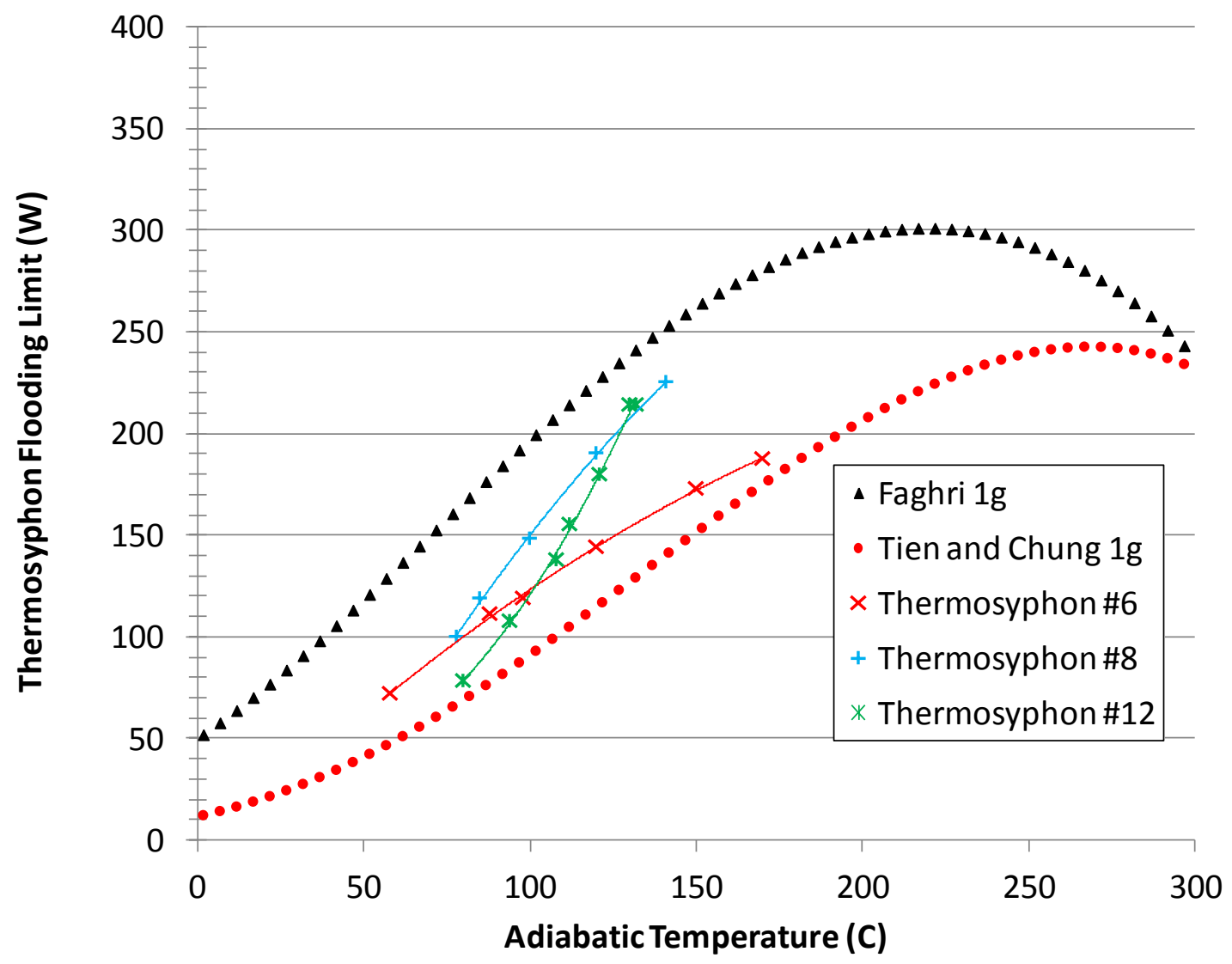

Figure 3.4 Initial individual thermosyphon flooding limits showing dissimilar results during fluid charge investigation

The fluid charge differences in these initial 12 units were attested to filling procedures that worked well with larger diameter thermosyphons but would prove difficult using the $0.125 \mathrm{in}$. (3.2 mm) fill tube associated with the 0.25 in. $(6.35 \mathrm{~mm})$ thermosyphons.

Before the thermosyphons were re-welded, a test was completed to determine, for this specific thermosyphon geometry, what the best fluid charge is, and how the amount of fluid charge affects the heat transfer limit. Fig. 3.5 reports the results as the charge was changes from 0.3 grams up to 


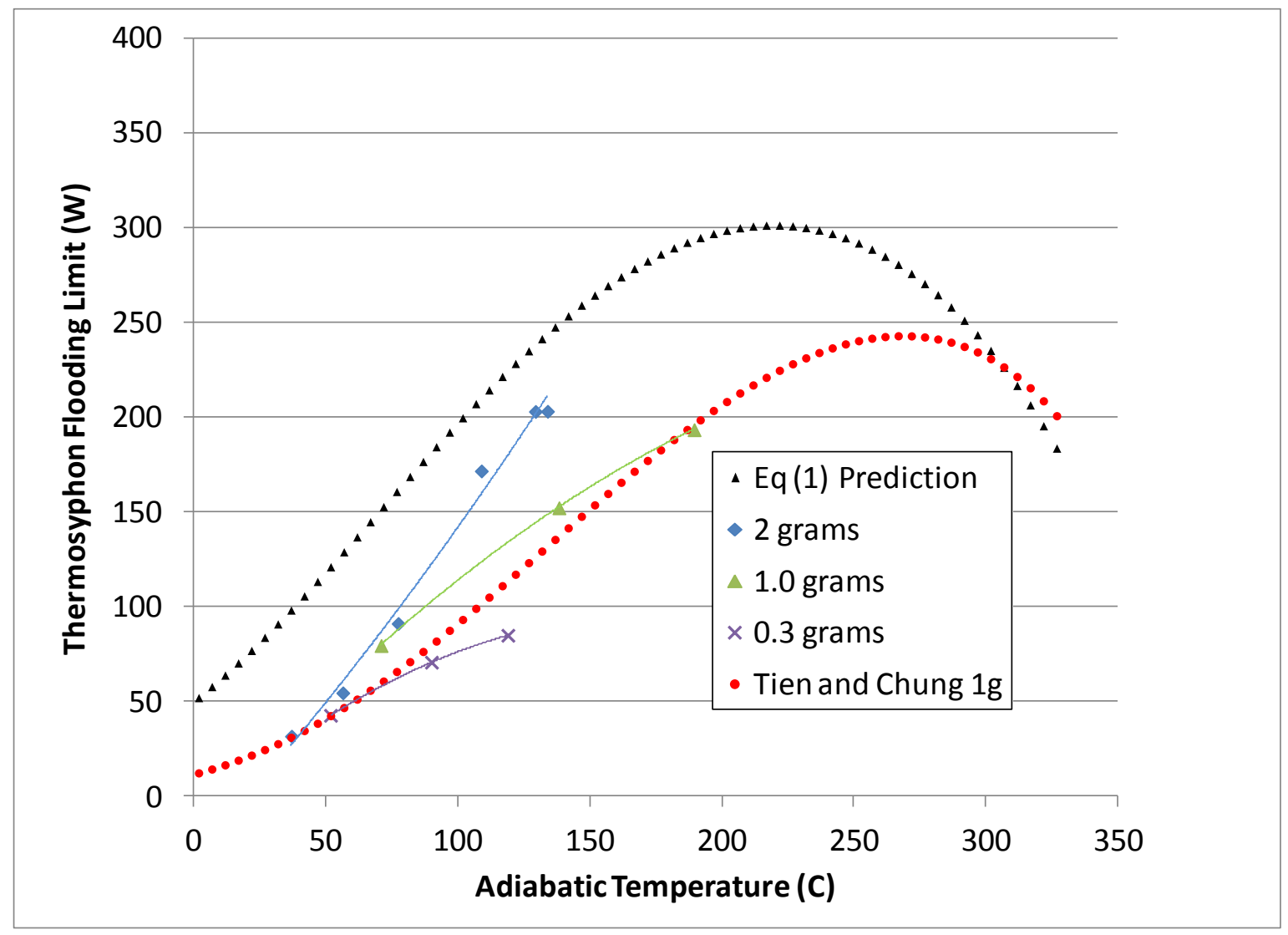

Figure 3.5 Effect of fluid charge on thermosyphon flooding limit

5.0 grams. The results are clear that fluid charge has a significant impact on the heat transfer limit of the thermosyphon. When using too little fluid, the evaporator dries out before ever getting to the flooding limit and when too much fluid was used, the heat pipe would not work at all. Although not reported in the figure, the maximum amount of fluid that could be used was around 3.0 grams. At 3.0 grams and above, the thermosyphons could not be started. Also worth mentioning is the fact that 2.0 grams of fluid took up 5 in. $(12.7 \mathrm{~cm})$ of the 24 in. $(60 \mathrm{~cm})$ total length. This volume of fluid was needed to achieve the maximum flooding limit, but may not be practical in some design applications. It was determined that 2.0 grams of fluid would be used as the new fluid charge. The 


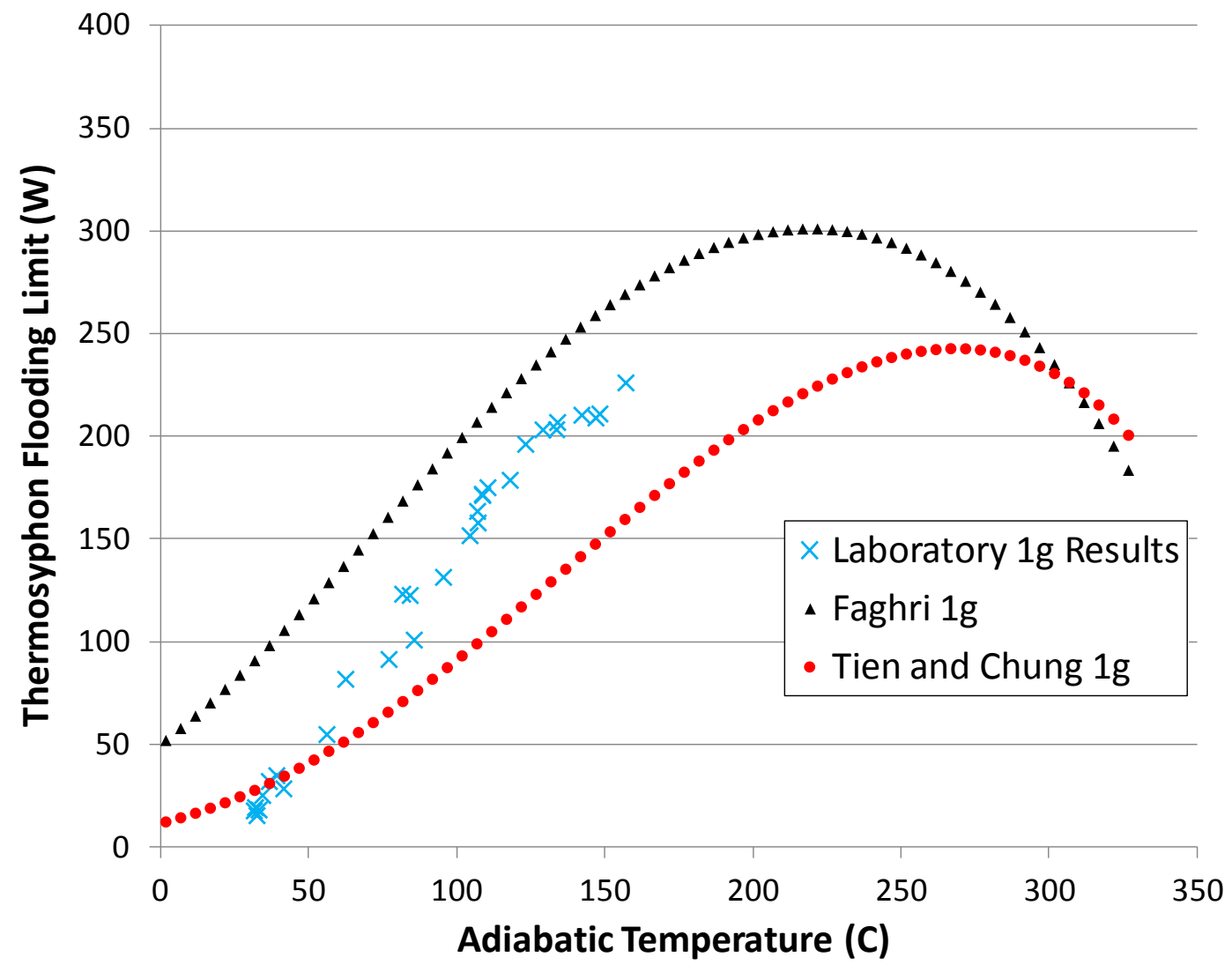

Figure 3.6 Flooding limit of correctly filled thermosyphons using $2.0 \mathrm{~g}$ of water.

$1 \mathrm{~g}$ laboratory testing was redone using the newly filled thermosyphons with 2.0 grams of working fluid. The new results are shown in figure 3.6 showing a much tighter grouping of the data.

Notice in Fig. 3.5 that the slope and curvature of the data directly relates to the fluid charge. The results suggest that the differences between the predictive models and the test data may very well be related to fluid charge and whether or not the flooding limit is actually reached, or if the evaporator is drying out before flooding occurs. Typically, after a flooding event starts, it is quickly followed by evaporator dryout, but knowing that the fluid charge determines which event happens first makes the analysis much more difficult. Through careful temperature measurement, both below, inside, and above the evaporator, it was possible with this experiment to determine whether dryout had 
occurred before or after flooding. With the use of a wicked evaporator, the dryout limit could be detected in the data when the lower evaporator temperature changed slope and started increasing before condenser temperatures started falling. The lower evaporator can be best described as a 1-in. adiabatic section just below the heater, which served as a fluid reservoir. As the fluid left the reservoir to increase the mass flow needed to transfer the increased heat output, the thermocouple in that section would show an increase in temperature. This signified the start of dryout and depending on the fluid charge, may or may not be close to the flooding limit. After some time, the evaporator section directly under the heater block would also dry out and start the familiar slope increase of the heater block temperature, which would ultimately limit the heat transfer. Conversely, when flooding occurred as shown in Fig. 3.2, the lower evaporator temperatures would initially not show signs of dryout, but the stalled heat transfer due to flooding would suddenly increase the heater block temperature. The timing of these events can be used to help determine whether or not flooding is actually occurring or if the thermosyphon is running out of working fluid as in the dryout case. Understanding this difference is key to finding the maximum heat transfer limit of the thermosyphons in all gravity fields.

The proposed theory that correlations between different sources might be explained by fluid charge and test methods, will be hard to prove without a large test program covering numerous thermosyphon geometries and working fluids, which is not under the scope of this project. As with many heat transfer and fluids experiments, it is important to update existing models to improve the understanding of the engineering and physics associated with the process and hardware. Chapter five will construct a new predictive model using the $1 \mathrm{~g}$ data in this chapter and reduced gravity lunar data in the following chapter. 


\section{Chapter 4: Reduced Gravity Testing}

\subsection{1 and 2012 Flight Campaigns}

The FOP awarded the proposal to conduct this research in the Fall of 2010 and provided a week of parabolic flight in Sept. 2011 and again in May 2012 under their recycle program. The Zero Gravity Corporation is the flight provider and uses a modified Boeing 727 named G-Force One (figure 4.1) to conduct the parabolic research. The NASA sponsored flights are run through the Reduced Gravity Office (RGO) located at the Ellington Field Joint Reserve Base in Houston TX, near the

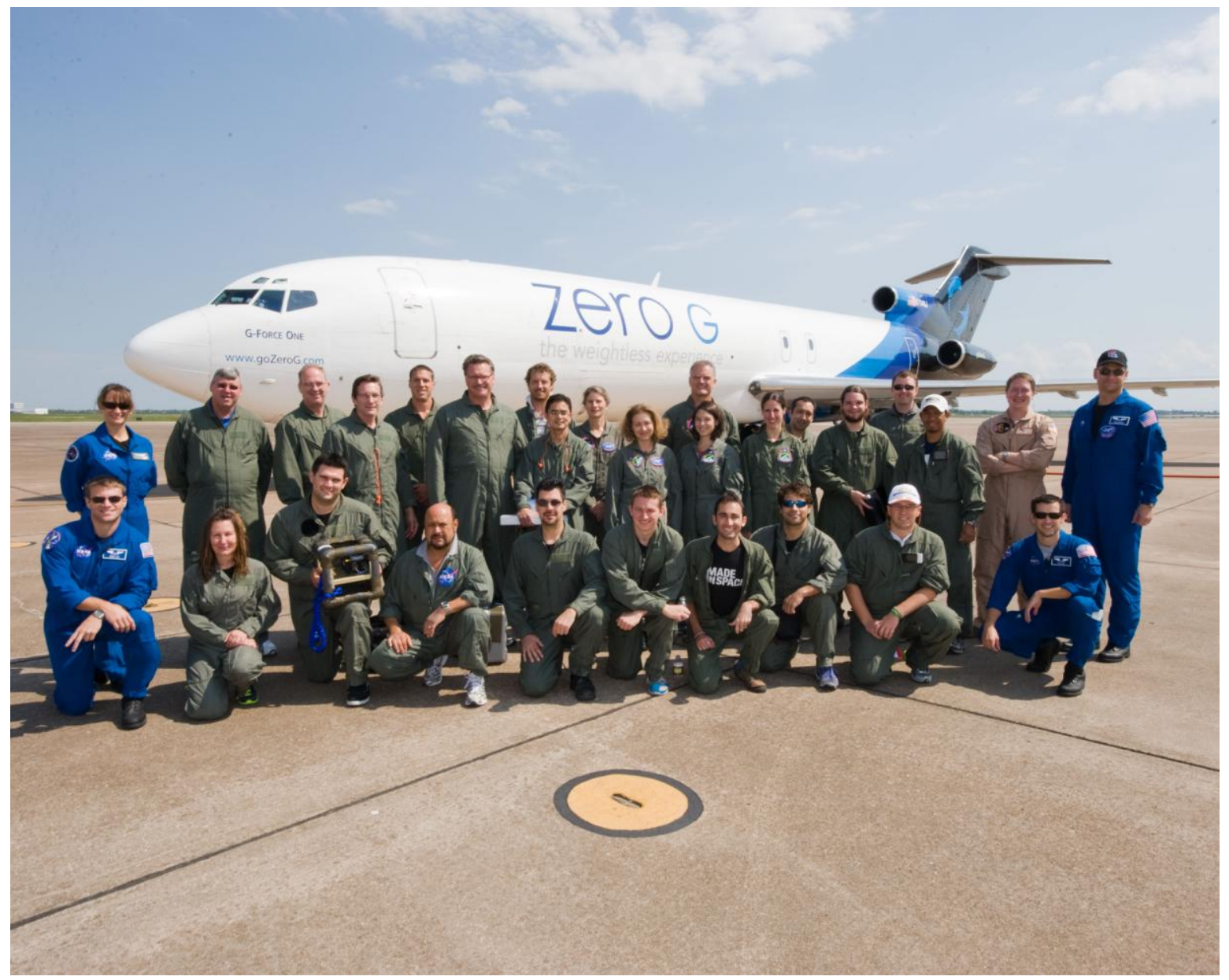

Figure 4.1 G-Force One aircraft and 2011 research teams. 
Johnson Space Center (JSC). Typically, each flight campaign is a weeklong effort with a total of 4 flights in 4 days, 40 parabolas per day, for a total of 160 parabolas. The number of parabolas at various gravity levels depends on the research experiments flying that particular week and is negotiated between RGO and the research groups prior to conducting flight operations. During the Sept. 2011 flight week RGO agreed to fly 12 lunar gravity parabolas, 3 Martian parabolas, and 25 zero gravity parabolas. These 40 parabolas were repeated for every flight during that flight campaign. For the May 2012 week a decision was made to cancel the Martian parabolas and instead get as many lunar parabolas as possible. This decision was made because 3 Martian parabolas did not give the thermosyphons enough time to reach their flooding limit. It was more important to maximize the number of lunar parabolas to try and collect more flooding data. The larger flooding data range obtained from the lunar correlations would incorporate the Martian gravity levels and predictions could be interpolated. Each flight of the May 2012 campaign consisted of 15 lunar gravity parabolas and 25 zero gravity parabolas. For reference, the Mars gravity field is $3.711 \mathrm{~m} / \mathrm{s}^{\wedge} 2$ or $0.376 \mathrm{~g}$ and the lunar gravity field is approximately $1.622 \mathrm{~m} / \mathrm{s}^{\wedge} 2$ or $0.1654 \mathrm{~g}$.

Most of the work in the first three chapters was completed in an effort to provide a successful experiment for the first flight in Sept. of 2011. Leading up to each flight were several iterations of the Test Equipment Data Package (TEDP, appendix C) that are reviewed by the FOP and the Reduced Gravity Office (RGO) to ensure that the experiment is safe for both personnel and aircraft. When arriving at Ellington Field, members from each team prepare their experiment for the Test Readiness Review (TRR) where a safety committee from JSC examines each experiment package and asks questions related to the research, experiment functionality, and most importantly, the safety features. After completion of the TRR, the teams load their experiment payloads onto the aircraft and prepare for the next day's flight. 


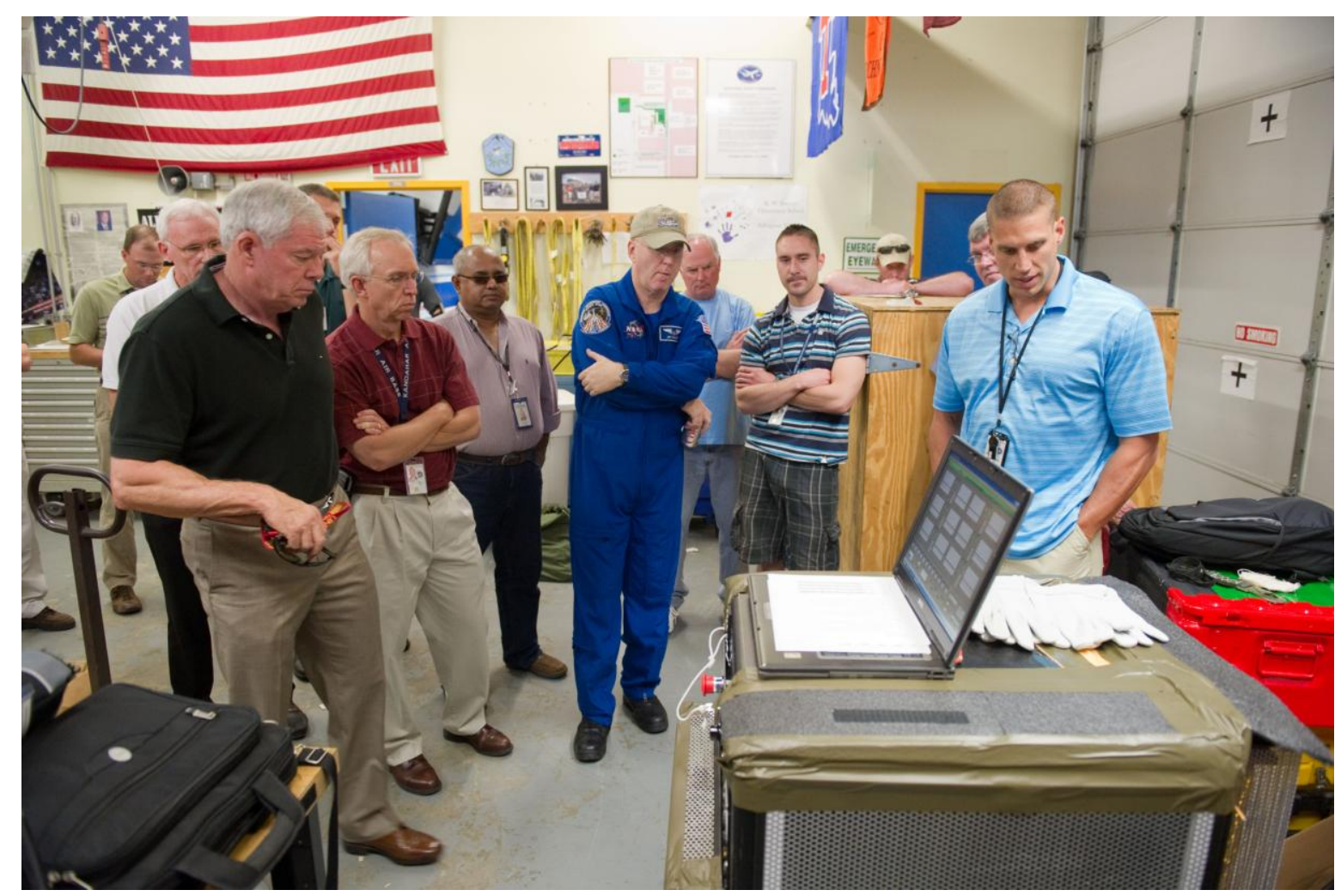

Figure 4.2 Pre-flight test readiness review at the reduced gravity office, Ellington Field.

On the flight day, approximately one hour before takeoff, the RGO flight crew briefs the day's flight operations and begins administering flight meds. Prior to takeoff, team members can perform ground operations to prepare experiments for flight. From a few minutes before takeoff, up to $10,000 \mathrm{ft}$, the cabin power is shut off and all researchers are seated at the rear of the aircraft. The powered down time period during takeoff is about 10 to 15 minutes depending on taxi time and climb rate. Once at $10,000 \mathrm{ft}$, the researchers are able to leave their seats and move to the experiments to begin preparing for parabolic operations. The time period from $10,000 \mathrm{ft}$ to parabolic maneuvers is approximately 10 minutes. 
The thermosyphons were operated close to their highest operating temperature prior to takeoff in an effort to keep the vapor flowing while the heaters were powerless and continually cooling. During the first flight week, it had become evident that insulating the thermosyphons during takeoff would help keep them operational and decrease the heat losses to the cabin environment. This higher starting temperature would allow a shorter warm-up time once at 10,000 $\mathrm{ft}$ and give the thermosyphons time to reach steady state. This modification was made for the May 2012 flight week and provided enough additional time to let the thermosyphons reach a near steady state temperature before parabolic operations. Pictures of the thermosyphon flooding experiment payload can be seen in figure 4.3.
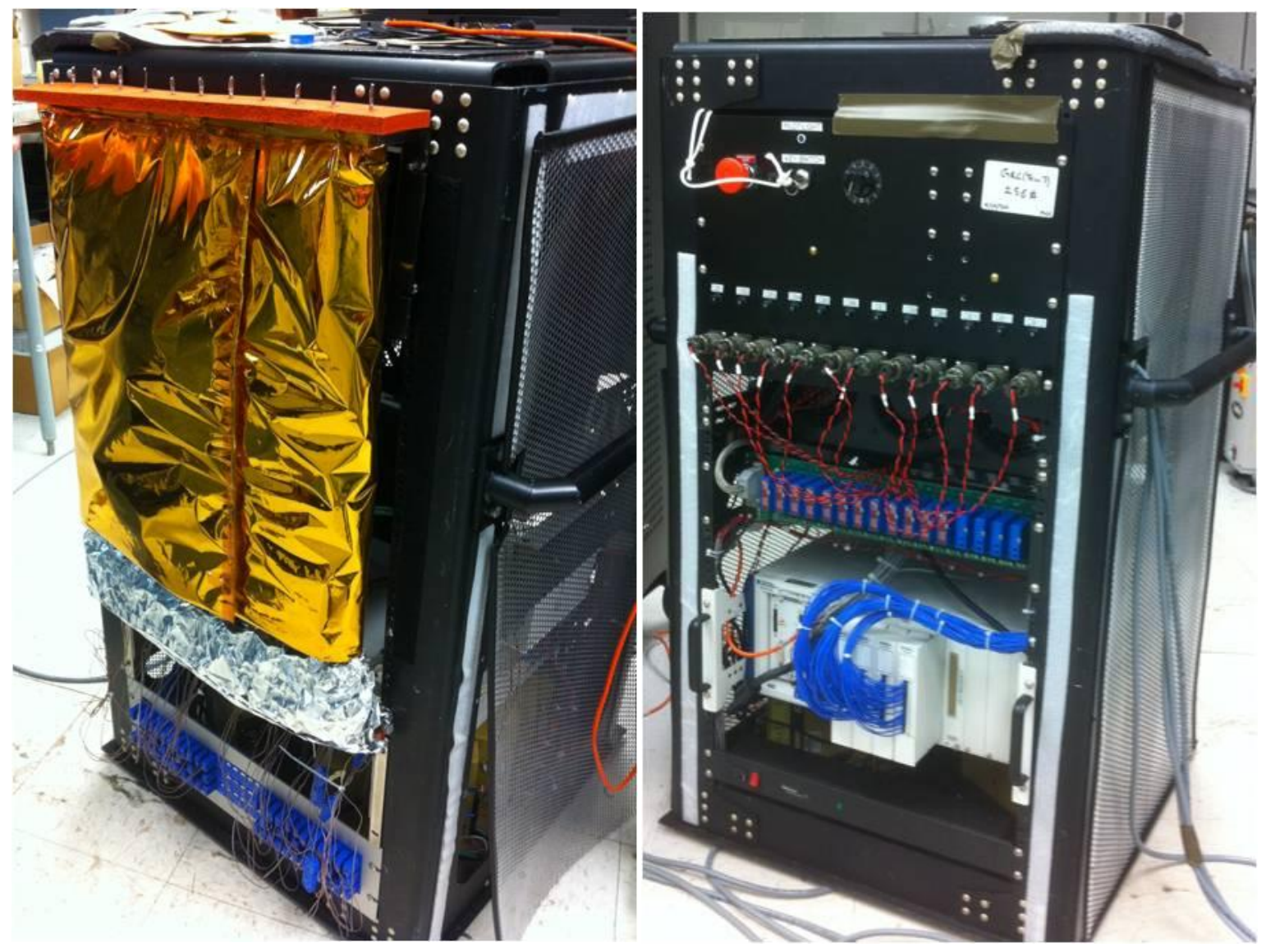

Figure 4.3 Thermosyphon Flooding Experiment 


\subsection{Reduced Gravity Data Analysis}

Initiating the flooding phenomenon during parabolic flights was more complicated than originally thought. Each parabola lasts approximately 80 seconds; 50-60 seconds of hyper-g at $1.8 \mathrm{~g}$ and 17 to 25 seconds at the reduced gravity target of zero, lunar, or Martian. Figure 4.4 shows a snapshot of data for thermosyphon \#8 taken during parabolic flight during the 2011 flight week. The left axis of the graph gives the power level in Watts and temperature in degrees Celsius. The horizontal axis gives the time elapsed in seconds and the right hand vertical axis provides the $g$ level produced by the 3 axis accelerometer mounted on the experiment rack. Three distinct Martian parabolas can be seen in the first few minutes of the data followed by the first six of twelve lunar parabolas. The gravity levels cannot be held exactly at the ideal levels due to the fact that the aircraft constantly has to adjust to the surrounding air. Small variations around the desired gravity levels can be seen in both reduced and hyper-g portions of the accelerometer data.

The flooding event can be seen taking place on the third lunar parabola using the constant power method as described in chapter 3. With the power held constant, the variable speed fan was increased to provide a cooler adiabatic temperature which forced the thermosyphon to cross the flooding limit. This can easily be depicted in the data as a sharp rise in the heater temperature and a sharp decrease in the condenser temperature. This is the tell tale sign that the heat transfer has been stalled and the thermosyphon is not moving vapor up to the condenser section.

Interestingly, the hyper-g pull of the aircraft forces the fluid from the condenser back to the evaporator to restart the heat transfer. This hyper-g push allows the thermosyphon to recover only to go into the next lunar gravity portion of the parabola where it stalls once again. This enabled the data analyst to make sure that the thermosyphon did in fact cross over into flooding by verifying 


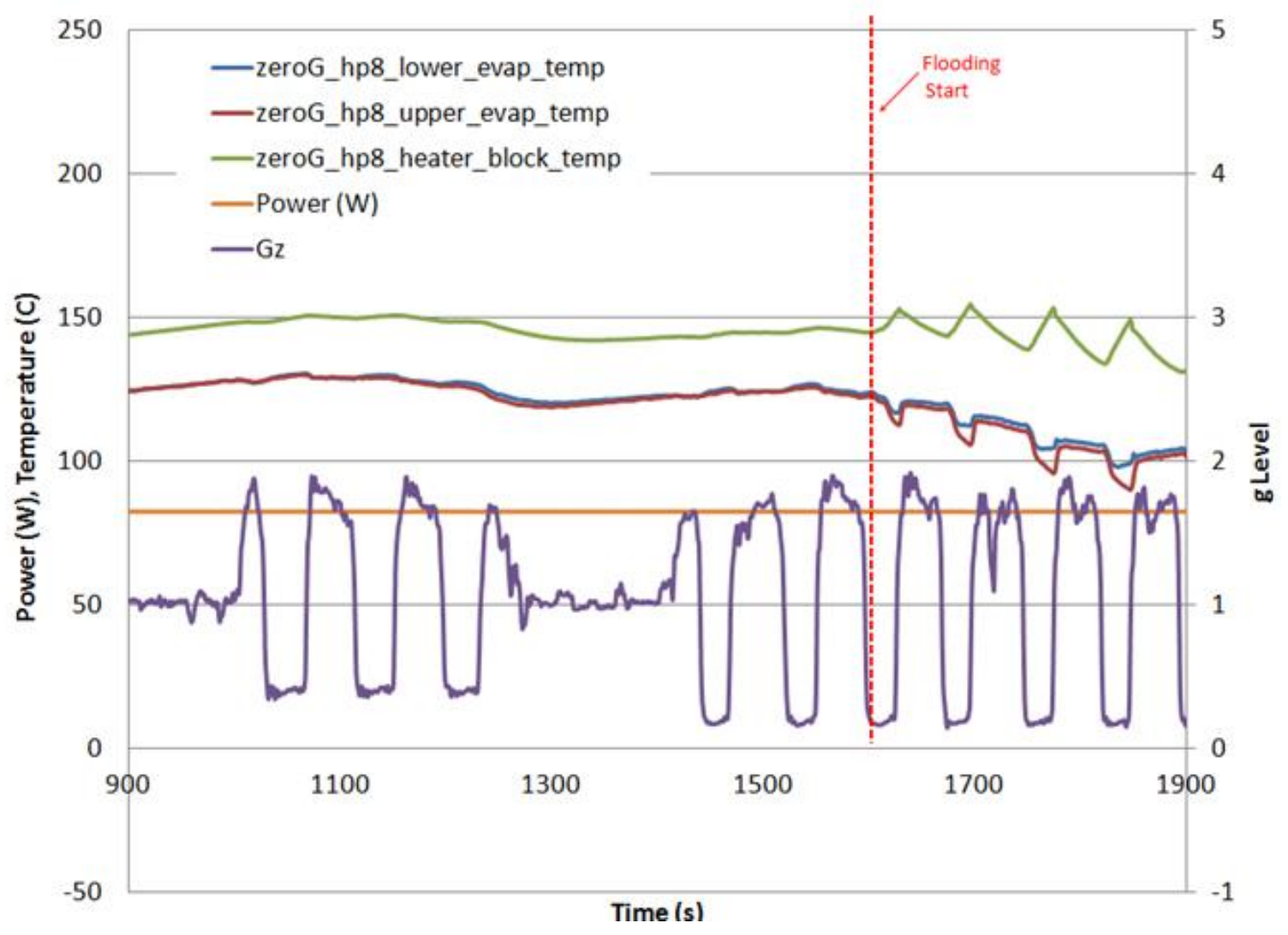

Figure 4.4 Flooding event data of thermosyphon number 8 taken during Martian and lunar gravity parabolas in Sept. 2011

multiple occurrences. Due to the fact that the thermosyphons could not work in zero gravity, all the flooding events needed to be captured during the lunar parabolas giving a total test time of approximately 15 to 20 minutes.

One of the most difficult tasks involved in parabolic testing was determining the correct power level and fan speed required to get close to the flooding limit without exceeding it. The $1 \mathrm{~g}$ laboratory testing as well as the parabolic testing confirmed that the slower the approach to the flooding limit, the higher the power level that could be obtained before flooding occurred. When the power level was set above the flooding limit, the thermosyphon would flood on the first parabola. This "First 
Parabola Flood" (FPF) would provide an upper bound to the heat transfer limit but not the precise flooding point. Figure 4.5 shows a good example of a FPF that almost made it through the first parabola but flooded half way through at a power level of 55W. Had the power been set at $50 \mathrm{~W}$ this thermosyphon may have continued to transfer heat into the second or third parabola giving an exact flooding power level. Having twelve thermosyphons in the array provided more opportunities to collect numerous flooding events throughout the flight. Even so, only 24 flooding events out of 96 attempts were recorded in the 2011 and 2012 flight weeks.

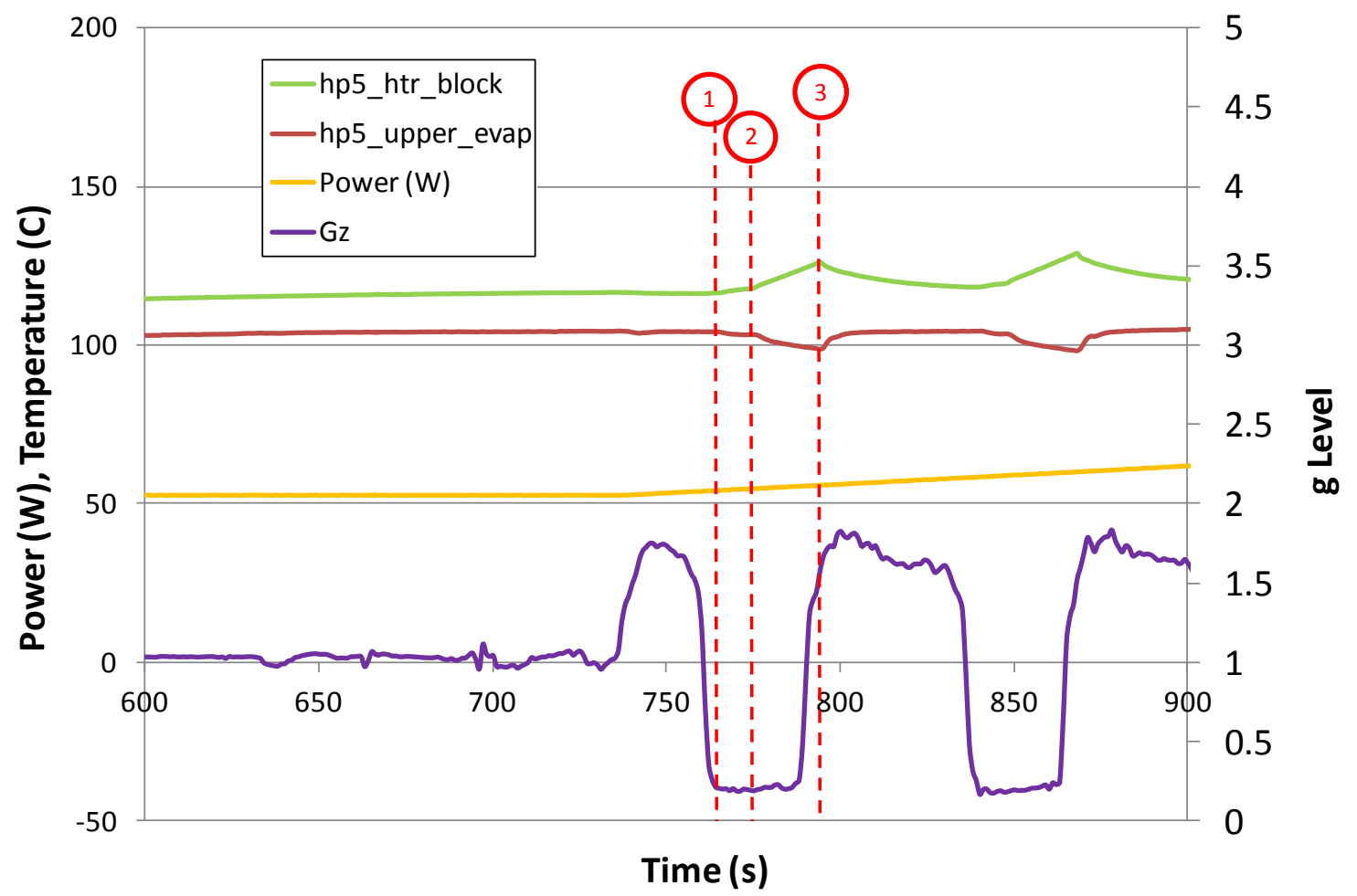

Figure 4.5 "First parabola flood" depicting 3 key events. 1) Lunar gravity forces decrease mass flow, heater temperature increases, upper evaporator temperature decreases. 2) Flooding occurs and heat transfer is stalled, slope change shows increase in heater temperature rate, no sign of recovery. 3) Hyper-g forces push fluid back to evaporator and cools heater until next parabola. 
After compiling all the data and performing the required analysis the flight data was compared to the predictive models to see if there were discrepancies. As with the $1 \mathrm{~g}$ testing, the test data did not confirm agreement with the model predictions. During the cooler temperatures the data seemed to agree well with Tien and Chung's model but as vapor temperatures increased it approached the Faghri model.

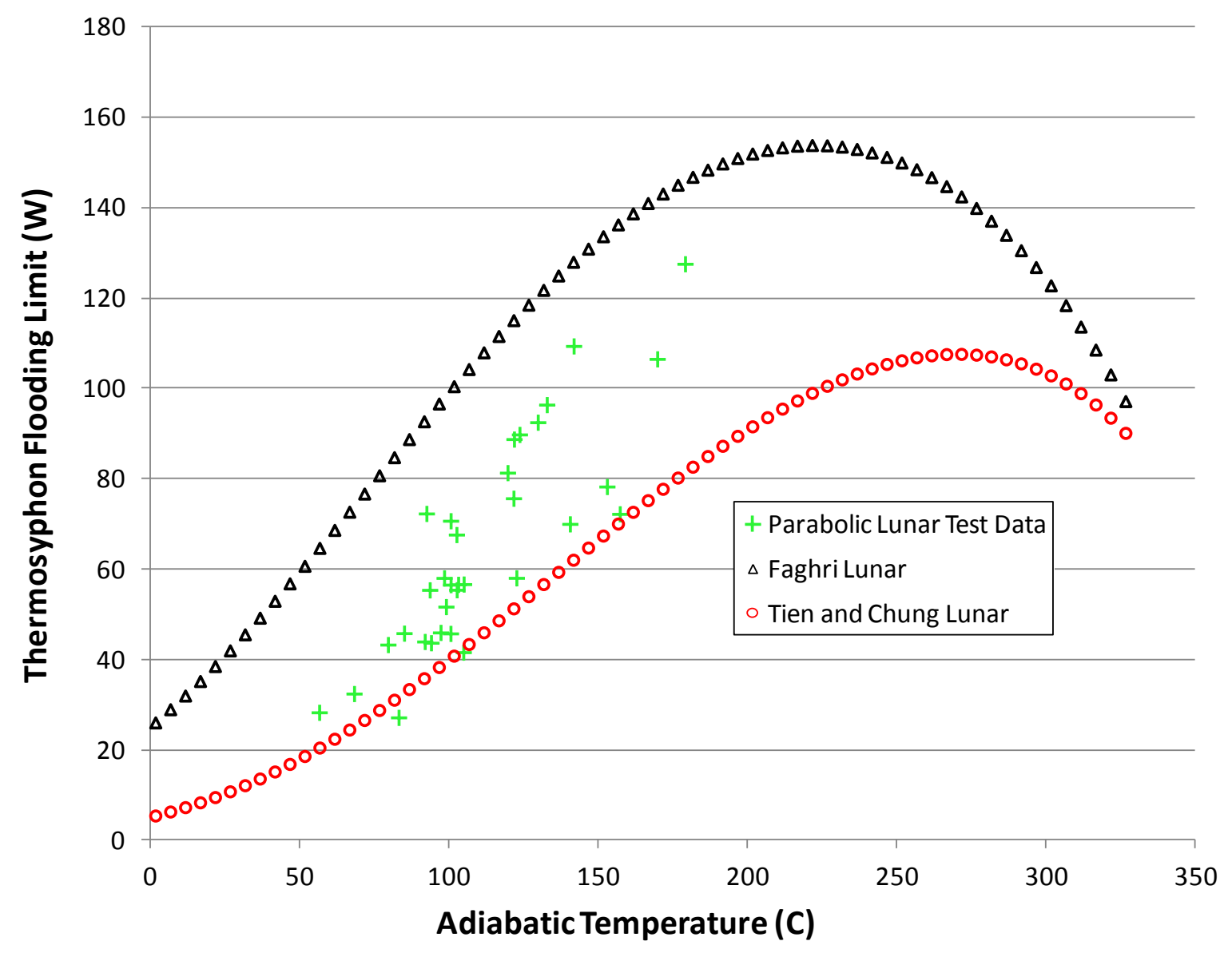

Figure 4.6 Parabolic flooding data during Lunar gravity compared to predictive models 


\section{Chapter 5: Data Correlation}

\subsection{Non-dimensional Analysis and Data Correlation}

In an effort to find a better correlation concerning the new flooding data, Faghri's equation was put into dimensionless form with the hopes that a new semi-empirical equation could be formed. The dimensionless form of equation (1.08) is shown as:

$$
\begin{gathered}
q=K B^{-1 / 4}(1-r)^{1 / 2}(r)^{-1 / 2}\left(1+r^{1 / 4}\right)^{-2} \\
q=\frac{Q_{\max }}{\rho_{v} h_{f g} A_{v} \sqrt{g D}} \\
B=\frac{D^{2} \rho_{l} g}{\sigma}(1-r) \\
K=\frac{1}{r^{0.14}} \tanh ^{2}\left(B^{1 / 8}\right)
\end{gathered}
$$

The right hand side of equation 5.01 is obtained directly from the fluid properties and the diameter of the thermosyphon and can be plotted as a function of temperature. The right hand side of equation 5.02 is plotted using the flooding limit from the test data as Qmax. Plots of the two equations are shown in figure 5.1. 

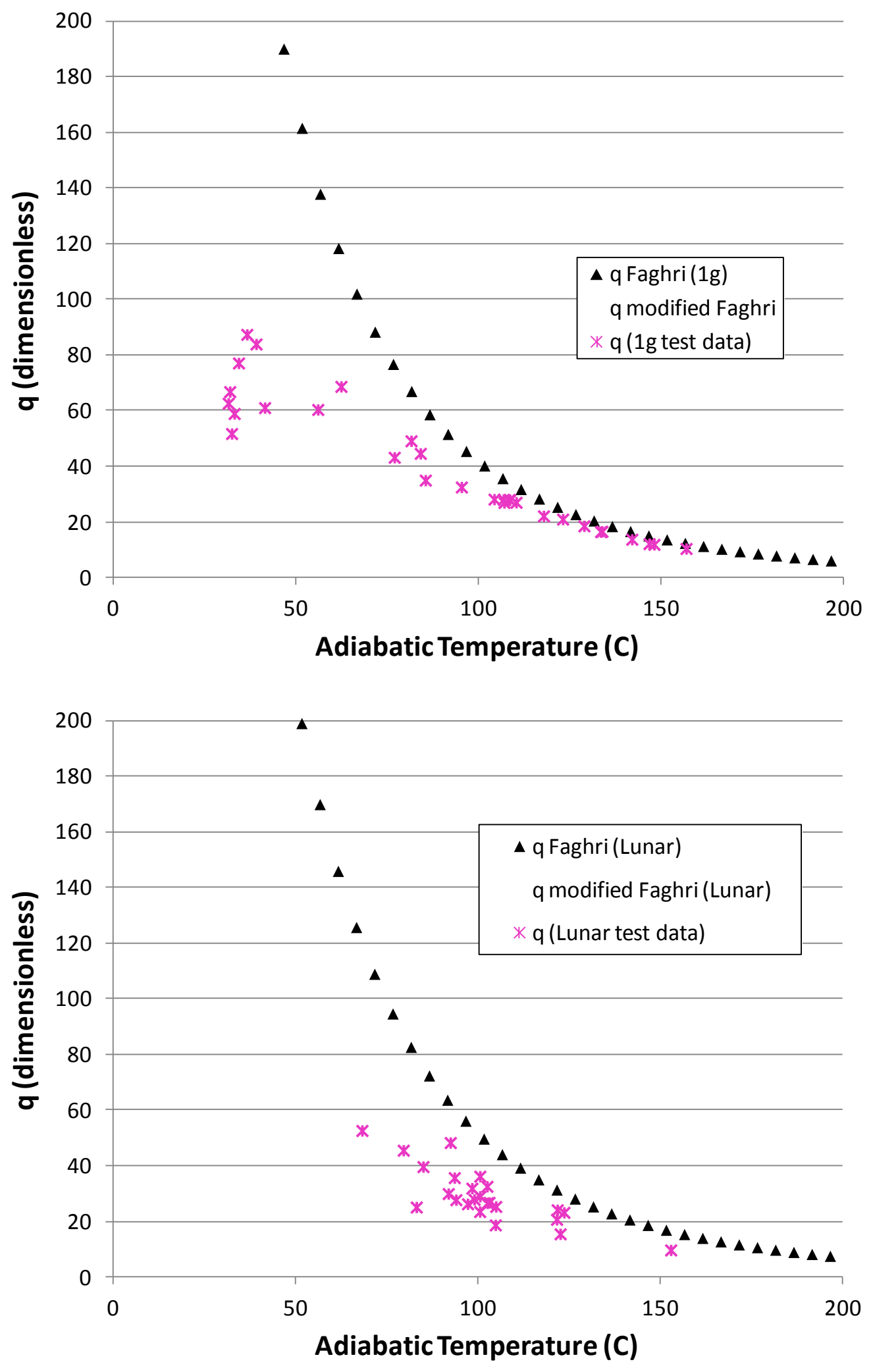

Figure 5.1 Non-dimensional parameter q from the original Faghri model vs. non-dimensional $\mathrm{q}$ test data at $1 \mathrm{~g}$, top, and Lunar gravity, bottom. 
Determining which non-dimensional group holds more prominence with the test data can be found by assigning and varying exponents to each group. During this process it was determined that setting the exponents for the Bond number B, and modified Kutateladze number $\mathrm{K}$ to zero made an accurate fit to the data. With these groups set to unity, the non dimensional flooding equation "q" became much simpler and relied solely on the ratio of the vapor density to the liquid density. The equation simplifies to:

$$
\text { Gibson } q=\frac{\sqrt{1-r}}{\sqrt{r}\left(1+r^{1 / 4}\right)^{2}}
$$

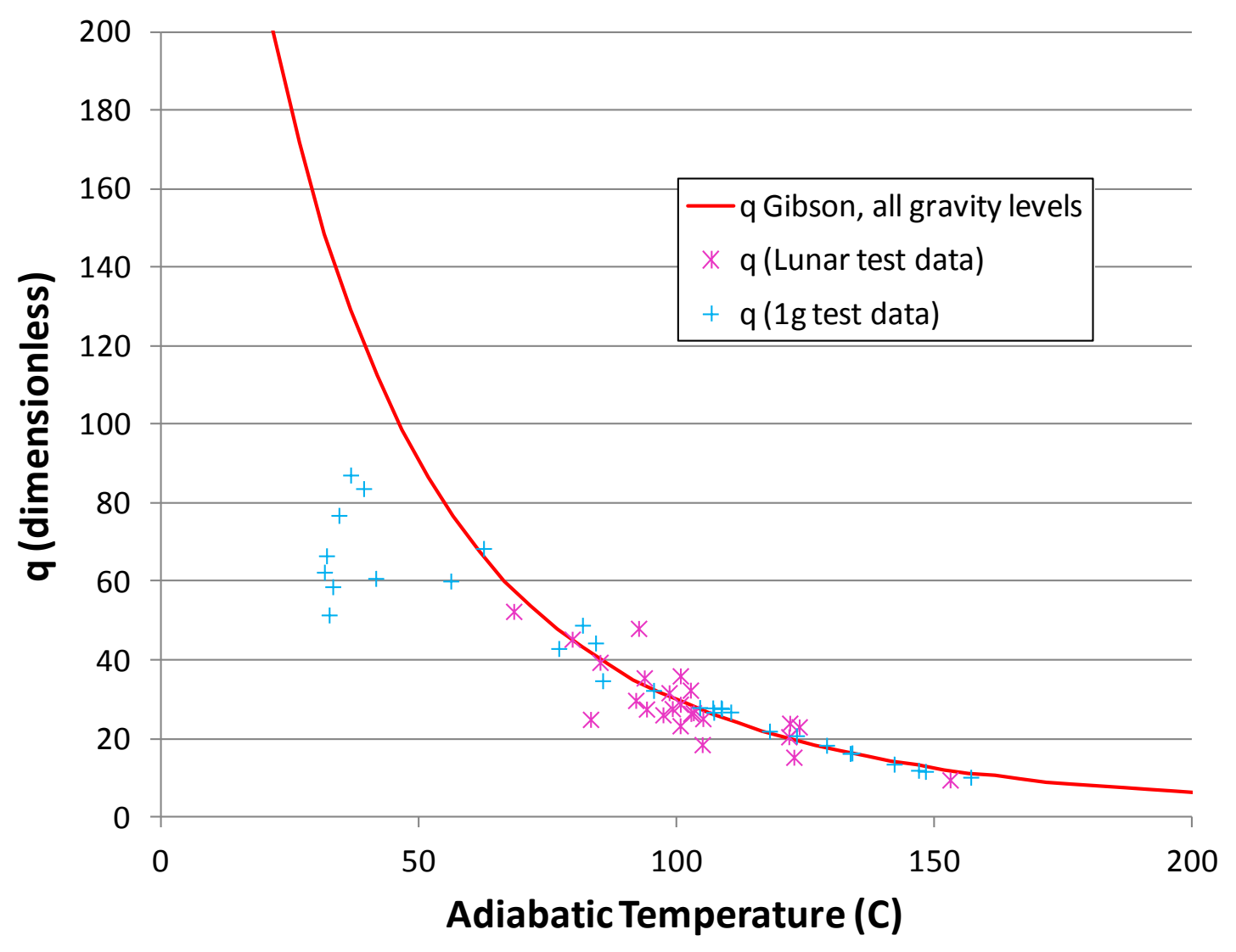

Figure 5.2 New non-dimensional Flooding Correlation " $q$ " showing gravity independence 
Plotting this function against both earth and lunar gravity data shows the uniqueness of the correlation and its independence from gravity levels (Fig. 5.2).

Taking if back to the dimensional form and solving for Qmax brings gravity, diameter, density, and enthalpy back into play as such:

$$
\text { Gibson } Q_{\max }=\frac{\rho_{v} A_{v} h_{f g} \sqrt{g D(1-r)}}{\sqrt{r}\left(1+r^{1 / 4}\right)^{2}}
$$

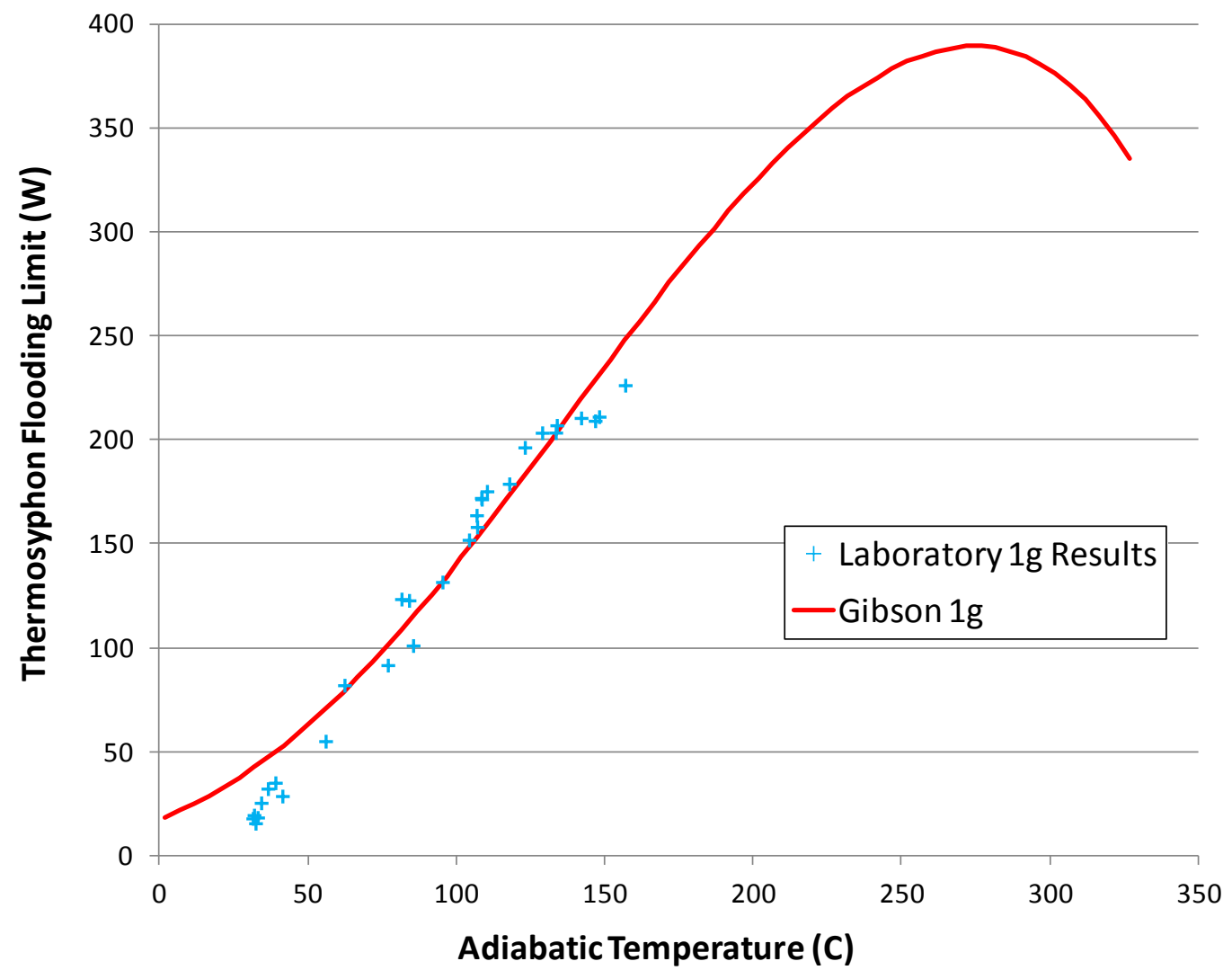

Figure 5.3 New Thermosyphon Flooding Correlation vs. 1g Test Data 


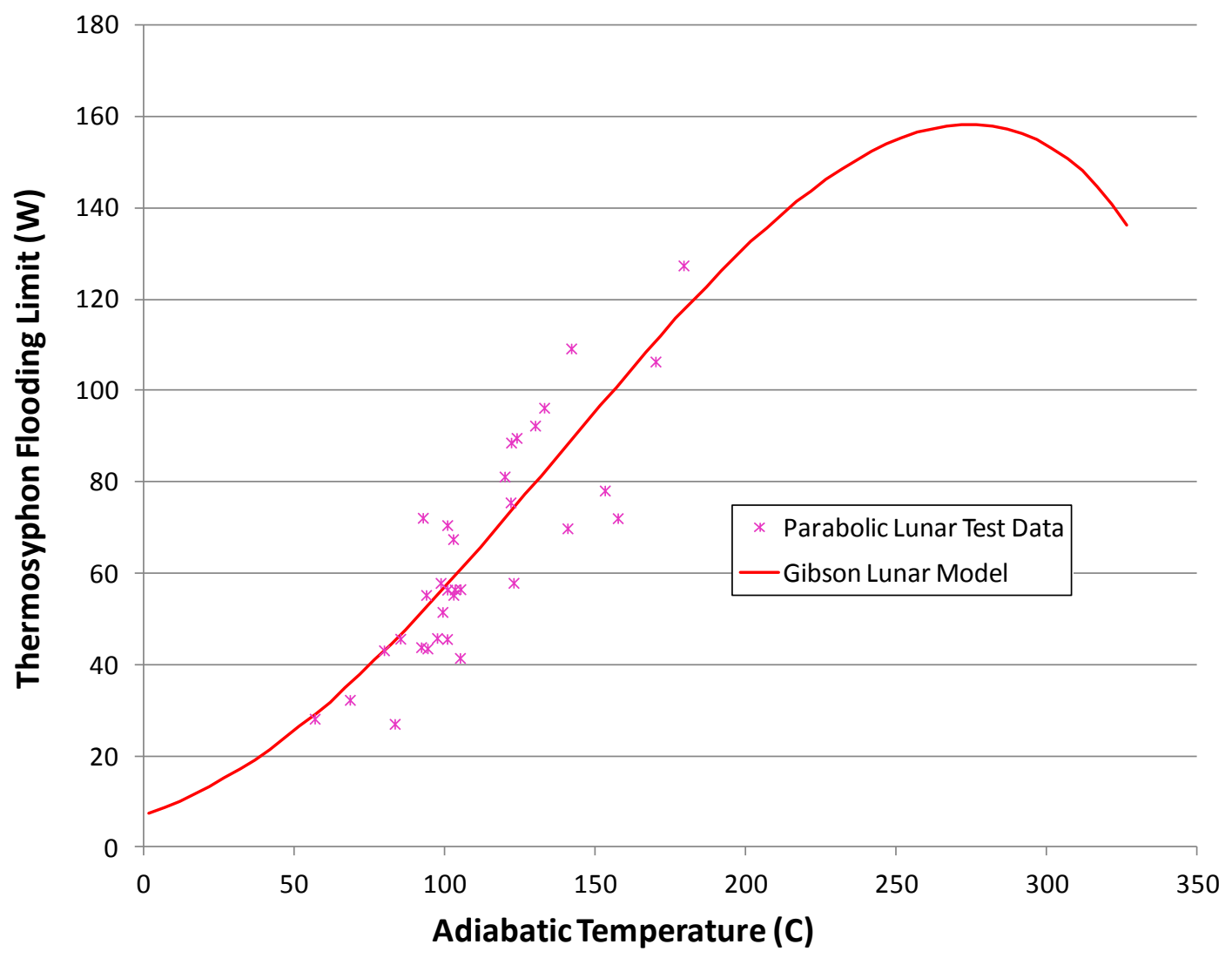

Figure 5.4 New Thermosyphon Flooding Correlation vs. Parabolic Lunar Test Data

The dimensional form also shows good agreement with the test data in both earth and lunar gravity fields (Figures 5.3 and 5.4). The data from the parabolic flights is a bit more sporadic which is understandable considering the nature of the gravity levels and the movement of the aircraft. During the data analysis it was evident that individual thermosyphons had better performance in some flights versus others. The presence of gravity disturbances in addition to the existing test variables could be seen with individual test units experiencing wider bands of flooding events. A statistical analysis of the errors associated with the experiment is included in appendix B. 
In the $1 \mathrm{~g}$ data of figure 5.1 and figure 5.3 is it observed that under 50 degrees Celsius the data is less repetitive and does not follow any of the models presented in this paper. This could possibly be a separate heat transfer limit, most likely the viscous limit, which can come into play at the lower operating heat fluxes and temperatures. The fact that the dimensionless parameter " $\mathrm{q}$ " shows a lot of variation at these lower temperatures as compared to the power Qmax is a good indicator that fluid properties, such as vapor density, may be dominating the results. The error analysis and additional explanation associated with the lower temperature data is included in appendix B.

It is also important to note that the surface tension component from the Bond number has been left out of the equations 5.06 and 5.07 which directly disagrees with leading correlations. Most literature claims that the surface tension is associated with wave instability at the evaporator throat and keeps the vapor shear forces from ripping fluid from the surface. One of the differences between this research and past work is the small diameter thermosyphons. There may be a point at small diameters where the fluid dynamics behave differently during flooding scenarios. 


\subsection{Conclusion}

The thermosyphon flooding limits are tested for the first time in reduced gravity. After two parabolic flights and several laboratory tests, the flooding heat transfer limit for thermosyphons in earth's gravity and lunar gravity is determined with a 95\% confidence level of $+/-5 \mathrm{~W}$. The nondimensional limit " $q$ " in Equation (5.06) is a function of the density ratio " $r$ " alone for both $1 \mathrm{~g}$ and lunar g. The dimensional form in equation (5.07) provides the flooding heat transfer limit in Watts using gravity as one of the function variables. The parabolic testing provides data in simulated lunar gravity and aided development of the new correlation with the density ratio.

The question of what flooding limit model is valid for a thermosyphon deployed in a reduced gravity environment such as the moon or Mars is addressed. Figure 1.6 shows that the Faghri and Tien and Chung models differ. The new flooding correlation from equation 5.07 shown in figure 5.5 gives confidence that thermosyphons proposed in the current lunar FPS design will not flood on the lunar surface.

Additional testing using different thermosyphon diameters and fluids will need to be completed to determine how well the new model holds up. History has shown that numerous thermosyphon flooding tests over several decades, from different sources, have been in disagreement. This reality leaves the opinion that each individual design should undergo testing, for the purpose of finding the heat transfer limits, in the laboratory, as well as in the relevant gravity environment, using the flight opportunities program and vehicle platforms. 


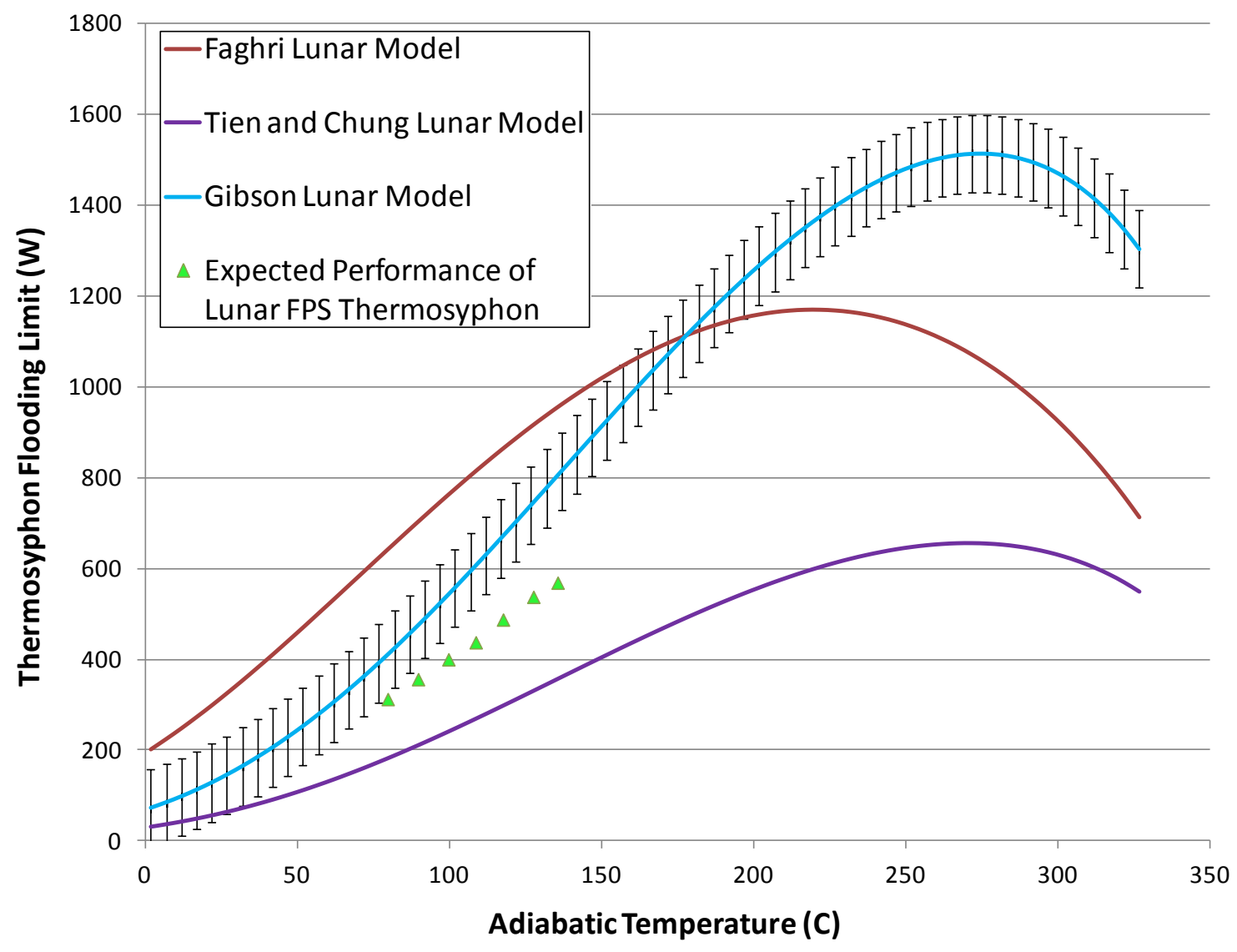

Figure 5.5 New thermosyphon flooding model, expected performance of an FPS thermosyphon on the lunar surface, and existing flooding models 


\section{Appendix A \\ One Dimensional Analysis}


The following work gives details of the one dimensional analysis discussed in chapter 1 . The analysis starts with the differential equation for the fluid flowing down along the tube walls. For reference, figure A.1 gives the graphical representation of the geometry and coordinate systems.

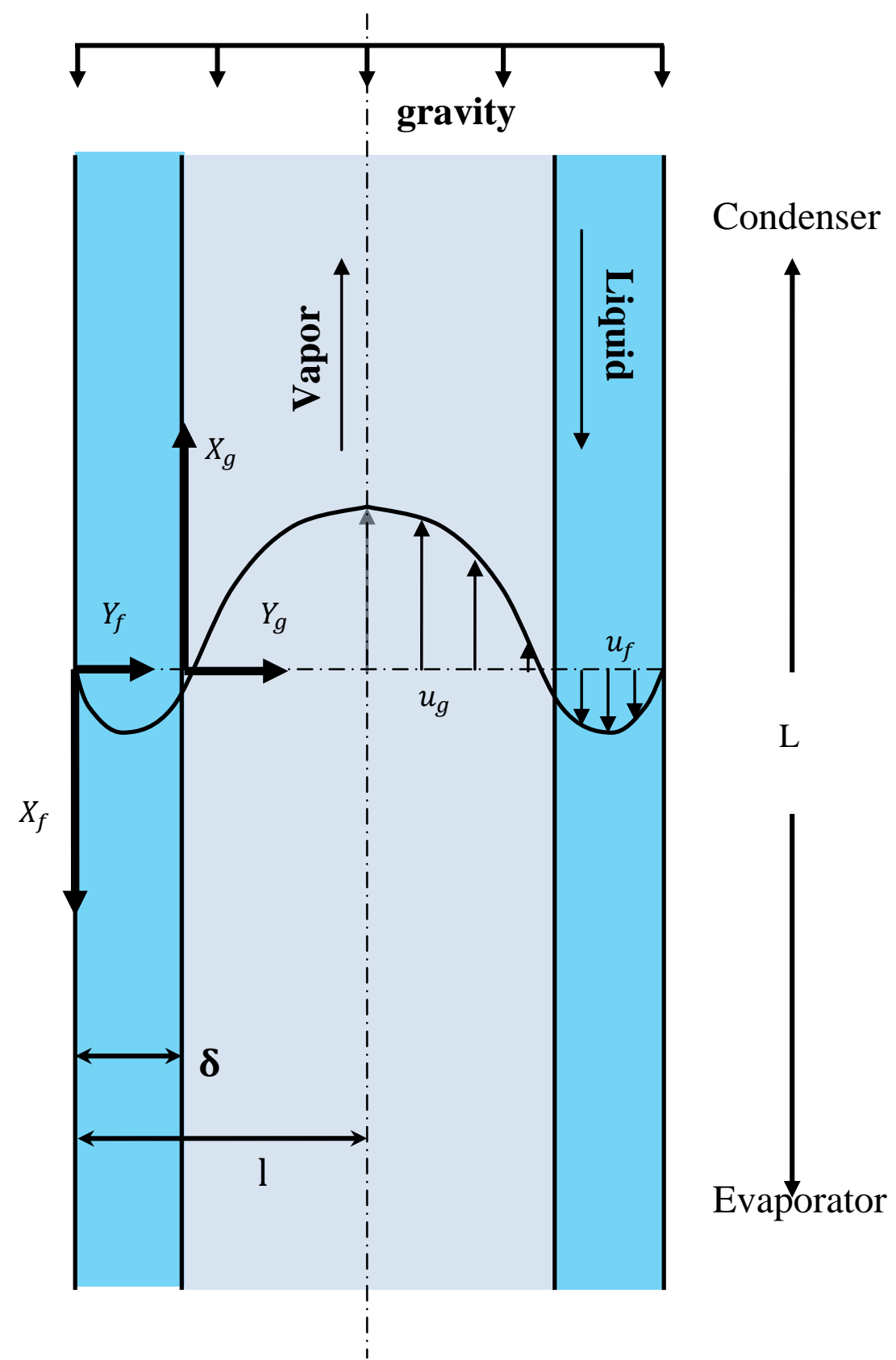

Figure A.1 One dimensional Diagram of the thermosyphon 


$$
\mu_{f}\left(\frac{d^{2} u_{f}}{d y_{f}^{2}}\right)-\frac{d P}{d x_{f}}+\rho_{f} g=0
$$

$$
\begin{array}{ll}
B C .1 & u_{f}=0 @ y_{f}=0 \\
B C .2 & \mu_{f} \frac{d u_{f}}{d y_{f}} @ \delta=-\tau_{f}=-\frac{\Delta P}{L}(l-\delta)
\end{array}
$$

Integrating twice using the given boundary conditions provides the desired fluid velocity profile as:

$$
\begin{aligned}
& u_{f}=\frac{y_{f}}{2 \mu_{f}}\left[\rho_{f} g\left(2 \delta-y_{f}\right)-\frac{\Delta P}{L}\left(2 l-y_{f}\right)\right] \\
& u_{f \delta}=\frac{\delta}{2 \mu_{f}}\left[\rho_{f} g(\delta)-\frac{\Delta P}{L}(2 l-\delta)\right]
\end{aligned}
$$

In order to obtain the mass flow rate of the fluid, the velocity is integrated over the fluid thickness between zero and delta and multiplied by the fluid density, giving the mass flow rate per unit width as:

$$
\dot{m}_{f}=\frac{l^{3}}{v_{f}}\left(\frac{\delta}{l}\right)^{2}\left\{\frac{\rho_{f} g \delta}{3 l}-\frac{\Delta P}{2 L}\left(1-\frac{\delta}{3 l}\right)\right\}
$$

Similar equations are developed for the vapor traveling up the center of the tube with the fluid as its boundary. The differential equation gives the following relationships: 


$$
\mu_{g}\left(\frac{d^{2} u_{g}}{d y_{g}^{2}}\right)+\frac{\Delta P}{L}=0
$$

$$
\begin{aligned}
& B C .1 \quad u_{g}=-u_{f} @ y_{g}=0 \\
& B C .2 \quad \frac{d u_{g}}{d y_{g}}=0 @ y_{g}=l-\delta
\end{aligned}
$$

Integrating to find the velocity profile of the gas gives:

$$
u_{g}=\frac{\Delta P}{L} \frac{y_{g}}{2 \mu_{g}}\left[2(l-\delta)-y_{g}\right]+\frac{\delta}{2 \mu_{f}}\left[\frac{\Delta P}{L}(2 l-\delta)-\rho_{f} g \delta\right]
$$

Integrating the vapor velocity between $\delta$ and $(l-\delta)$ and multiplying by the vapor density gives the mass flow rate per width as:

$$
\dot{m}_{g}=\frac{\Delta P}{L} \frac{l^{3}}{v_{g}}\left[\frac{1}{3}\left(1-\frac{\delta}{l}\right)^{3}+\frac{\mu_{g}}{\mu_{f}} \frac{\delta}{l}\left(1-\frac{\delta}{l}\right)\left(1-\frac{\delta}{2 l}\right)-\frac{\rho_{g} g l^{3}}{2 v_{f}}\left(\frac{\delta}{l}\right)^{2}\left(1-\frac{\delta}{l}\right)\right]
$$

The $\frac{\mu_{g}}{\mu_{f}}$ term drops out as it is $<<1$ giving:

$$
\dot{m}_{g}=\frac{\Delta P}{L} \frac{l^{3}}{v_{g}}\left[\frac{1}{3}\left(1-\frac{\delta}{l}\right)^{3}-\frac{\rho_{g} g l^{3}}{2 v_{f}}\left(\frac{\delta}{l}\right)^{2}\left(1-\frac{\delta}{l}\right)\right]
$$


Continuity ensures that the mass flows must be equal between the fluid and vapor. Setting the mass flow equations equal to each other and solving for $\Delta \mathrm{P} / \mathrm{L}$ gives:

$$
\frac{\Delta P}{L}=\frac{\frac{1}{3} \rho_{f} g\left(\frac{\delta}{l}\right)^{3}}{\frac{v_{f 1}}{v_{g} 3}\left(1-\frac{\delta}{l}\right)^{3}+\frac{1}{2}\left(\frac{\delta}{l}\right)^{2}\left(1-\frac{\delta}{3 l}\right)}
$$

Equation (1.04) can be applied to the following one dimensional analysis as follows:

$$
\dot{m}_{f}=\dot{m}_{g}=\frac{Q}{2 w h_{f g}}
$$

Inserting $\frac{\Delta P}{L}$ back into the fluid mass flow equation (A.06), and plugging into (A.14) gives an expression relating $\mathrm{Q}$ as a function of $\delta / l$ as:

$$
\frac{Q_{\max } v_{f}}{2 w h_{f g} \rho_{f} g l^{3}}=\frac{1}{3}\left(\frac{\delta}{l}\right)^{3}\left[1+\frac{3}{2} \frac{v_{g}}{v_{f}}\left(\frac{\delta}{l}\right)^{2}\left(1-\frac{\delta}{3 l}\right)\left(1-\frac{\delta}{l}\right)^{-3}\right]^{-1}
$$

Assuming negligible differences between the rectangular and cylindrical dimensions of the tube wall, a change is made to try and match the non-dimensional power parameter " $q$ " as described in chapter 5. In order to achieve this, the following assumptions are made: 


$$
\begin{gathered}
2 w=2 \pi l ; \text { Area of the vapor }=A_{v}=\pi l^{2} \\
q=\frac{Q_{\max }}{h_{f g} \rho_{g} A_{v} \sqrt{g D}}=\frac{l \sqrt{g D} \rho_{f}}{3 v_{f} \rho_{g}}\left(\frac{\delta}{l}\right)^{3}\left[1+\frac{3}{2} \frac{v_{g}}{v_{f}}\left(\frac{\delta}{l}\right)^{2}\left(1-\frac{\delta}{3 l}\right)\left(1-\frac{\delta}{l}\right)^{-3}\right]^{-1}
\end{gathered}
$$

The following one dimensional work was left out of the data analysis sections of the paper because it was not found to be entirely accurate when compared to the data, but it did give insight into the fluid dynamics associated with the liquid vapor shear in thermosyphons. A graph of the thermosyphon axial thermal power, Qmax in Eq. (A.15), vs. several values of $\delta / l$ for the $1 \mathrm{~g}$ laboratory case is shown in figure A.2. Values were chosen that accurately scaled the curves with the latest model produced from this research. The curve that best represents the $1 \mathrm{~g}$ model has a $\delta / l$ value of 0.04 which corresponds to a water fluid charge of approximately 0.8 grams, assuming all the fluid is in motion. As described in the paper, a fluid charge of 2.0 grams was found to give the best results. The equation gives a good representation of the flooding limit but determination of the $\operatorname{correct} \delta / l$ ratio that would allow the model to be used as a predictive tool would be difficult.

The non-dimensional form from equation (A.16) was also compared to the latest model using representative values of $\frac{\delta}{l}$. The results are shown in figure A.3 and give a good approximation to the shape and scale of the latest model representing the test data. 

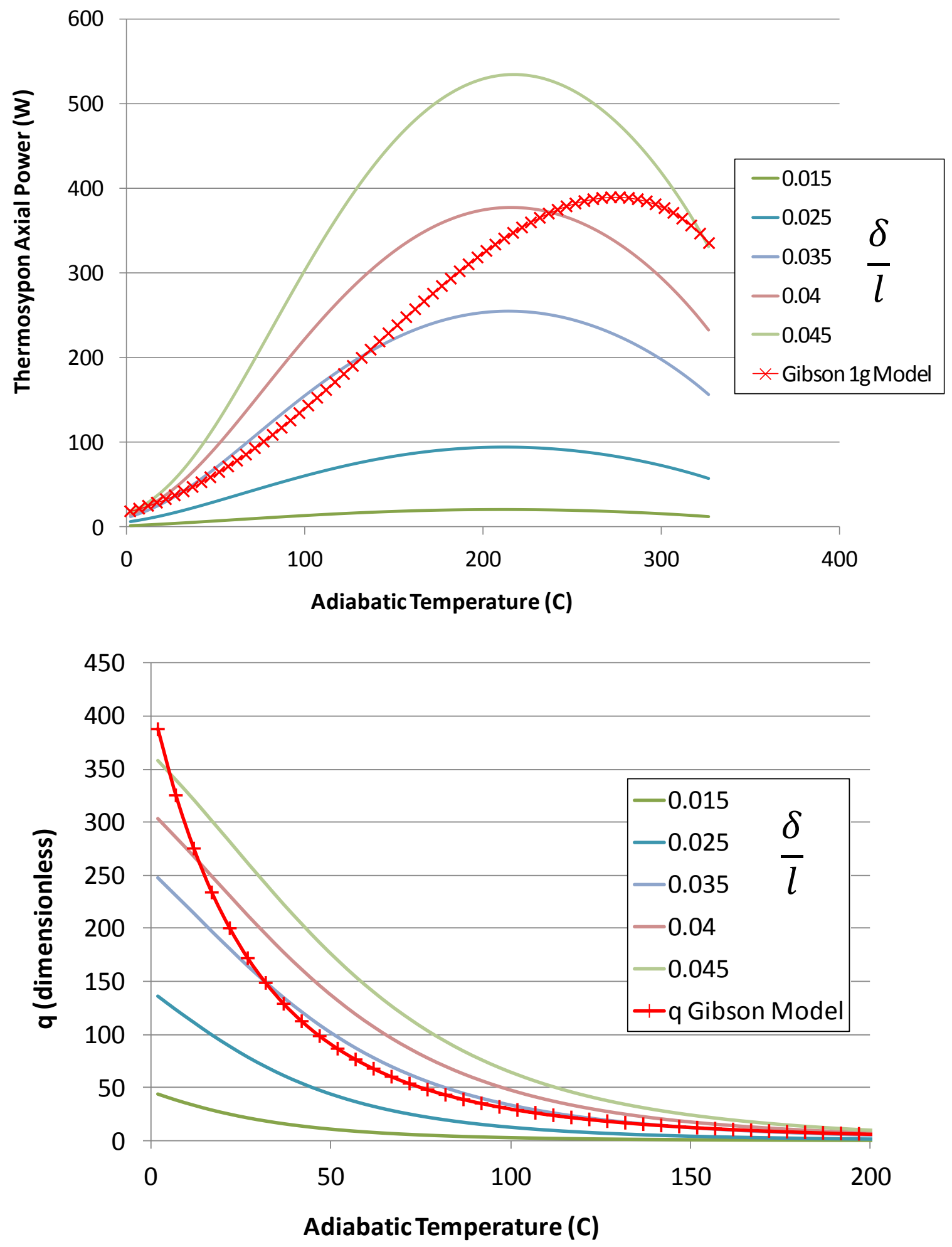

Figure A.2 Top: One dimensional analysis of the thermosyphon axial power limits vs. several $\frac{\delta}{l}$ ratios. Bottom: Non-dimensional power parameter " $\mathrm{q}$ " from the one dimensional analysis as compared to different values of $\frac{\delta}{r}$ and the latest flooding model. 


\section{Appendix B \\ Error Analysis}


The error associated with the test data was analyzed to compare it to the new flooding model that was formulated through this research. The goal was to quantify the amount of error, identify the source of the error, and determine the confidence level of the new flooding model.

The following standard deviation equation was used to quantify the amount of error between the new predictive flooding model and the test data.

$$
\sigma=\sqrt{\frac{\sum_{i}^{N}\left(y_{i}-y_{p}\right)^{2}}{N-1}} ; y_{p}=\text { model prediction }
$$

Data from both $1 \mathrm{~g}$ and lunar test results were graphically analyzed using error bars as can be seen in figure C.1. As mentioned in chapter 5, the lower temperature data from the $1 \mathrm{~g}$ testing did not match the model and it was assumed that the heat transfer limit seen in this temperature range was not a flooding event. The $1 \mathrm{~g}$ data was split into two groups to help identify the error difference between the $1 \mathrm{~g}$ data greater than and less than 60 degrees Celsius. The error analysis enforces the theory that the data falling below 60 degree Celsius is most likely not the flooding limit with a one sigma value of $+/-25 \mathrm{~W}$ which is more than $50 \%$ error at that power level. In order to start the thermosyphons from room temperature, an evaporator temperature of 30 to 60 degrees Celsius was needed and was influenced by the amount of non condensable gas (NCG), or lack of vacuum, in the thermosyphon. It is believed that the amount of NCG in the thermosyphons affected the heat transfer limit at the low end of the operating range and provided data associated with the viscous limit and not the flooding limit. This shows that the new flooding model should not be used below the temperature of 60 degrees Celsius when water is the working fluid. The lunar testing did not result in any data below 57 degrees Celsius and thus this error was not seen. 

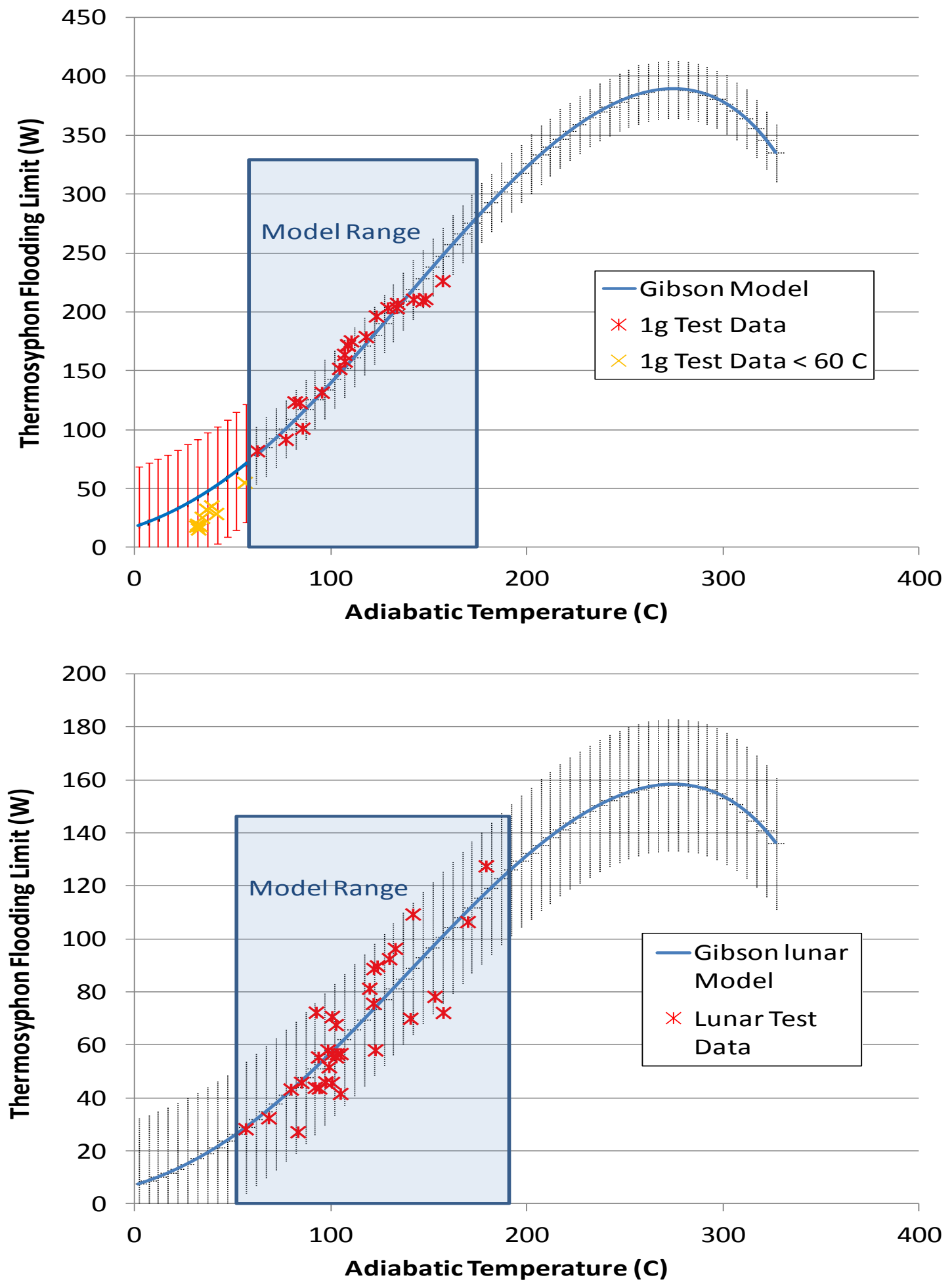

Figure B.1 Standard deviation of the $1 \mathrm{~g}$ and Lunar test data compared to the new flooding model. 
The lunar gravity data from the parabolic flight had a deviation of $12.59 \mathrm{~W}$ from the model and the $1 \mathrm{~g}$ laboratory data had a deviation of $12.58 \mathrm{~W}$. Although numerically similar, the percentage of these values compared to the vertical axis flooding limit for the $1 \mathrm{~g}$ and lunar data was much different as can be seed in figure C.1. In effort was made to try and understand the differences between the higher percentage error associated with the parabolic flight. Figure B.2 shows a typical three axis acceleration plot during parabolic maneuvers and depicts the deviation of the lunar gravity levels from the $0.1654 \mathrm{~g}$ target. The deviation of the gravity level from the target was then used to determine its impact on the total measured error and was found to be $0.6 \mathrm{~W}$ of the 12.6 total,

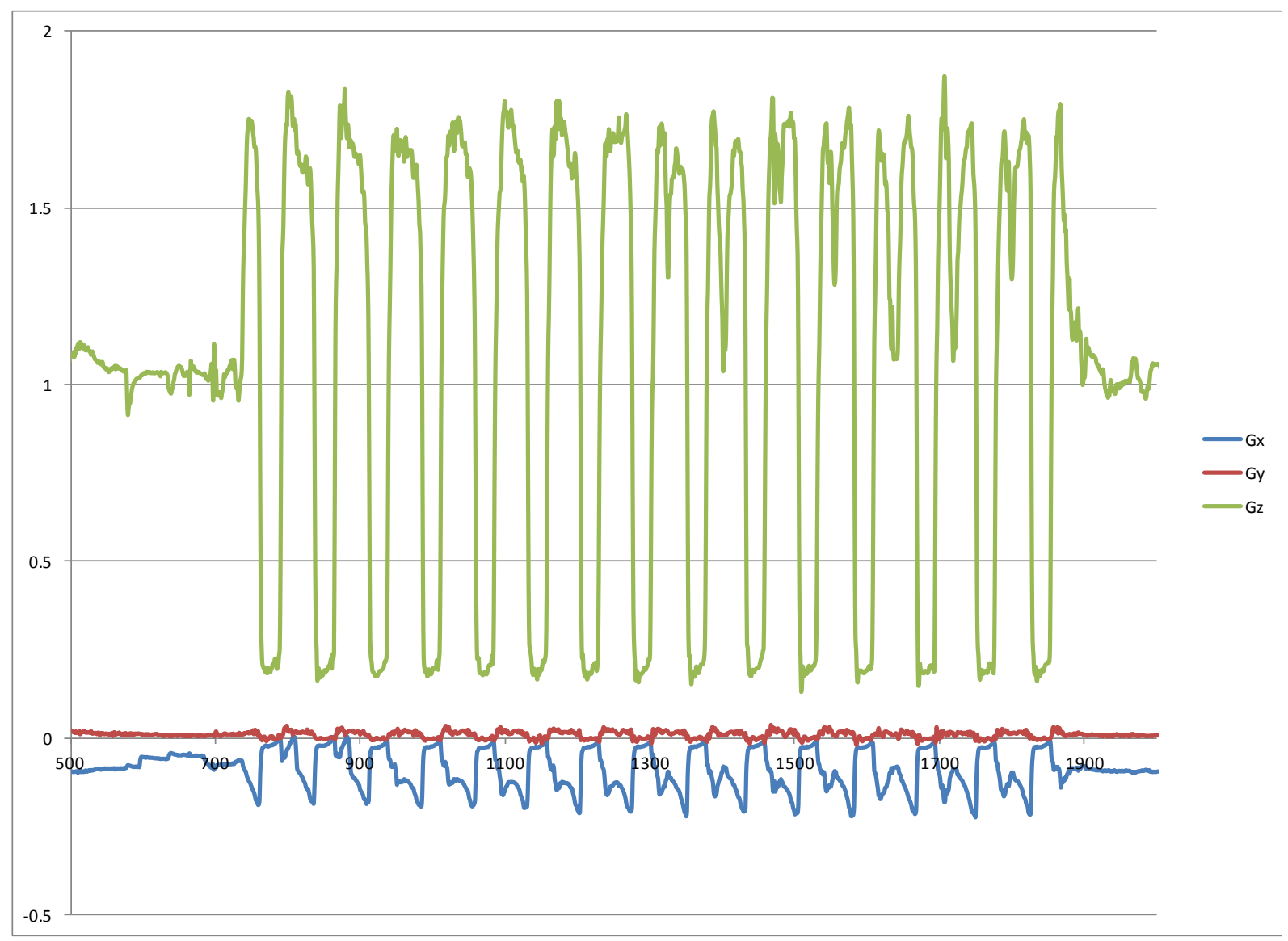

Figure B.2 3 axis accelerometer data during typical lunar gravity parabolas. 
approximately $5 \%$. Although not proven, it is believed that these error differences between the laboratory and parabolic flights are probably related to the vibration and pitch of the aircraft which can affect the fluid dynamics of the flooding phenomenon.

A confidence interval using the tabulated data was also calculated using equations B-02 and B-03 to gain assurance that the new flooding model would accurately predict a new data set. A confidence level of $95 \%$ was used for the calculations and resulted in values of $+/-5.4 \mathrm{~W}$ and $4.3 \mathrm{~W}$ for the $1 \mathrm{~g}$ and lunar test data respectively.

$$
\begin{gathered}
\text { confidence interval }=y_{p} \pm z \frac{\sigma}{\sqrt{N}} \\
z=\Phi^{-1}(\Phi(\mathrm{z})) ; \Phi(\mathrm{z})=1-\frac{\alpha}{2} ; \alpha=1-(\text { confidence level })
\end{gathered}
$$

Graphs of the data are shown in figures B.3. The test data and statistical analysis are shown in tables B.1 and B.2 for both lunar and $1 \mathrm{~g}$ testing. 

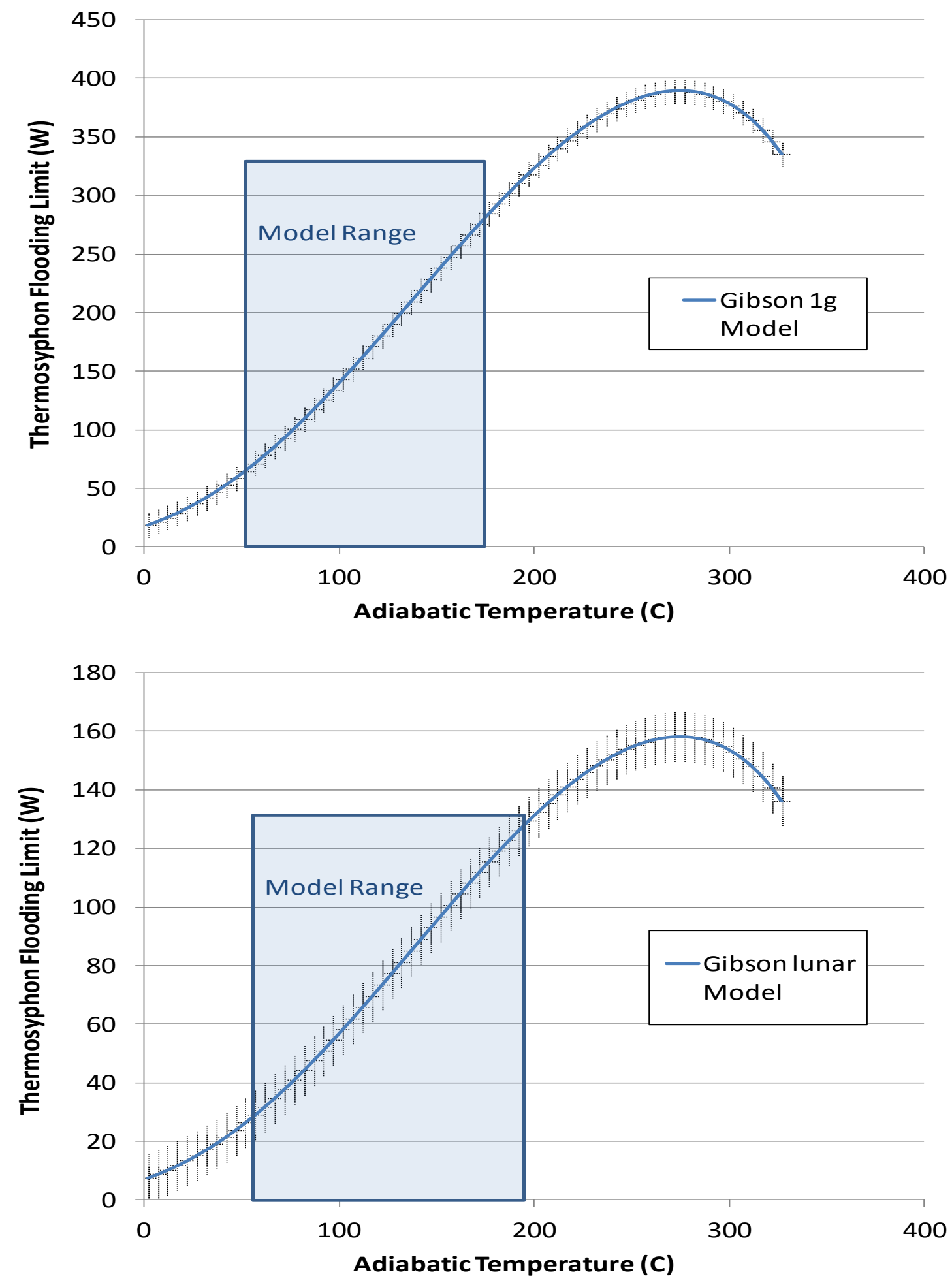

Figure B.3 The 95\% confidence interval for the $1 \mathrm{~g}$ and lunar model 


\begin{tabular}{|c|c|c|c|c|c|c|c|c|c|}
\hline \multirow{2}{*}{$\begin{array}{c}\text { Lunar } \\
\text { Ad. Temp (C) }\end{array}$} & \multicolumn{2}{|l|}{ Flight Data } & \multicolumn{2}{|c|}{ Model Prediction } & \multirow{2}{*}{$\frac{\left(y_{i}-y_{p}\right)^{2}}{q}$} & \multirow{2}{*}{$\frac{\left(y_{i}-y_{p}\right)^{2}}{\mathrm{Q}(\mathrm{W})}$} & & \multirow[b]{2}{*}{$q$} & \multirow[b]{2}{*}{$\mathrm{Q}(\mathrm{W})$} \\
\hline & $\mathrm{Q}(\mathrm{W})$ & $q(y i)$ & $q(y p)$ & $Q(W)$ & & & & & \\
\hline 57 & 28.13 & 74.30 & 76.58 & 28.99 & 5.19 & 0.74 & \multirow{3}{*}{$\sigma=\sqrt{\frac{\sum_{i}^{N}\left(y_{i}-y_{p}\right)^{2}}{N-1}}$} & \multirow[b]{3}{*}{5.29} & \multirow[b]{3}{*}{12.55} \\
\hline 68 & 32.28 & 52.43 & 58.03 & 35.72 & 31.33 & 11.87 & & & \\
\hline 80 & 43.12 & 45.35 & 45.10 & 42.88 & 0.06 & 0.06 & & & \\
\hline 83 & 27.01 & 24.93 & 41.78 & 45.26 & 283.98 & 333.18 & \multirow{3}{*}{$N$} & \multirow[b]{3}{*}{33} & \multirow[b]{3}{*}{33} \\
\hline 85 & 45.65 & 39.46 & 40.20 & 46.50 & 0.55 & 0.73 & & & \\
\hline 92 & 43.80 & 29.77 & 34.86 & 51.30 & 25.94 & 56.16 & & & \\
\hline 93 & 72.13 & 48.10 & 34.47 & 51.69 & 185.79 & 417.80 & \multirow{3}{*}{$\frac{\sigma}{\sqrt{N}}$} & & \multirow[b]{3}{*}{2.19} \\
\hline 94 & 55.22 & 35.50 & 33.72 & 52.46 & 3.14 & 7.61 & & & \\
\hline 94 & 43.53 & 27.57 & 33.43 & 52.78 & 34.34 & 85.60 & & 0.92 & \\
\hline 97 & 45.81 & 26.10 & 31.37 & 55.07 & 27.84 & 85.76 & \multirow{3}{*}{$\alpha$} & & \multirow[b]{3}{*}{0.05} \\
\hline 99 & 57.87 & 31.71 & 30.65 & 55.93 & 1.13 & 3.76 & & & \\
\hline 99 & 51.52 & 27.67 & 30.28 & 56.38 & 6.82 & 23.63 & & 0.05 & \\
\hline 101 & 45.59 & 23.31 & 29.40 & 57.49 & 37.03 & 141.62 & \multirow{3}{*}{$\Phi(\mathrm{z})=1-\frac{\alpha}{2}$} & & \multirow[b]{3}{*}{0.98} \\
\hline 101 & 56.38 & 28.80 & 29.38 & 57.52 & 0.34 & 1.30 & & & \\
\hline 101 & 70.52 & 36.01 & 29.38 & 57.52 & 44.07 & 168.98 & & 0.98 & \\
\hline 103 & 67.46 & 32.37 & 28.29 & 58.96 & 16.64 & 72.27 & \multirow{3}{*}{$z=\Phi^{-1}(\Phi(\mathrm{z}))$} & \multirow[b]{3}{*}{1.95} & \multirow[b]{3}{*}{1.95} \\
\hline 103 & 55.25 & 26.44 & 28.24 & 59.02 & 3.27 & 14.27 & & & \\
\hline 103 & 56.44 & 26.61 & 27.99 & 59.37 & 1.91 & 8.58 & & & \\
\hline 105 & 41.44 & 18.51 & 27.09 & 60.65 & 73.58 & 368.87 & \multirow{3}{*}{$z \frac{\sigma}{\sqrt{N}}$} & \multirow[b]{3}{*}{1.80} & \multirow[b]{3}{*}{4.28} \\
\hline 105 & 56.50 & 25.14 & 27.02 & 60.74 & 3.55 & 17.96 & & & \\
\hline 120 & 81.16 & 23.33 & 20.66 & 71.88 & 7.11 & 86.08 & & & \\
\hline 122 & 75.50 & 20.51 & 19.95 & 73.42 & 0.32 & 4.31 & & & \\
\hline 122 & 88.59 & 23.95 & 19.89 & 73.56 & 16.51 & 225.92 & & & \\
\hline 123 & 57.89 & 15.30 & 19.61 & 74.19 & 18.57 & 265.80 & & & \\
\hline 124 & 89.62 & 23.02 & 19.26 & 74.98 & 14.13 & 214.13 & & & \\
\hline 130 & 92.33 & 20.08 & 17.34 & 79.76 & 7.47 & 157.98 & & & \\
\hline 133 & 96.22 & 19.31 & 16.48 & 82.12 & 8.00 & 198.67 & & & \\
\hline 141 & 69.83 & 11.49 & 14.51 & 88.20 & 9.13 & 337.38 & & & \\
\hline 142 & 109.20 & 17.42 & 14.22 & 89.17 & 10.21 & 401.27 & & & \\
\hline 153 & 78.09 & 9.52 & 11.93 & 97.87 & 5.81 & 391.14 & & & \\
\hline 157 & 72.05 & 7.95 & 11.17 & 101.19 & 10.35 & 849.30 & & & \\
\hline 170 & 106.34 & 8.91 & 9.27 & 110.66 & 0.13 & 18.69 & & & \\
\hline 179 & 127.38 & 8.79 & 8.10 & 117.46 & 0.47 & 98.50 & & & \\
\hline
\end{tabular}

Table B.1 Lunar parabolic flight data and statistical analysis 


\begin{tabular}{|c|c|c|c|c|c|c|c|c|c|}
\hline \multirow{2}{*}{$\begin{array}{l}\text { Ig } \\
\text { Ad. Temp (C) }\end{array}$} & \multicolumn{2}{|c|}{ Laboratory Data } & \multicolumn{2}{|c|}{ Model Prediction } & \multirow{2}{*}{$\frac{\left(y_{i}-y_{p}\right)^{2}}{\mathrm{q}}$} & \multirow{2}{*}{$\frac{\left(y_{i}-y_{p}\right)^{2}}{\mathrm{Q}(\mathrm{W})}$} & & \multirow[b]{2}{*}{$q$} & \multirow[b]{2}{*}{$\mathrm{Q}(\mathrm{W})$} \\
\hline & $\mathrm{Q}(\mathrm{W})$ & $q(y i)$ & $q(y p)$ & $\mathrm{Q}(\mathrm{W})$ & & & & & \\
\hline 62.58 & 81.63 & 68.46 & 66.54 & 79.34 & 3.69 & 5.24 & \multirow{3}{*}{$\sigma=\sqrt{\frac{\sum_{i}^{N}\left(y_{i}-y_{\nu}\right)^{2}}{N-1}}$} & & \\
\hline 77.18 & 91.28 & 42.99 & 47.71 & 101.31 & 22.30 & 100.57 & & & \\
\hline 81.79 & 123.08 & 48.92 & 43.21 & 108.72 & 32.61 & 206.47 & & 2.50 & 12.58 \\
\hline 84.33 & 122.45 & 44.39 & 40.94 & 112.92 & 11.94 & 90.86 & \multirow{3}{*}{$N$} & \multirow[b]{3}{*}{21} & \multirow[b]{3}{*}{21} \\
\hline 85.70 & 100.72 & 34.78 & 39.78 & 115.20 & 24.98 & 209.46 & & & \\
\hline 95.59 & 131.28 & 32.31 & 32.53 & 132.19 & 0.05 & 0.82 & & & \\
\hline 104.54 & 151.56 & 27.95 & 27.34 & 148.25 & 0.37 & 10.98 & \multirow{3}{*}{$\frac{\sigma}{\sqrt{N}}$} & & \\
\hline 107.08 & 163.41 & 27.86 & 26.06 & 152.90 & 3.21 & 110.49 & & & \\
\hline 107.27 & 157.77 & 26.74 & 25.97 & 153.25 & 0.59 & 20.51 & & 0.55 & 2.74 \\
\hline 108.69 & 171.73 & 27.86 & 25.29 & 155.87 & 6.61 & 251.30 & \multirow{3}{*}{$\alpha$} & \multirow[b]{3}{*}{0.05} & \multirow[b]{3}{*}{0.05} \\
\hline 108.81 & 171.13 & 27.67 & 25.24 & 156.09 & 5.91 & 226.27 & & & \\
\hline 110.57 & 174.93 & 26.81 & 24.42 & 159.36 & 5.70 & 242.56 & & & \\
\hline 118.09 & 178.55 & 21.94 & 21.32 & 173.45 & 0.39 & 25.99 & \multirow{3}{*}{$\Phi(\mathrm{z})=1-\frac{\alpha}{2}$} & & \multirow[b]{3}{*}{0.98} \\
\hline 123.34 & 196.07 & 20.78 & 19.43 & 183.42 & 1.80 & 160.09 & & & \\
\hline 129.18 & 203.10 & 18.35 & 17.58 & 194.61 & 0.59 & 72.20 & & 0.98 & \\
\hline 133.75 & 203.19 & 16.26 & 16.28 & 203.39 & 0.00 & 0.04 & \multirow{3}{*}{$z=\Phi^{-1}(\Phi(\mathrm{z}))$} & & \multirow[b]{3}{*}{1.95} \\
\hline 134.10 & 206.70 & 16.39 & 16.18 & 204.07 & 0.04 & 6.88 & & & \\
\hline 142.29 & 210.25 & 13.54 & 14.16 & 219.87 & 0.38 & 92.53 & & 1.95 & \\
\hline 147.03 & 208.87 & 11.97 & 13.13 & 228.97 & 1.33 & 404.12 & \multirow{3}{*}{$z \frac{\sigma}{\sqrt{N}}$} & & \multirow[b]{3}{*}{5.35} \\
\hline 148.37 & 210.85 & 11.70 & 12.85 & 231.54 & 1.32 & 427.98 & & & \\
\hline 157.17 & 226.00 & 10.21 & 11.22 & 248.30 & 1.02 & 497.34 & & 1.06 & \\
\hline
\end{tabular}

Table B.2 $1 \mathrm{~g}$ Laboratory data and statistical analysis 


\section{Appendix C \\ Test Equipment Data Package}




\section{Thermosyphon Flooding in Reduced Gravity Environments}

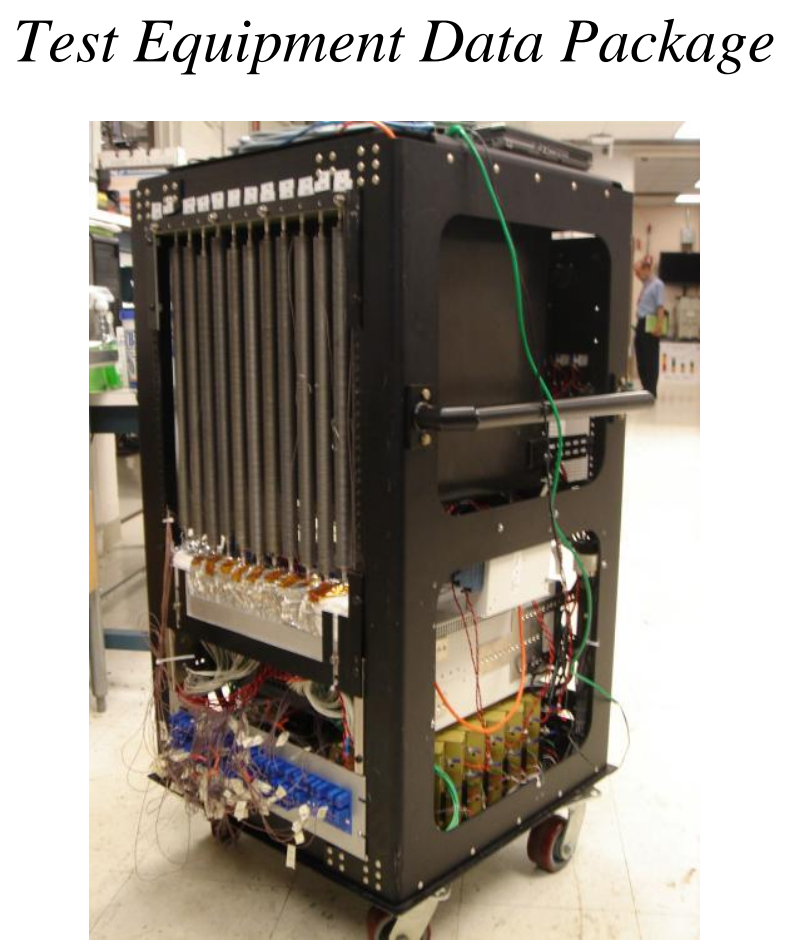

\section{April 3, 2012}

Space Power and Propulsion Division

NASA Glenn Research Center

21000 Brookpark Rd.

Cleveland, OH 44135

Marc Gibson

James Sanzi

Damir Ljubanovic
PI

HTLE

ETE marc.a.gibson@nasa.gov james.l.sanzi@nasa.gov Damir.ljubanovic-1@nasa.gov

Team Contact: $\quad$ Marc Gibson; 216-433-5562

marc.a.gibson@nasa.gov 


\section{REVISION HISTORY}

\begin{tabular}{|c|l|c|}
\hline Revision & \multicolumn{1}{|c|}{ Description } & Date \\
\hline TEDP-1.0 & Initial Release & $08 / 08 / 11$ \\
\hline TEDP-1.1 & $\begin{array}{l}\text { Back up flyer, Structural Verification Calculations \& Casters } \\
\text { Added, EP30HT-LO Data Sheets Removed }\end{array}$ & $08 / 24 / 11$ \\
\hline TEDP-1.2 & $\begin{array}{l}\text { Structural Verification Calculations Updated, Vertical } \\
\text { Equipment Rack, Laptop Computer Storage, Caster Installation } \\
\text { and Removal }\end{array}$ & $09 / 01 / 11$ \\
\hline TEDP-1.3 & $\begin{array}{c}\text { Structural Verification Section Updated, Hazards Analysis } \\
\text { Updated, Flight Manifest Updated }\end{array}$ & $09 / 14 / 11$ \\
\hline TEDP-1.4 & Thermosyphon inner rack attachment details, Figure 6b & $11 / 04 / 11$ \\
\hline TEDP-1.5 & $\begin{array}{c}\text { Recycle 2012 changes, basic word changes to reflect fully } \\
\text { wicked heat pipes that will be flown in 1/6 g and zero gravity; } \\
\text { changes to max. Amperage with real time monitoring and } \\
\text { adjustable limits based on flight; change of PI and flight } \\
\text { manifest. }\end{array}$ & $1 / 20 / 2012$ \\
\hline TEDP-1.6 & Section 5a was added for hinged access to heat pipes & \\
\hline TEDP-1.7 & Electrical Questionnaire attached to end of document & $3 / 17 / 2012$ \\
\hline TEDP-1.8 & Removed Don Jaworske from Flight Manifest on page 5 & $3 / 28 / 2012$ \\
\hline
\end{tabular}




\section{QUICK REFERENCE DATA SHEET}

Principal Investigator: Marc Gibson

Contact Information: marc.a.gibson@nasa.gov, (216) 433-5562

Experiment Title: Thermosyphon Flooding in Reduced Gravity Environments

Work Breakdown Structure (WBS): 887359.04.01.05.03

Flight Date(s):

Overall Assembly Weight: 275 [lbs.]

Assembly Dimensions (L, W, H): 24.0, 24.0, 42.19 [in]

Equipment Orientation Requests: The zero-g flight approved Vertical

Equipment Rack which holds the experiment equipment will be bolted to the floor of the aircraft. Heat Pipe side of experiment will face toward cabin wall.

Proposed Floor Mounting Strategy (Bolts/Studs or Straps): Bolts

Gas Cylinder Requests (Type \& Quantity): No

Overboard Vent Request (Yes or No): No

Power Requirement (Voltage and Current Required): 115 VAC, 20 amps (Max amperage is monitored and adjustable for each flight to accommodate RGO requirements. In past flights RGO gave us limits that we verified before each flight.

Free Float Experiment (Yes or No): No

Flyer Names for Each Proposed Flight Day: Marc Gibson, Damir Ljubanovic, Jim Sanzi as follows: Flt. Day 1: MG, DL, JS; Flt Day 2: MG, DL, JS, Flt Day 3: MG, DL,JS; Flt. Day 4: MG, DL,JS

Camera Pole and/or Video Support: No 


\section{Table of Contents}

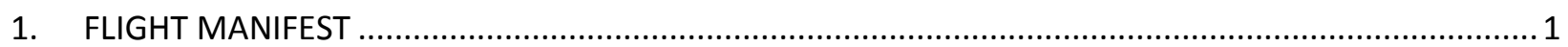

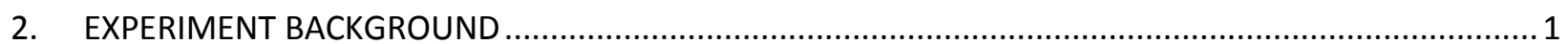

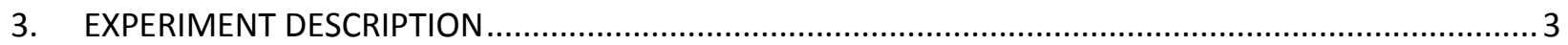

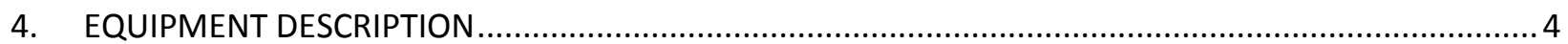

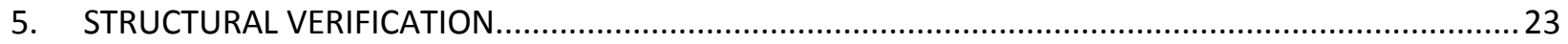

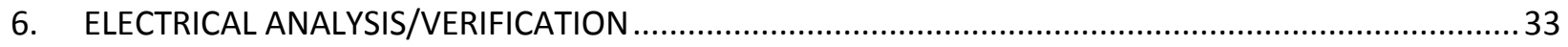

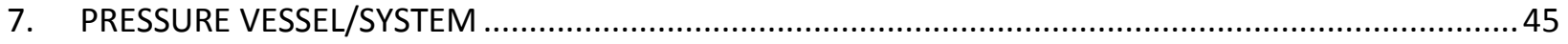

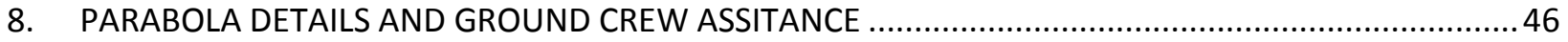

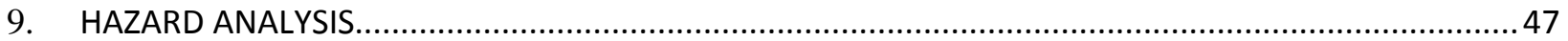

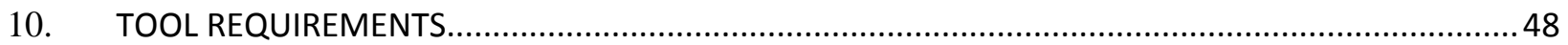

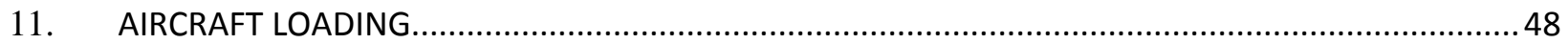

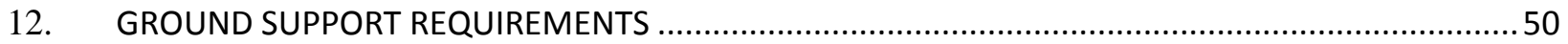

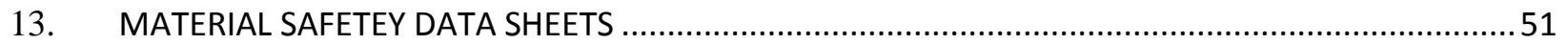

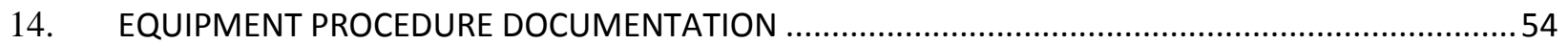

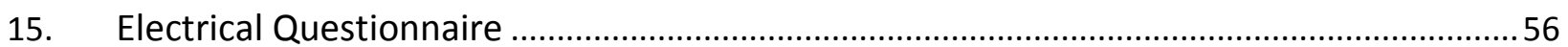




\section{FLIGHT MANIFEST}

Flight One: Marc Gibson, Damir Ljubanovic, Jim Sanzi

Flight Two: Marc Gibson, Damir Ljubanovic, Jim Sanzi

Flight Three: Marc Gibson, Damir Ljubanovic, Jim Sanzi

Flight Four: Marc Gibson, Damir Ljubanovic, Jim Sanzi

Backup Flyer, on call: N/A

\section{EXPERIMENT BACKGROUND}

Normal Operation

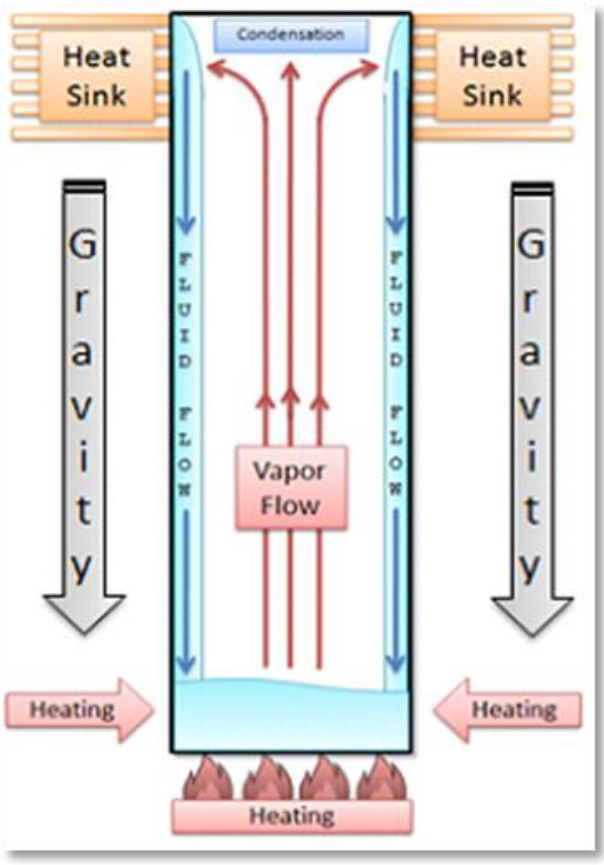

Figure $1[1]$
Flooding

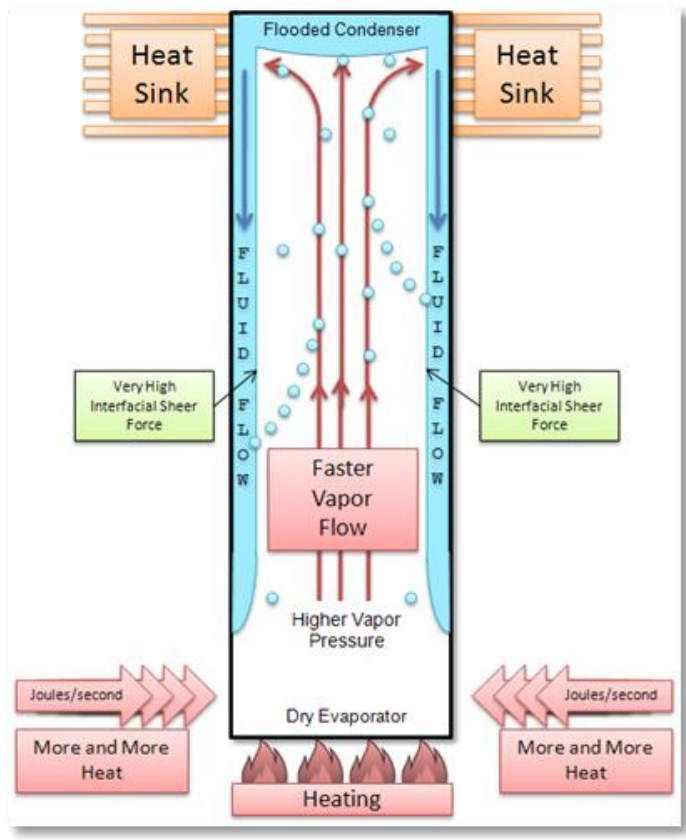

Figure 2 [1]

The fundamental equations governing heat pipe technology have been developed over the years. These relatively simple devices can vary in size from, but are not limited to, pen-size to several meters in length. Heat pipes can be used in a variety of applications, ranging from thermal conductors in a CPU heat sink to 
environmental control, as seen with the Trans-Alaskan Pipeline. Though the fundamental equations governing the operation of heat pipes have been developed, validating the models in $1 / 6 \mathrm{~g}$ and zero $\mathrm{g}$ has never been done. Flooding correlations are being developed under this research for both wicked and wickless heat pipes. The wickless heat pipes (often referred to as thermosyphons) will not work in zero gravity and therefore be flown in lunar gravity parabolas. The fully wicked heat pipes will function in zero gravity where their heat transport limits will be studied. There will be 8 thermosyphons and 4 heat pipes flown under this research flight campaign. The thermosyphons will be turned off for the zero gravity parabolas.

Heat pipes, while simple, are constrained by heat transfer limits associated with the flow of the working fluid through its thermodynamic cycle. One of the more common limits for thermosyphons in reduced gravity is the flooding limit. The limit that occurs most often with wicked heat pipes in microgravity is the capillary limit. This research effort will continue the thermosyphon flooding limits performed in lunar gravity during the 2011flight campaign as well as address the capillary limits of heat pipes in zero gravity. This will be accomplished by flying both thermosyphons and heat pipes, with the only difference being the wick structure in the heat pipe specimens. The capillary limit occurs in microgravity when the amount of power applied to the heat pipe exceeds the pumping capacity of the heat pipe wick structure to return liquid from the condenser, in essence starving the evaporator. The capillary limit is influenced not just by the design of the heat pipe but also by gravitational acceleration. For instance, a heat pipe with specific dimensions and 100 Watts of power flowing through it might not hit the limit here on Earth; however, if it were placed in a microgravity environment the same heat pipe could exceed its capillary limit. The Low-g flight experiment will allow us to compare a numerical model that predicts heat pipe limits with real life results in order to validate the model. 


\section{EXPERIMENT DESCRIPTION}

Purpose: The purpose of this experiment is to study the effect that gravitational acceleration has heat transfer limits of two-phase heat pipes.

Objective: The recorded data will be used to determine whether or not our numerical model is accurate in predicting heat pipe flooding.

Layout: The experiment consists of twelve, nineteen inch long heat pipes, mounted to an internal rack that fits into a Zero-G flight approved vertical equipment rack, which will be bolted to the floor. Also in this rack, there are the 12 power supplies, which are bolted to a $1 / 4$ in. aluminum plate located at the lowest region on the rack.

Experiment: A range of power will be applied over the twelve heat pipes. For instance, if $100 \mathrm{~W}$ were applied to the first heat pipe and $144 \mathrm{~W}$ applied to the twelfth, the step, or interval, between each heat pipe would be $12 \mathrm{~W}$. This will, in a sense, create a spectrum which can be adjusted by increasing or decreasing the power, along with adjusting the change in power between the heat pipes. The maximum power going through a heat pipe will not exceed $200 \mathrm{~W}$. Heat is removed from the system via forced air cooling and a range of cooling can be applied by incrementing fan speed.

Thermocouples, strategically placed on all 12 heat pipes, will relay information to a data acquisition system. Temperature and acceleration data will be gathered each second along the parabolic trajectory of the Zero-G aircraft and will be sent to a laptop computer in order to observe the effect that gravity has on heat pipe flooding. Under normal operation, the heat pipes are isothermal; however, at the onset of flooding, the thermocouple in the heater block begins to increase indicating that that region is becoming liquid-starved.

Our correlation model will be used to determine the initial conditions that will be applied to the heat pipes during flight. Adjustments will be made to 
the power and cooling settings in order to gather data and to compare the experimental data with predicted results.

\section{EQUIPMENT DESCRIPTION}

\begin{tabular}{|c|c|c|c|}
\hline Equipment & $\begin{array}{c}\text { Dimensions }(\mathrm{L} ; \mathrm{W} ; \mathrm{H}) \\
\text { [in] }\end{array}$ & $\begin{array}{l}\text { Weight } \\
\text { [lbs.] }\end{array}$ & Type of Hardware \\
\hline Equipment Rack & $24.0 ; 24.0 ; 42.19$ & 60 & Experimental \\
\hline Power Supplies (x12) & $1.7 ; 6.4 ; 9.4$ & 50 & Experimental \\
\hline $\begin{array}{l}\text { Data Acquisition } \\
\text { System (DAS) }\end{array}$ & $16 ; 17 ; 7$ & 45 & Experimental \\
\hline Heat Pipes (x12) & N/A & \multirow{3}{*}{15} & Experimental \\
\hline Heater Blocks & $1.0 ; 1.0 ; 2.6$ & & Experimental \\
\hline Cartridge Heaters (x48) & N/A & & Experimental \\
\hline Thermocouples & N/A & \multirow{4}{*}{5} & Experimental \\
\hline Plugs & N/A & & Experimental \\
\hline Circuit Breakers (x13) & $\mathrm{N} / \mathrm{A}$ & & Experimental \\
\hline Emergency Cutoff & N/A & & Experimental \\
\hline Internal Racks & N/A & 25 & Experimental \\
\hline Cooling Fan System & N/A & 15 & Experimental \\
\hline Laptop & $12.0 ; 12.0 ; 1.5$ & 10 & Experimental \\
\hline Other Electronics/Cords & N/A & 45 & Experimental \\
\hline
\end{tabular}

***Note: Also see the table in the structural analysis section 


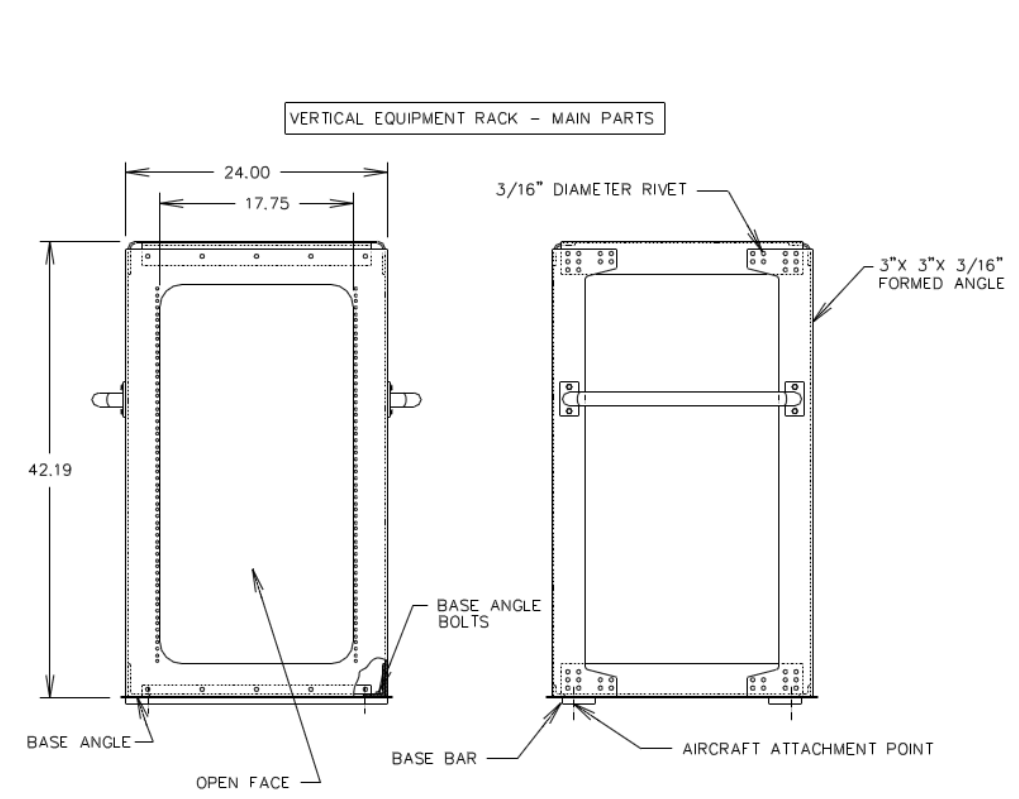

Figure 3 (units: inches)

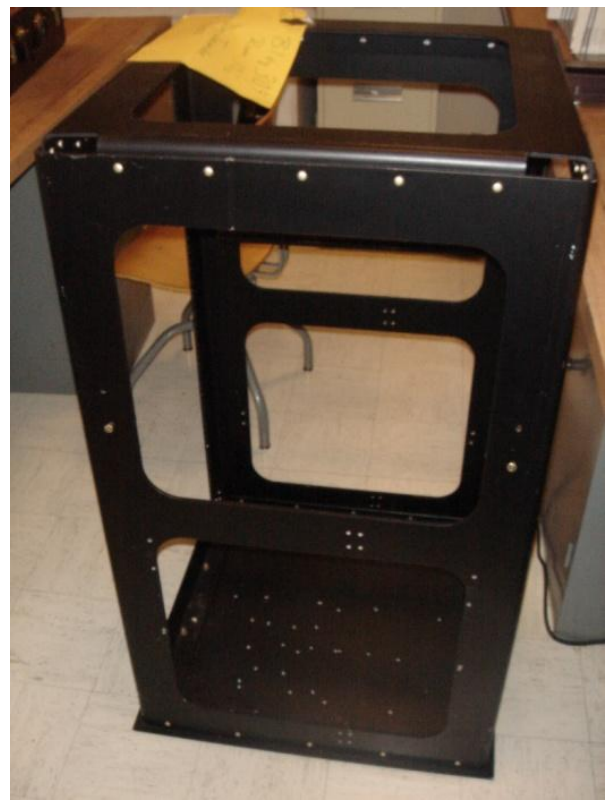

Figure 4

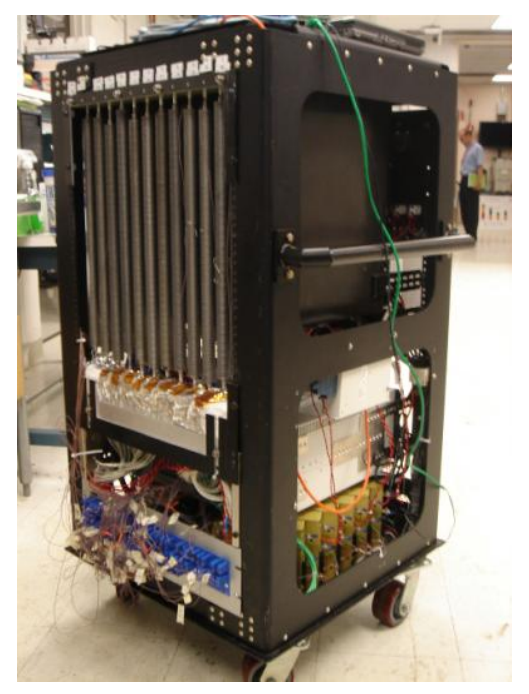

Figure 5 Full Equipment Rack

The Aluminum 6061-T6 Flight Rack was designed for low-g flight and is the structural support for our experiment. The inner rack that holds the heat pipes in 
place, along with the DAS, power supplies, and other equipment is attached to this frame.

\section{HEAT PIPES}

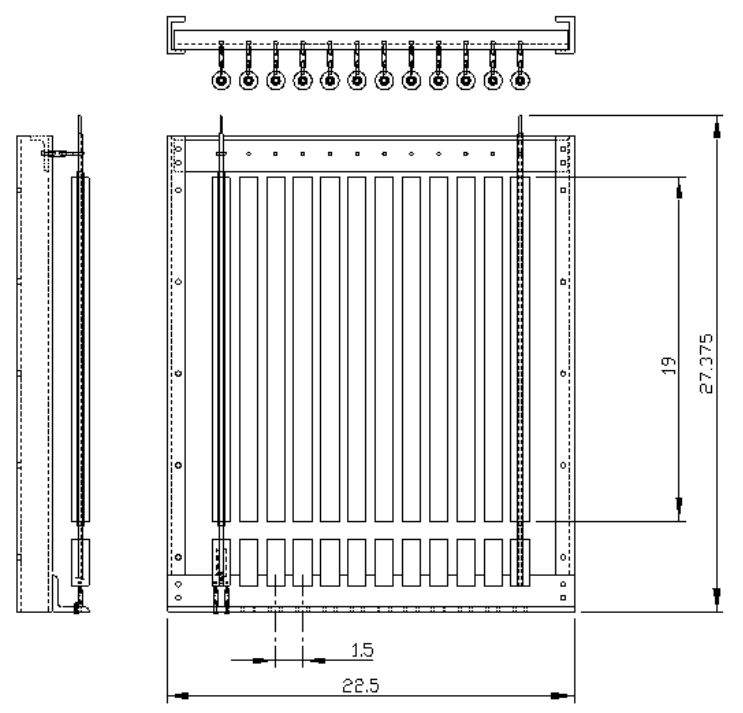

Figure 6 Outline of Heat Pipe Assembly

The twelve, $19 \mathrm{in}$. long Titanium CP-3 heat pipes are attached to an inner rack as seen in Figure 6 and $6 \mathrm{~b}$. This inner rack is connected to the inside of the equipment rack for support. The heat pipes have an outer diameter of 0.247 in, along with a wall thickness of 0.032 in. During the experiment, the temperature of the heat pipes could reach $400 \mathrm{~K}$. The working fluid for all heat pipes is distilled water. Though not shown in Figure 7, a guard is to be placed over the heat pipes to prevent accidentally touching of the hot surfaces. 


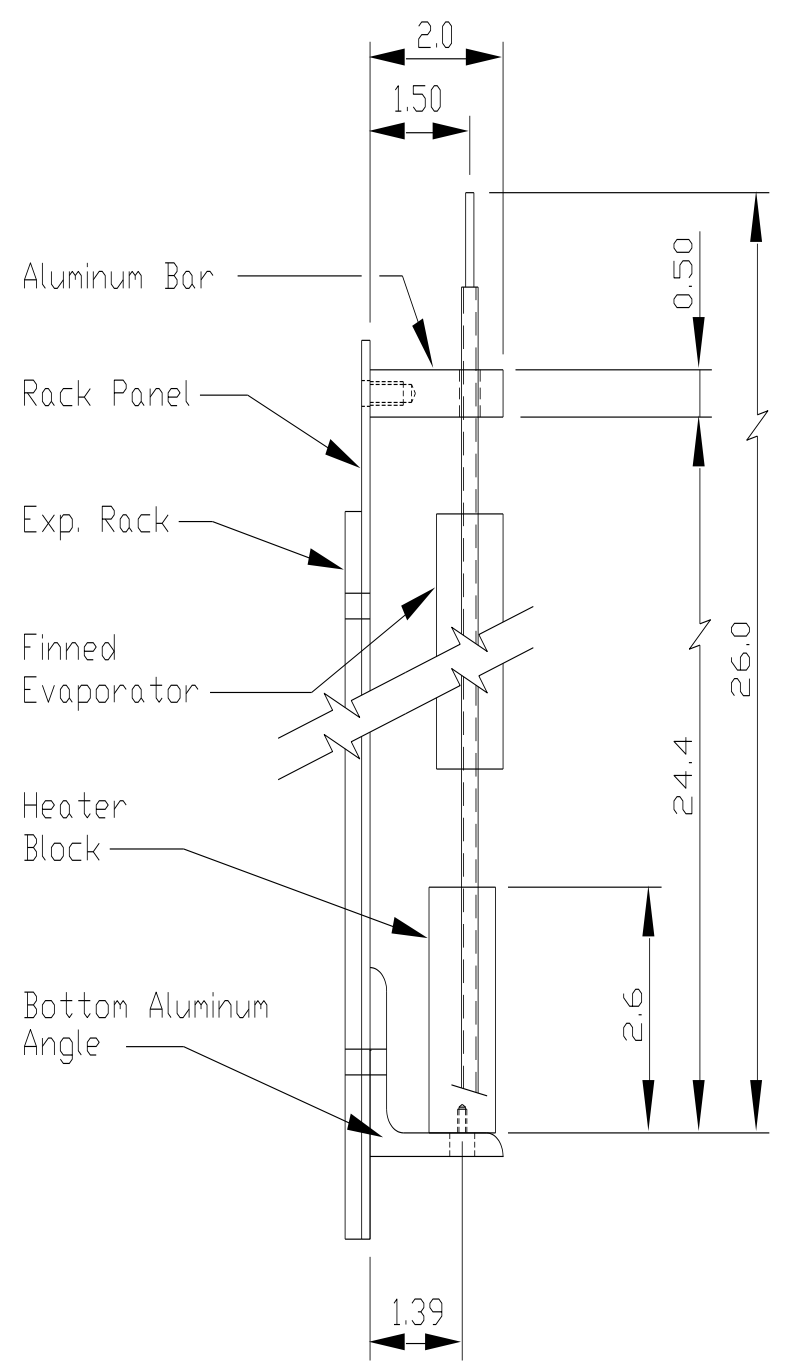

Figure $6 b$ 


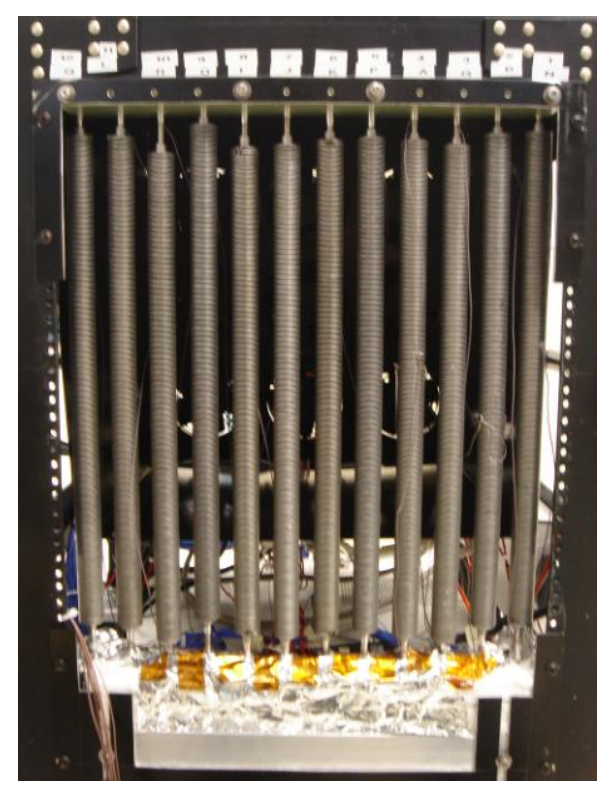

Figure 7Photo of Heat Pipe Array

\section{CARTRIDGE HEATERS}

Cartridge Heater Drawing

Cartridge Heater Photo
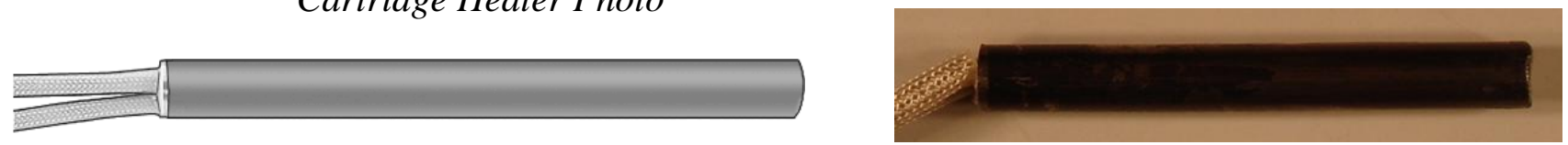

Figure 8

Figure 9

The $200 \mathrm{~W}, 0.25$ " O.D., 2" long cartridge heaters fit into the cartridge heater blocks and provide thermal power to the heat pipes. Since the thermosyphons will not function in a zero-g environment, precautions will be taken to make sure the cartridge heaters are not functioning during a zero-g parabola. Their maximum operating temperature, however, is $1141 \mathrm{~K}$, so overheating should not be a problem. 


\section{CARTRIDGE HEATER BLOCKS}

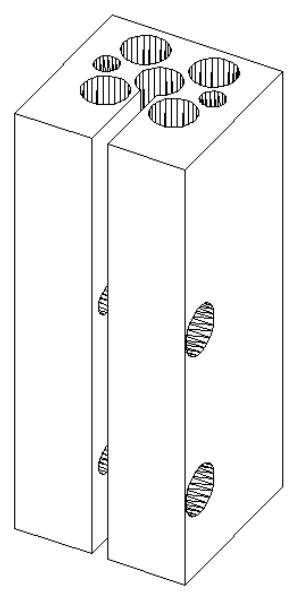

Tech Sketch of Heater Block

Heater Blocks

Photo
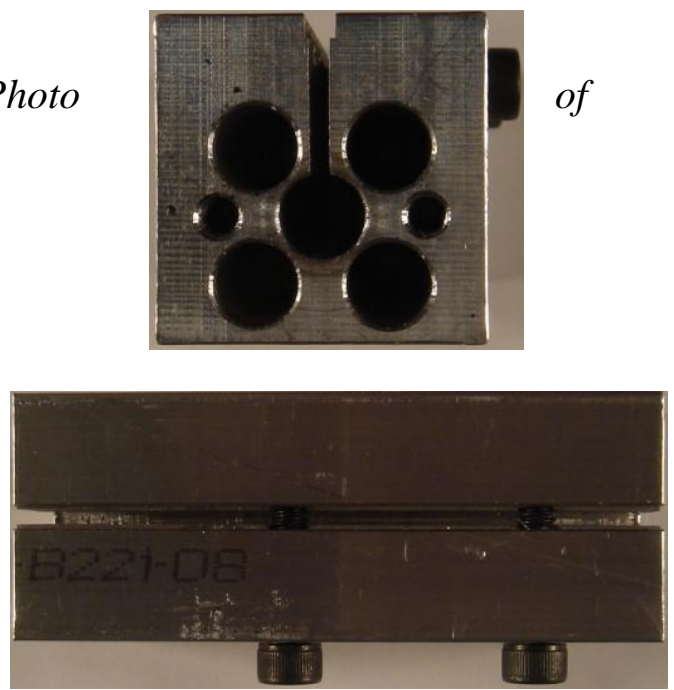

Figure 10

Figure 11

The Aluminum cartridge heater blocks transfer the thermal energy generated by the cartridge heaters to the heat pipes. Four cartridge heaters fit into one block, and each heat pipe has one heater block. The heat from the heater blocks is dissipated by the heat pipes and their radial fin heat sinks.

\section{THERMOCOUPLES}

Simple Thermocouple Circuit

Actual Size of Selected Thermocouple 

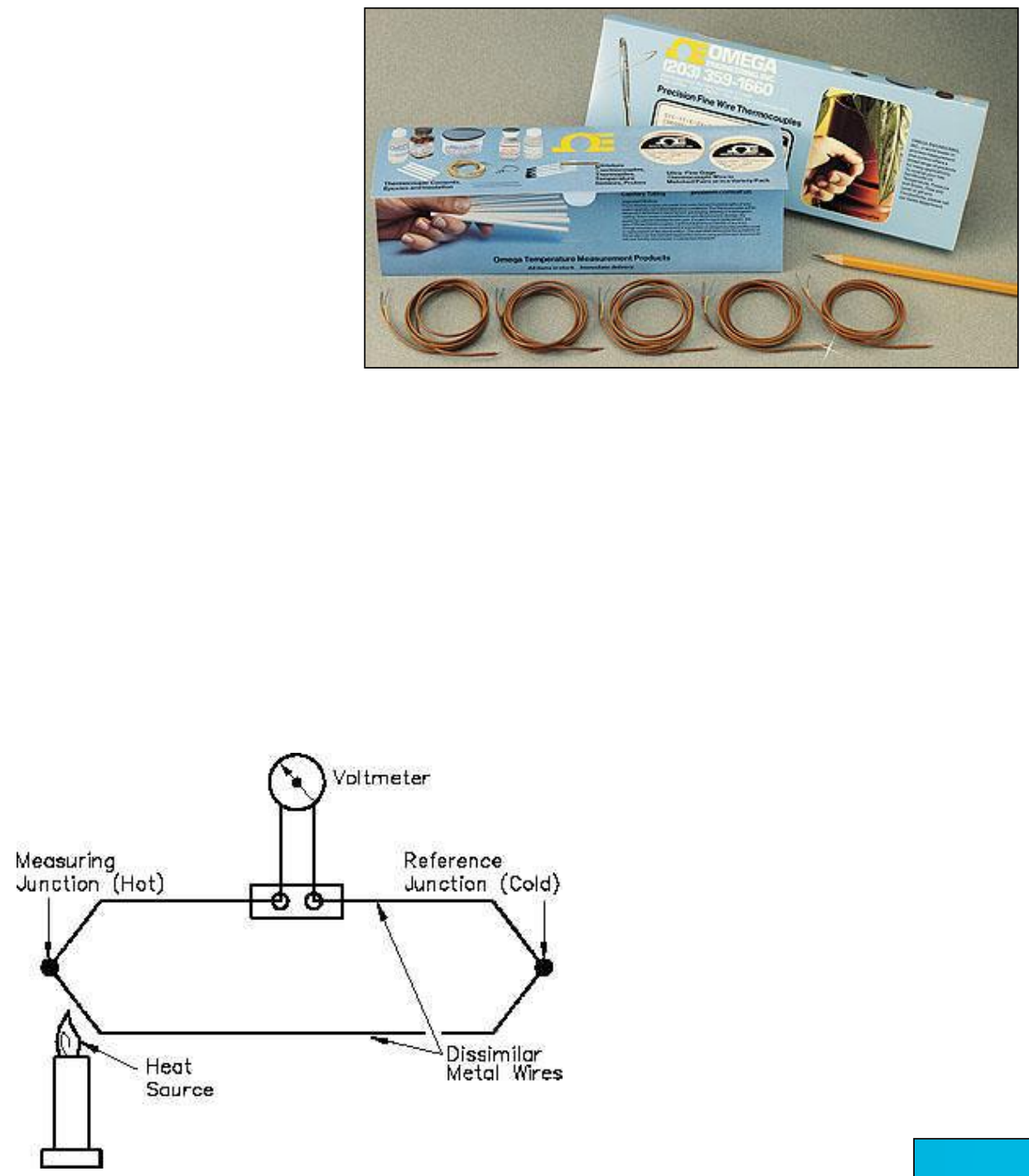

Figure 12

Figure 13

Insulated Thermocouples

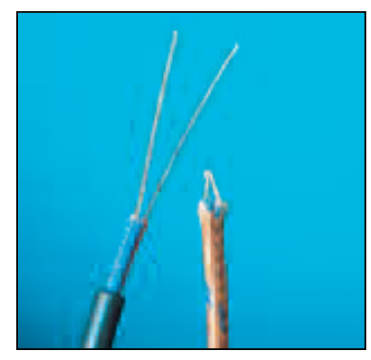


Figure 14

Type $\mathrm{T}$ glass braid thermocouples with an operating temperature range of $23 \mathrm{~K}$ to $623 \mathrm{~K}$ are bonded to each heat pipe by high temperature aluminum tape at specific locations along each heat pipe. These will allow us to monitor the temperatures of the heat pipes in order to detect whether or not a heat pipe is flooding (evaporator dry out).

\section{$\underline{\text { ELCIs }}$}

TRC 30mA trip 120V/20A ELCI's (SKU: TRC-26140-010) were tested successfully on the flight power supplies and did not trip when plugging in four of the power supplies through one power cord as originally wired. NASA RGO uses these ELCIs on occasion and these ELCIs will be utilized here. The TRC ELCIs will be wired with amphenol connectors to plug in to the Aircraft Power Panel (120VAC) supply.

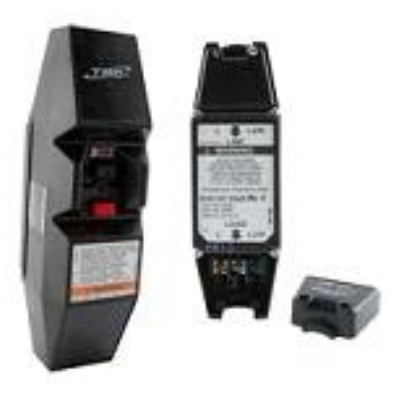

\section{TRC $\circledast$ ELCI 120/20A \& 240V/20A In-Line Attachable}

SKU: TRC-26140-010

\section{$\underline{\text { AC Current Transducers }}$}

Four A/CTE-50 EnergyControl.com Part Number: ACI A/CTE-50 AC current transducers were installed in order to measure $\mathrm{AC}$ current for each of the four 
circuits. The output of all four transducers was utilized to monitor the AC amperage being drawn by each of the four circuits.

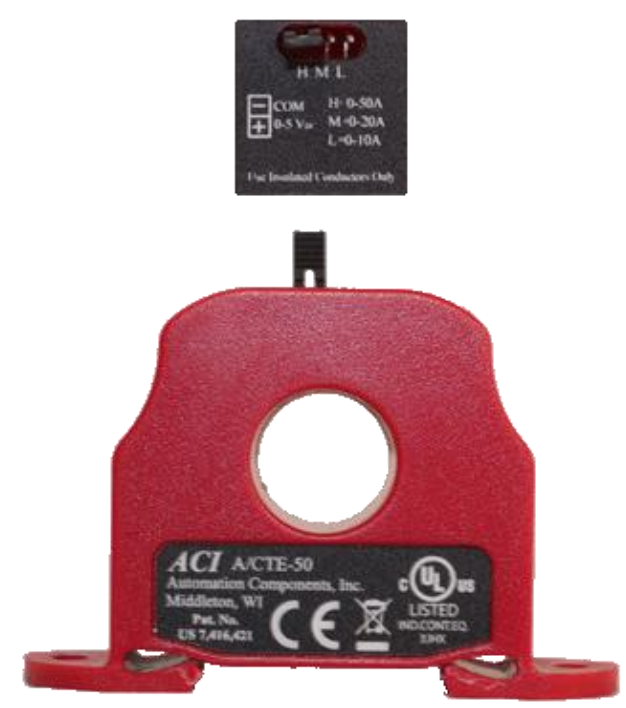




\section{POWER SUPPLIES}

Power Supply Photos

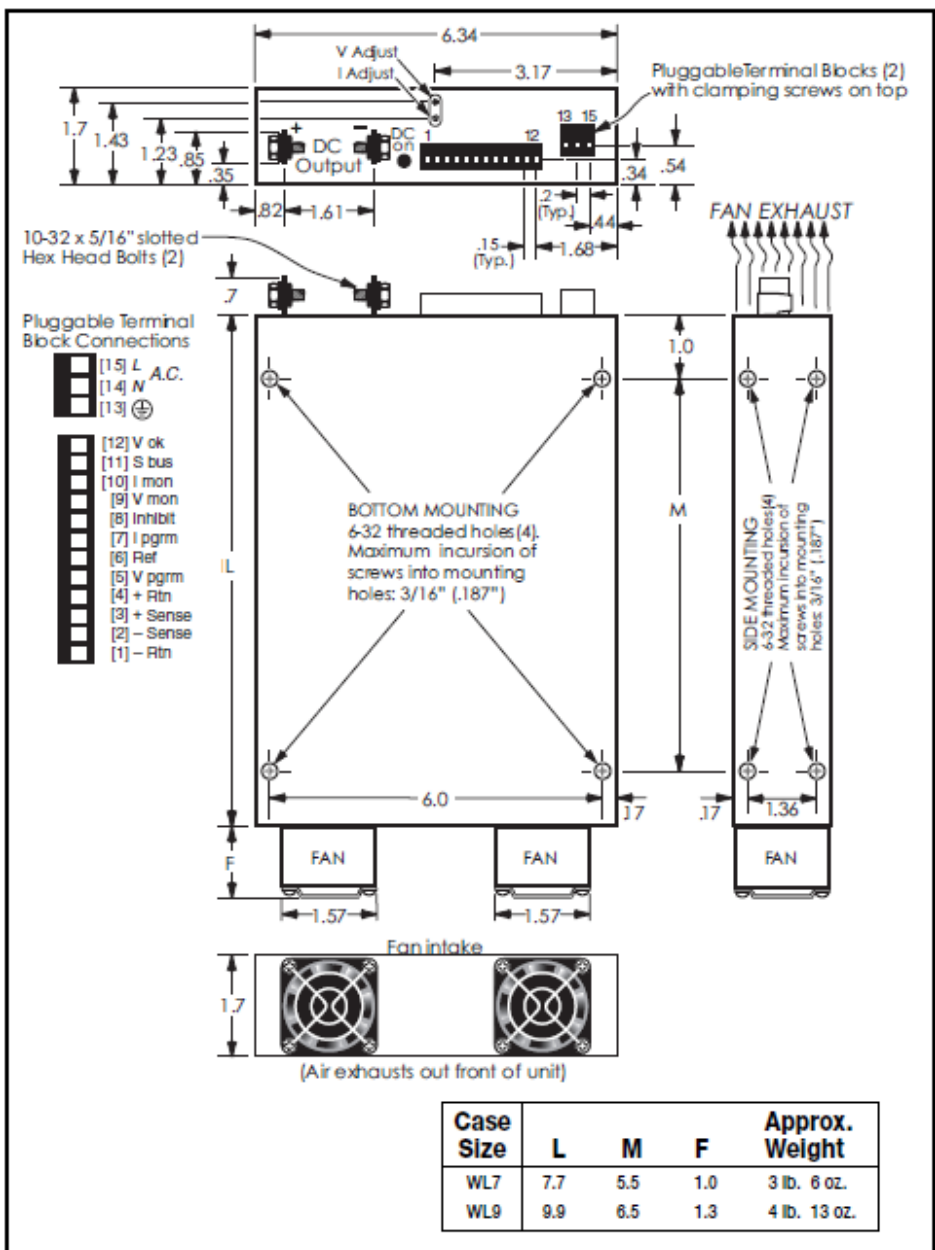

Figure 15
Power Supply Drawing
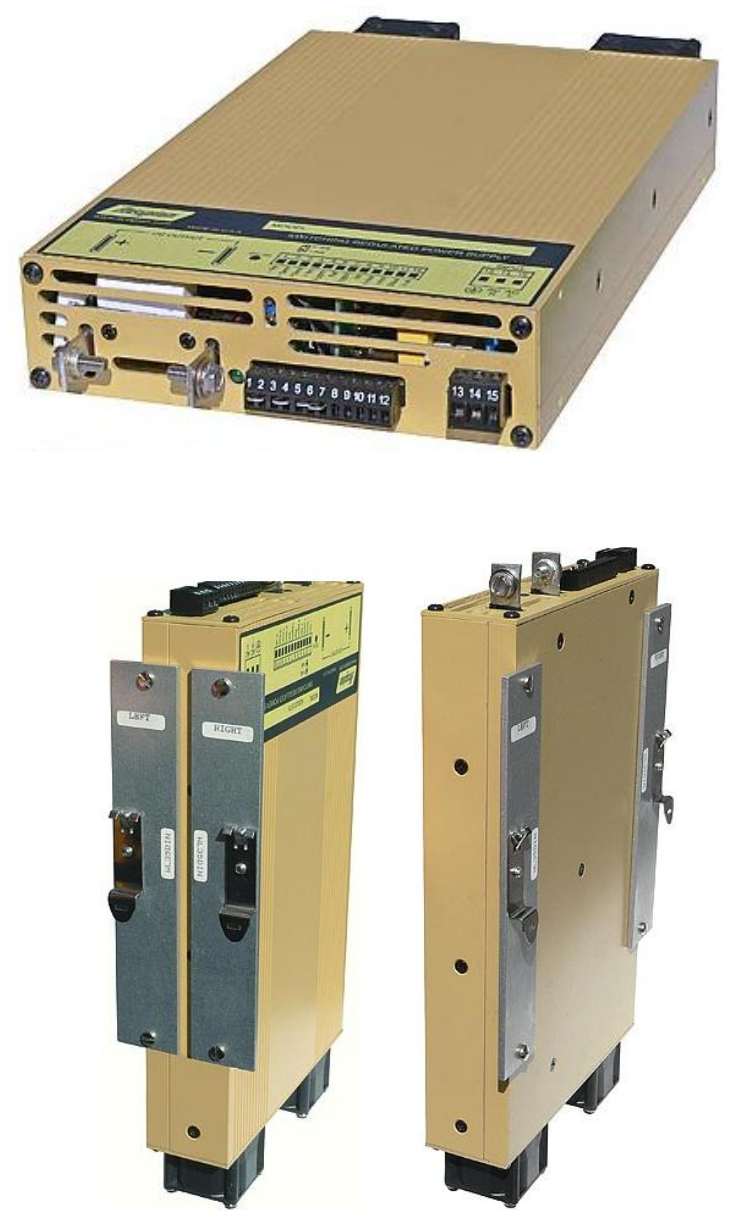

Figure 16

There are a total of 12 power supplies included in our experiment. Each power supply supplies power to the cartridge heaters in one cartridge heater block (4 active heaters per block), which in turn heats the heat pipe. The heat pipes are cooled by radial finned extended surface tubes, by natural convection. 


\section{POWER SUPPLY SPECIFICATIONS}

Input Voltage: 90-265 VAC, 49-420 Hz, single phase, or 110-350 Vdc.

208 VAC 3-phase is also available (see Options).

AC input (maximum): 8A (WL7 case), 12A (WL9 case)

DC input (maximum): 5.75A (WL7 case), 8.8A (WL9 case).

DC input may be connected without regard to polarity.

Inrush current: Cold start, (thermistor limiter) 33A peak @115 VAC (typical); 65A peak @ 230 VAC (typical).

Startup Time: $800 \mathrm{mS}$ (typical).

Input Undervoltage: An input of less than $90 \mathrm{VAC}$ will not damage power supply.

Power Factor:0.99 (typical) at 115 VAC, $60 \mathrm{~Hz}$ and full load. Complies with EN61000-3-2.

Regulation (in constant voltage mode):

Line Regulation: $\pm 0.05 \%$

Load Regulation: $\pm 0.05 \%$

Regulation, Ripple (in constant current mode):

Line Regulation: $\pm 0.2 \%$ or $30 \mathrm{~mA}$.

Load Regulation: $\pm 0.5 \%$ or $100 \mathrm{~mA}$.

Current Ripple: $0.5 \%$ rms.

Ambient Operating Temperature: 0 to $+71^{\circ} \mathrm{C}$.

Temperature Coefficient (after 30 minute warm-up):

Voltage mode: $\pm 0.02 \% /{ }^{\circ} \mathrm{C}$ (typical).

Current mode: $\pm 0.1 \% /{ }^{\circ} \mathrm{C}$ (typical).

Drift (voltage mode or current mode): $\pm 0.1 \%$ (typical) over 8 hours, after 30 minute warmup.

Storage Temperature: -40 to $+85^{\circ} \mathrm{C}$.

Holdup Time: $20 \mathrm{mS}$ minimum with full load.

Transient Response: $300 \mu \mathrm{S}$ to return to $\pm 1 \%$ of output setting. Maximum of $\pm 3 \%$ output excursion following a load step change from $50 \%$ to $100 \%$.

Polarity: Output is floating and may be used in either polarity.

Remote Sensing: Compensates up to 0.5 volt drop per output line.

Output Adjustment: Voltage and current output adjustments are located on the front. Output adjustment may also be controlled by using remotely located potentiometers.

Output Programming: The output voltage and current may be programmed from 0 to full rating by means of control voltage inputs of 0 to $+10 \mathrm{Vdc}(0$ to $+5 \mathrm{Vdc}$ for models with option "C5"). 
Voltage mode accuracy: $0.5 \%$. Current mode accuracy: $3 \%$ for models with greater than 10 amps output current and $4 \%$ for models with less than 10 amps output current. Accuracy percentages do not apply below $5 \%$ of output rating.

Voltage Monitor Terminal: Permits remote monitoring of output voltage, stepped down by a ratio of 10:1 (for $3.3 \mathrm{v}$ to $90 \mathrm{v}$ models) or $100: 1$ (for $100 \mathrm{v}$ to $135 \mathrm{v}$ models). Accuracy is $0.5 \%$ of maximum rated output voltage.

For models with 0-5v programming option "C5": Permits remote monitoring of output voltage, stepped down by a ratio of 10:1 (for 3.3v to $45 \mathrm{v}$ models) or 100:1 (for $48 \mathrm{v}$ to $135 \mathrm{v}$ models). Accuracy is $0.5 \%$ of maximum rated output voltage.

Current Monitor Terminal: For models with greater than 10 amps output current: permits remote monitoring of output current, stepped down by a ratio of $100 \mathrm{mV} / \mathrm{Amp}$ (accuracy is $3 \%$ of maximum rated output current). For models with less than 10 amps output current: permits remote monitoring of output current, stepped down by a ratio of $1000 \mathrm{mV} / \mathrm{Amp}$ (accuracy is $3 \%$ of maximum rated output current).

For models with 0-5v programming option "C5": For models with greater than 45 amps output current: permits remote monitoring of output current, stepped down by a ratio of 10 $\mathrm{mV} / \mathrm{Amp}$ (accuracy is $5 \%$ of maximum rated output current). For models with less than 45 amps output current: permits remote monitoring of output current, stepped down by a ratio of 100 $\mathrm{mV} / \mathrm{Amp}$ (accuracy is $3 \%$ of maximum rated output current).

Overload/Short Circuit Protection: A short or overload forces the power supply into constant current mode, with automatic recovery.

Overvoltage Protection: Latches power supply OFF, reset by momentarily removing AC input power.

Thermal Protection: Thermostat(s), self-resetting.

Internal Failure Protection: Provided by internal fuse.

Output Inhibit: Applying between +3 and +15 Vdc to the Inhibit terminal will disable the supply. 'Output Enable' is also available (see Options).

Output Indicator (DC on): Green LED.

Switching Frequency: $110 \mathrm{kHz}$ (typical).

EMI: Designed to meet FCC Part 15 and EN55022, Class A.

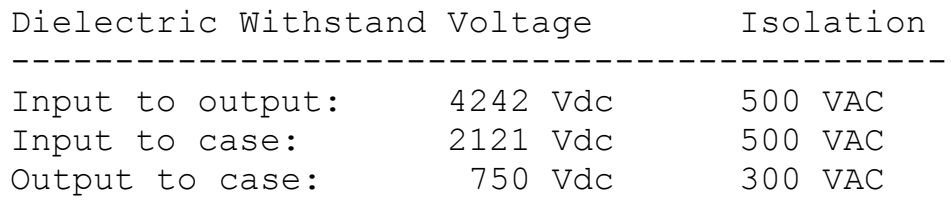

Cooling: Forced-air cooled; air enters rear of power supply and exits from front cover. 


\section{DATA ACQUISITION SYSTEM (DAS)}

NI PXI-1052 Chassis

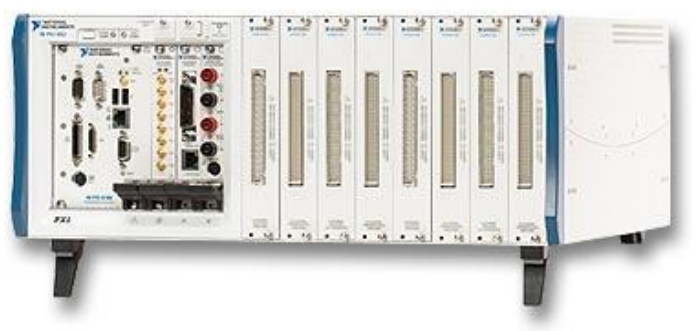

Figure 17
DAS Attached to Equipment Rack

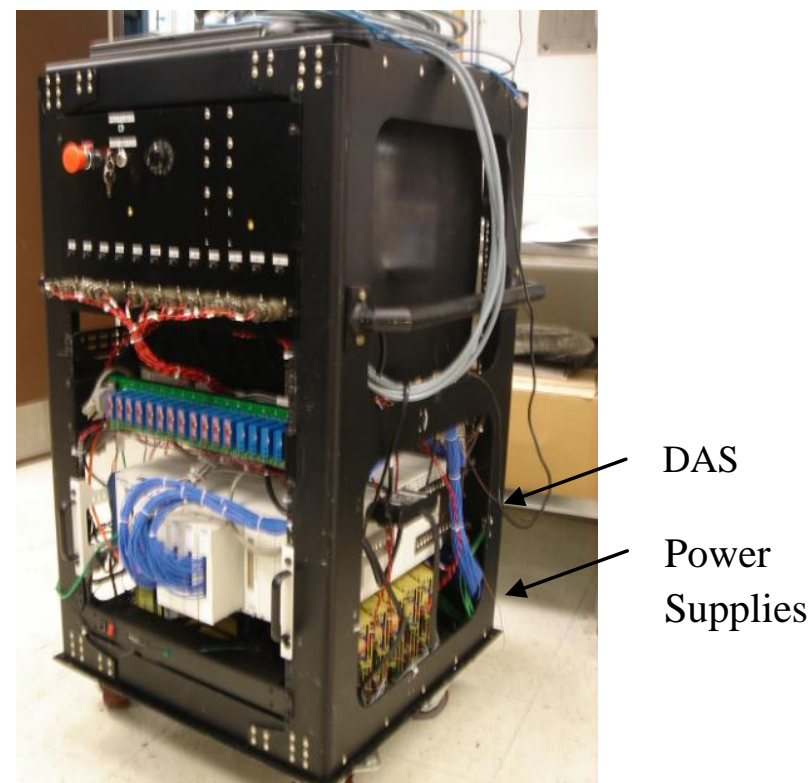

Figure 18

Embedded Control Module

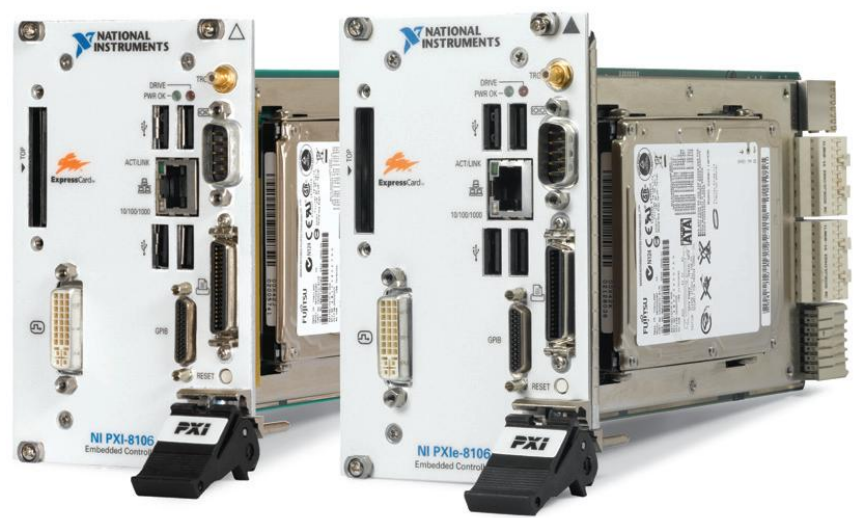

Figure 19

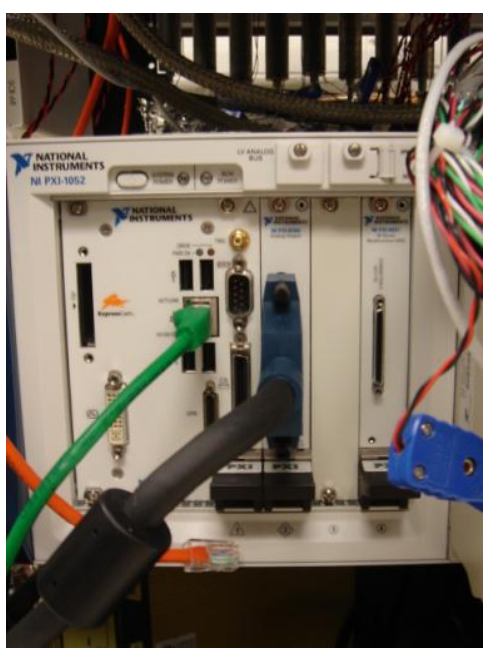

The DAS (see figures $10 \& 12$ ) is a collection of embedded modules that control and gather data from the experiment, which are inserted into a NI PXI-1052 
chassis (see Figure 13). The gathered data is sent to a laptop computer where it is analyzed and displayed in an appropriate manner, i.e. graphs and charts. Types of data that will be gathered are acceleration data, heater block voltage and current data, and voltage readings from the thermocouples, which are turned into temperatures by the DAS.

\section{CIRCUIT BREAKERS}

Circuit Breaker

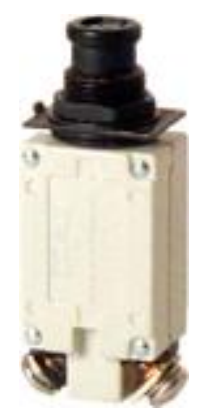

Figure 20
Trip Curve

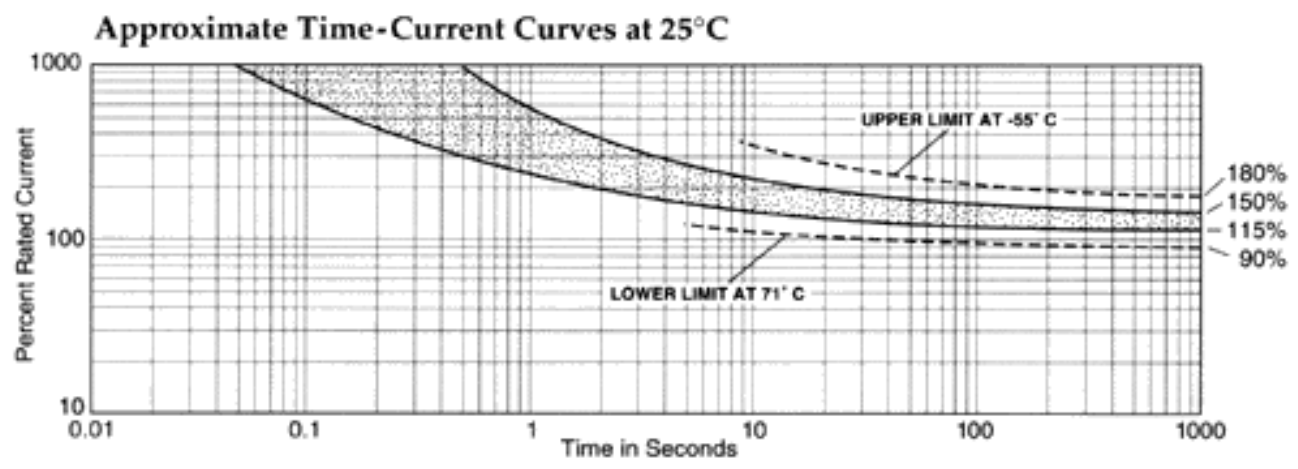

Figure 21

12 Klixon 0.5 to 20 amp, single-phase, non-compensated, high performance circuit breakers (one per heat pipe) prevent the power system from over-loading. These circuit breakers are specifically designed for use in airborne vehicles. 


\section{EMERGENCY CUTOFF SWITCH}

Photo of E-Cutoff on Experimental Setup
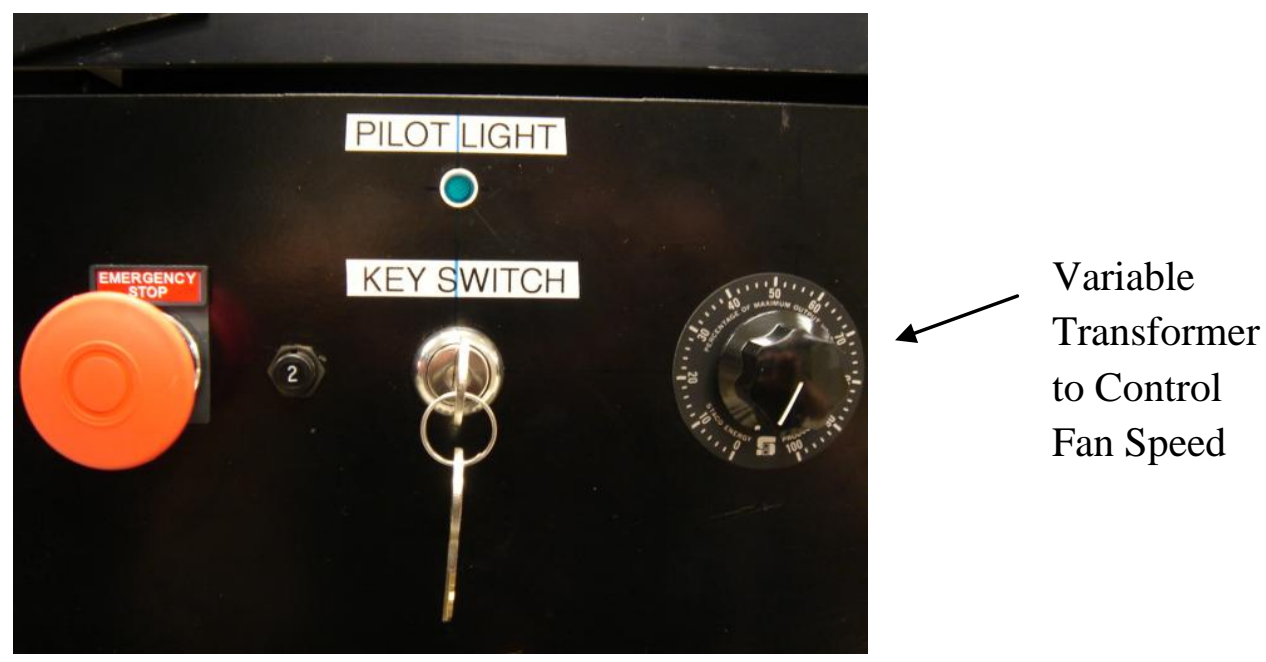

Figure 22

In the event of an emergency, the $120 \mathrm{VAC} / \mathrm{DC}$ push-pull emergency cutoff switch can be pressed to cut power to the entire experiment.

\section{VARIABLE TRANSFORMER}

Specs

\begin{tabular}{|c|c|c|c|c|c|c|c|c|c|c|c|c|c|c|}
\hline \multirow{4}{*}{ PART NO. } & \multirow{4}{*}{ WRING } & \multicolumn{2}{|c|}{ INPUT } & \multicolumn{5}{|c|}{ OUTPUT } & \multirow{4}{*}{$\begin{array}{c}\text { SHAFT } \\
\text { ROTATION } \\
\text { FOR } \\
\text { VOLTAGE } \\
\text { INCREASE }\end{array}$} & \multirow{2}{*}{\multicolumn{3}{|c|}{$\begin{array}{c}\text { TERMINAL CONNECTIONS } \\
\text { (For increasing Voltage) } \\
\text { As Viewed from Base End }\end{array}$}} & \multirow{4}{*}{$\begin{array}{c}\text { SCHE- } \\
\text { MATIC } \\
(\mathrm{Pg} 8 \& 9)\end{array}$} & \multirow{4}{*}{$\begin{array}{l}\text { NET } \\
\text { WT. } \\
\text { LBS. }\end{array}$} \\
\hline & & \multirow{3}{*}{ VOLTS } & \multirow{3}{*}{ HERTZ } & \multirow{3}{*}{ VOLTS } & \multirow{2}{*}{\multicolumn{2}{|c|}{$\begin{array}{l}\text { CONSTANT } \\
\text { CURRENT } \\
\text { LOAD }\end{array}$}} & \multirow{2}{*}{\multicolumn{2}{|c|}{$\begin{array}{l}\text { CONSTANT } \\
\text { IMPEDANCE } \\
\text { LOAD }\end{array}$}} & & & & & & \\
\hline & & & & & & & & & & & & & & \\
\hline & & & & & $\begin{array}{l}\text { MAX } \\
\text { AMPS }\end{array}$ & $\begin{array}{l}\text { MAX } \\
\text { KVA }\end{array}$ & $\begin{array}{c}\text { MAX } \\
\text { AMPS }\end{array}$ & $\begin{array}{l}\text { MAX } \\
\text { KVA }\end{array}$ & & Input & Jumper- & Output & & \\
\hline \multirow{3}{*}{291} & \multirow{3}{*}{$\begin{array}{l}\text { Single } \\
\text { Phase }\end{array}$} & \multirow{3}{*}{120} & \multirow{2}{*}{$50 / 60$} & \multirow{2}{*}{$0-120$} & \multirow{2}{*}{3.0} & \multirow{2}{*}{0.36} & \multirow{2}{*}{3.5} & \multirow{2}{*}{0.42} & $\mathrm{CW}$ & $1-2$ & - & $1-3$ & \multirow{3}{*}{1} & \multirow{3}{*}{$21 / 2$} \\
\hline & & & & & & & & & $\mathrm{CCW}$ & $1-2$ & - & $2-3$ & & \\
\hline & & & 60 & $0-132$ & 3.0 & 0.40 & - & - & CW & $1-4$ & - & $1-3$ & & \\
\hline
\end{tabular}

Figure 23

The Staco Energy Products' type 291 variable transformer controls the speed of the cooling fans (see Figure 22). 


\section{COOLING FANS}

3D CAD Drawing

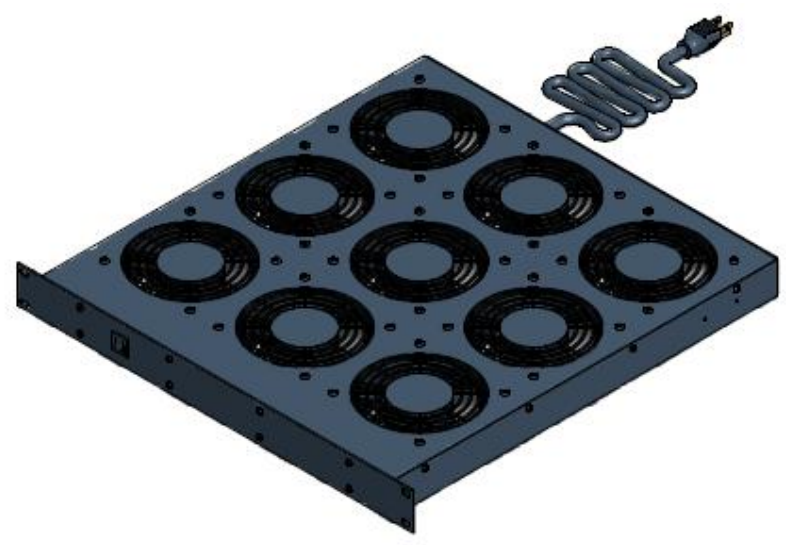

Array Specs

\section{Finish - Black Textured Powder Paint}

Rated - 115 VAC, 60 Hz, 3 Amps

Free Flow Air Delivery - 900 CFM

Approvals - cURAus Recognized UL507 and CSA C22.2 No.113

ACCESSORIES INCLUDED

Mounting Instructions

Rear Mount Brackets \& Hardware

Extension Brackets \& Hardware

Figure 25

A $3 \times 3$ array of cooling fans cools the heat pipes.

$\underline{\text { LAPTOP }}$

Photo of Laptop

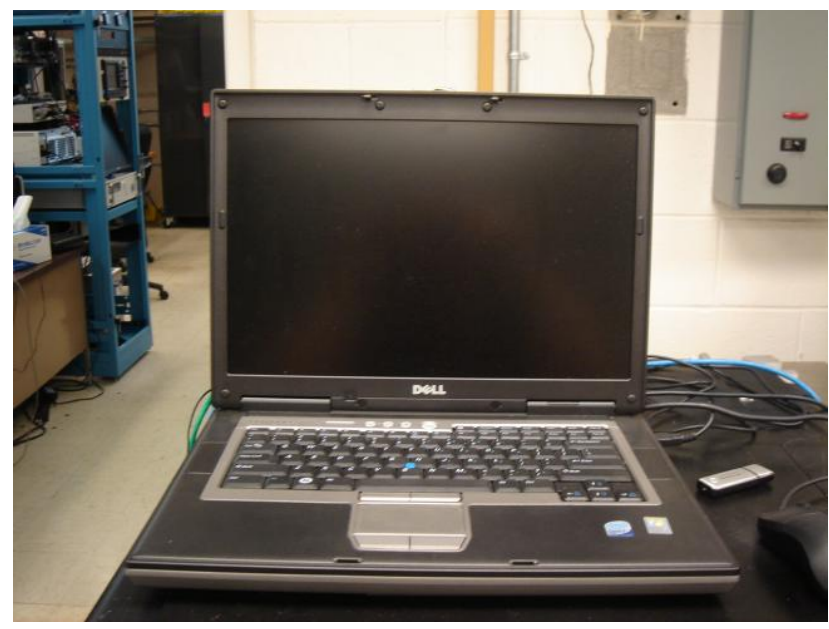

Figure 26

The Dell laptop is mounted atop the experiment. It controls the experiment and records data. We will put the computer in the storage bin during takeoff and landing. 


\section{ACCELORAMETER}

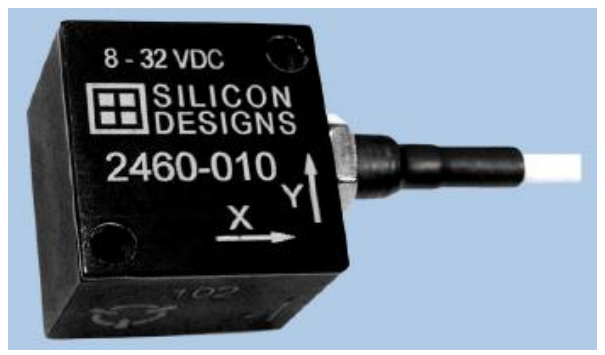

Figure 27

The Silicon Designs 3-axis accelerometer is used to gather acceleration data to be used in conjunction with heat pipe temperature data.

\section{$\underline{\text { SHIELDED CABLE }}$}

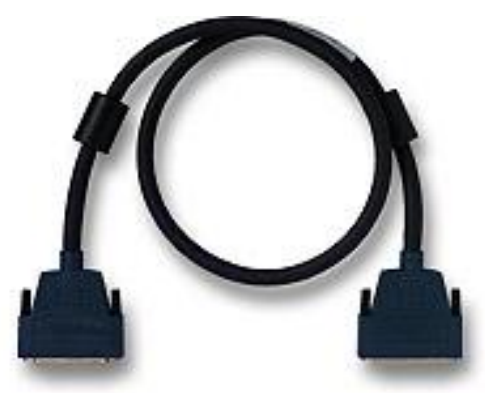

Figure 28

The shielded 68-conductor cable connects the National Instruments SCB-68 analog output connector block (see below) to the DAS. 


\section{ANALOG OUTPUT CONNECTOR BLOCK}

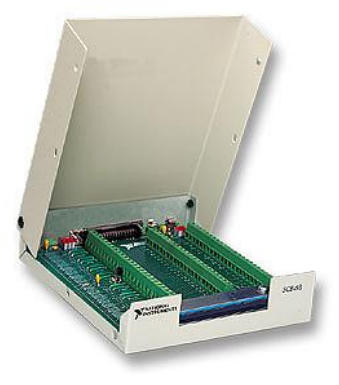

Figure 29

Analog output connector block for the NI PXI-6704 (DAS module) high resolution analog output board for PXI 16-bit, 32 DC analog output.

\section{ISOLATED VOLTAGE OUTPUT SIGNAL CONDITIONING MODULE}

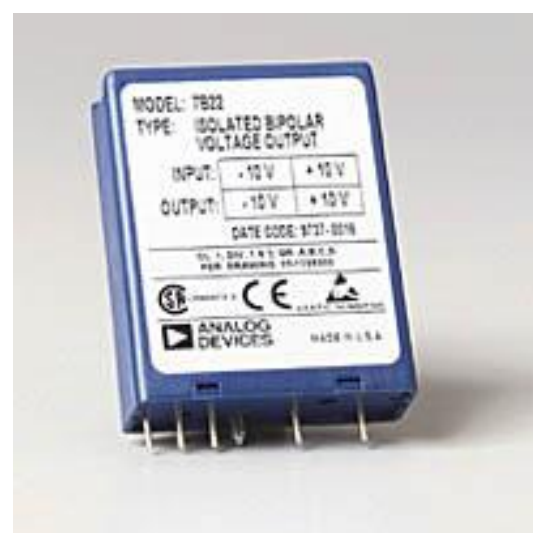

Figure 30

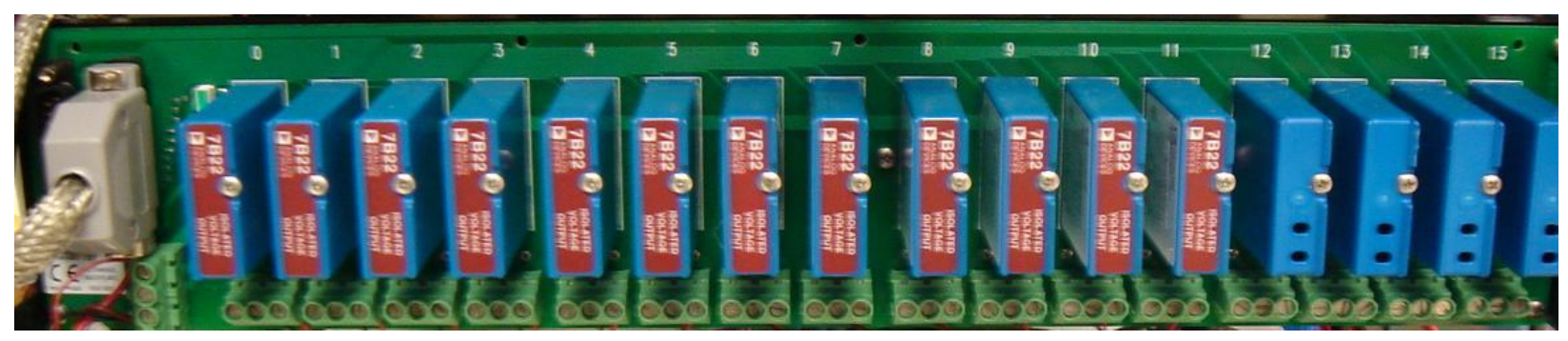

Figure 31 
The 7B22 is a unity gain single-channel signal conditioning output module that interfaces and filters $\mathrm{a} \pm 10 \mathrm{~V}$ input signal and provides an isolated precision output of $\pm 10 \mathrm{~V}$. 


\section{STRUCTURAL VERIFICATION}

TACO flight experiment component weights and center of gravity data:

\section{Thermosyphon Array in Controlled Operation (TACO) Assembled Rack Mass Properties}

\begin{tabular}{|c|c|c|c|c|}
\hline \multirow[b]{2}{*}{ Component } & \multirow[b]{2}{*}{$\begin{array}{c}\text { Mass } \\
\text { (lb.) }\end{array}$} & \multicolumn{3}{|c|}{ Center of Mass } \\
\hline & & $\begin{array}{l}\text { "X" } \\
\text { (in.) }\end{array}$ & $\begin{array}{l}\text { "Y" } \\
\text { (in.) }\end{array}$ & $\begin{array}{l}\text { "Z" } \\
\text { (in.) }\end{array}$ \\
\hline Flight Rack Top, Sides \& Handles & 41 & 0.0 & 0.0 & 27.2 \\
\hline Flight Rack Bottom & 19 & 0.0 & 0.0 & 0.0 \\
\hline Plate / Power Supplies & 50 & 0.0 & 0.0 & 6.0 \\
\hline Computer / Top Plate & 10 & 0.0 & 0.0 & 44.0 \\
\hline NI Data Acq. Unit & 45 & 0.0 & 0.0 & 11.5 \\
\hline Thermosyphon Rack & 15 & 0.0 & 11.0 & 26.0 \\
\hline Cooling Fan Rack & 10 & 0.0 & -6.0 & 30.5 \\
\hline Front Control Panel & 10 & 0.0 & -10.5 & 35.0 \\
\hline Power Strip & 5 & 0.0 & -10.8 & 4.5 \\
\hline Rear Upper Elect. Rack & 5 & 0.0 & 10.5 & 20.3 \\
\hline Rear Lower Elect. Rack & 5 & 0.0 & 11.0 & 4.8 \\
\hline Cooling Air Duct & 5 & 0.0 & -5.0 & 27.0 \\
\hline Plates \& Brackets & 20 & 0.0 & 0.0 & 16.0 \\
\hline Electronics \& Fasteners & 15 & 0.0 & -2.0 & 16.0 \\
\hline
\end{tabular}




\begin{tabular}{|l|c|c|c|c|} 
Thermocouples \& Plugs & 5 & 0.0 & 0.0 & 16.0 \\
\hline Cables \& Power Cords & 10 & 0.0 & 0.0 & 16.0 \\
\hline \multicolumn{4}{|l|}{} \\
\hline Total Assembly & $\mathbf{2 7 0}$ & $\mathbf{0 . 0}$ & $\mathbf{0 . 0}$ & $\mathbf{1 6 . 7}$ \\
\hline
\end{tabular}

There are four rack attachment holes on a pattern 20" center-to-center and symmetrical with the rack. The coordinate system's origin is located at the rack's base, and the center of the square pattern of four attachment locations. Note however that in order to satisfy overall loading constraints on the total experiment rack, the rack should be oriented so that its "Front" faces laterally.

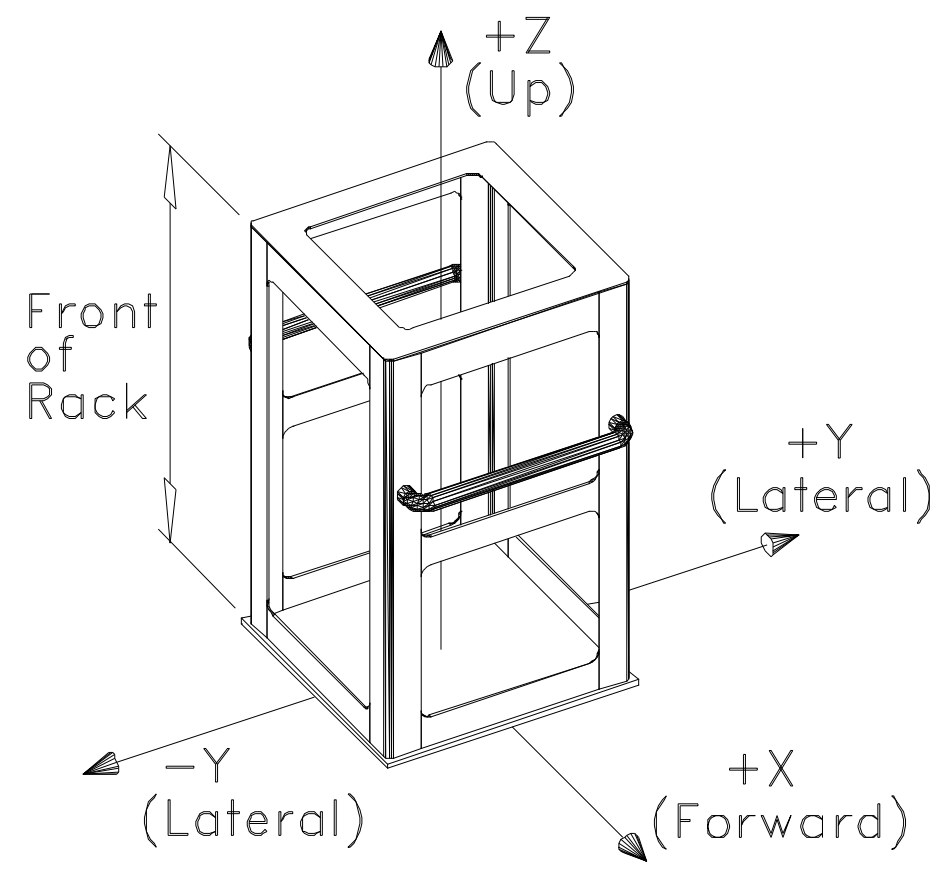




\begin{tabular}{|l|c|}
\hline 1) Power Supply (1 of 12) Attachment to Base Plate \\
\hline Center of Gravity at $(x=0, y=0, z=3$ ) relative to power supply base plate & Margin of Safety \\
\hline Case 1: Horizontal 9g, 4 \#6-32 screws in shear & 48 \\
\hline Case 2: Horizontal 9g, prying action, 2 \#6-32 screws in tension & 10 \\
\hline Case 3: Up 2g, 4 \#6-32 screws in tension & 212 \\
\hline Case 4: Down 6g $\rightarrow$ rests directly on Base Plate & $\mathrm{n} / \mathrm{a}$ \\
\hline
\end{tabular}

\section{2) 12 Power Supplies \& Base Plate}

Center of Gravity at $(x=0, y=0, z=6)$ relative to experiment rack

Case 1: Horizontal 9g, 2 1/4-20 screws in shear

Case 2: Up 2g, 2 1/4-20 screws in tension

Case 3: Down 6g $\rightarrow$ Base Plate rests directly on Experiment Rack

Margin of Safety

7

22

$\mathrm{n} / \mathrm{a}$

\section{3) National Instruments Data Acquisition Unit}

Center of Gravity at $(x=0, y=0, z=11.5)$ relative to experiment rack

Case 1: Forward 9g, $10 \sim$ \#8-32 screws in shear

Case 2: Forward 9g, $4 \sim$ \#10-32 screws in tension

Case 3: Up 2g, $10 \sim$ \#8-32 screws in shear

Case 4: Down 6g, $10 \sim$ \#8-32 screws in shear

Case 5: Down 6g, 8 \#10-32 screws in shear

Margin of Safety

15

12

See Case 1

See Case 1

17

\section{4) Entire Experiment Rack on Attachment Bolts}

Center of Gravity at $(x=0, y=0, z=11.5)$ relative to experiment rack

Case 1: Forward (Horizontal) 9g, screws in shear

Margin of Safety

3.1 


\begin{tabular}{|l|c|}
\hline Case 2: Forward 9g, prying action, screws in tension & 1.3 \\
\hline Case 3: Up 2g, screws in tension & 14 \\
\hline Case 4: Down 6g $\rightarrow$ Experiment Rack rests directly on plane's floor & $\mathrm{n} / \mathrm{a}$ \\
\hline
\end{tabular}




\section{5a Calculation Sheet}

Description: $\quad$ TACO Hinged Thermosyphon Rack Structural Verification

Project Title: $\quad$ Thermosyphon Array in Controlled Operation Experiment

Project Number: 09009

Filename: $\quad$ "TACO Hinged Thermosyphon Rack Analysis 2012-Feb-14.docx"

Engineer: $\quad$ Ed Sechkar / ASRC Aerospace Corp.

Date: $\quad$ February 14, 2012

\section{5a. STRUCTURAL VERIFICATION Modified Thermosyphon Rack}

The TACO flight experiment has been modified such that the Thermosyphon Rack is now located outside of the overall experiment rack. The Thermosyphon Rack is now attached at its lower edge by a hinge assembly, and near its upper edge by a steel bracket and a pattern of bolts.

The hinge assembly consists of a $1 / 2$ " diameter stainless steel rod welded to the 2 " 2 2"x $1 / 4$ " aluminum angle which supports the lower ends of the thermosyphons. The rod is welded to the angle with six $1 / 4$ " fillet welds, each approximately $3 / 4$ " long. At each end of the rod, there is a stainless steel strap, $1 / 32$ " thick $\times 0.5$ " wide, which wraps around the rod and is bolted to the overall experiment rack with a \#8-32 stainless steel bolt through a 1"x1"x3/8" thick spacer made from an extruded aluminum profile.

The upper ends of the thermosyphons are contained by a $1 / 2$ " thick aluminum bar. This bar is attached to a 1/8" thick steel bracket with four \#10-32 bolts. The bracket is attached to the overall experiment rack with four \#8-32 bolts. 
The following photographs and sketches show the assembly details.

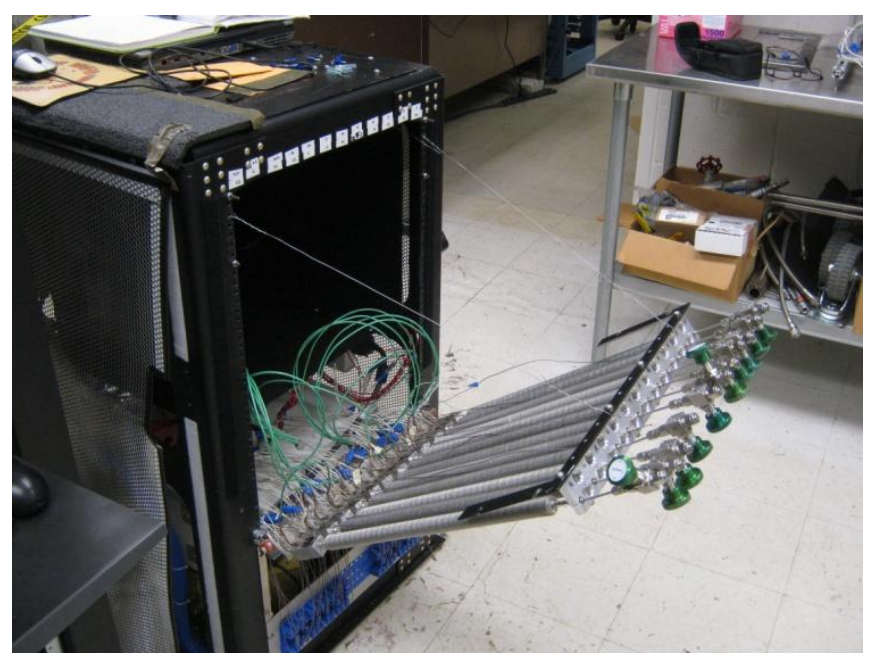

Figure 5a-1: Hinged Thermosyphon Rack

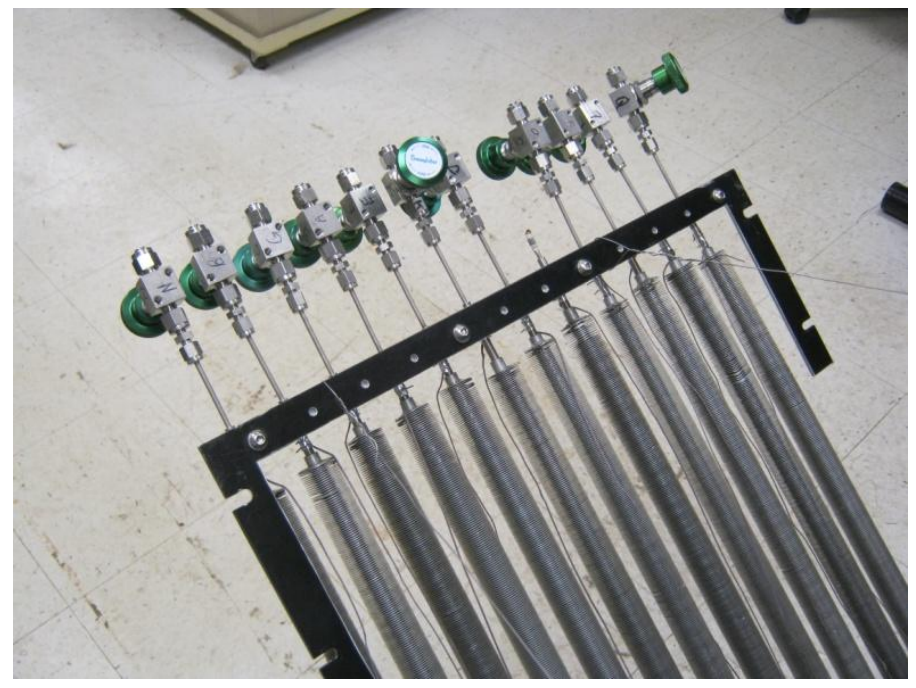

Figure 5a-2: Steel Bracket Attached to Top of Thermosyphon Rack 


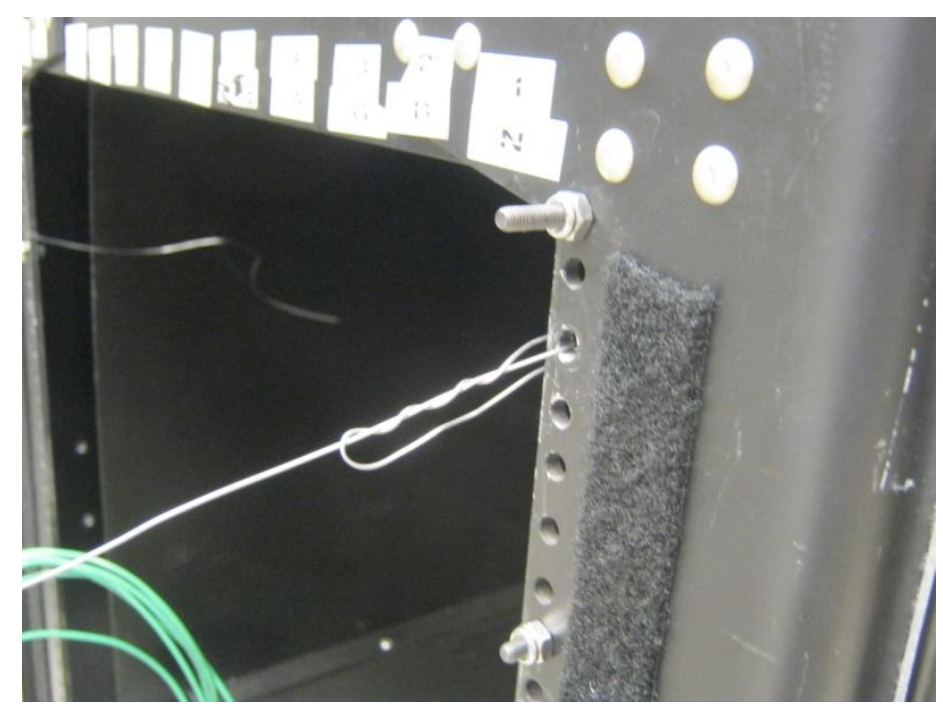

Figure 5a-3: Bolts for Fastening Steel Bracket to Overall Experiment Rack

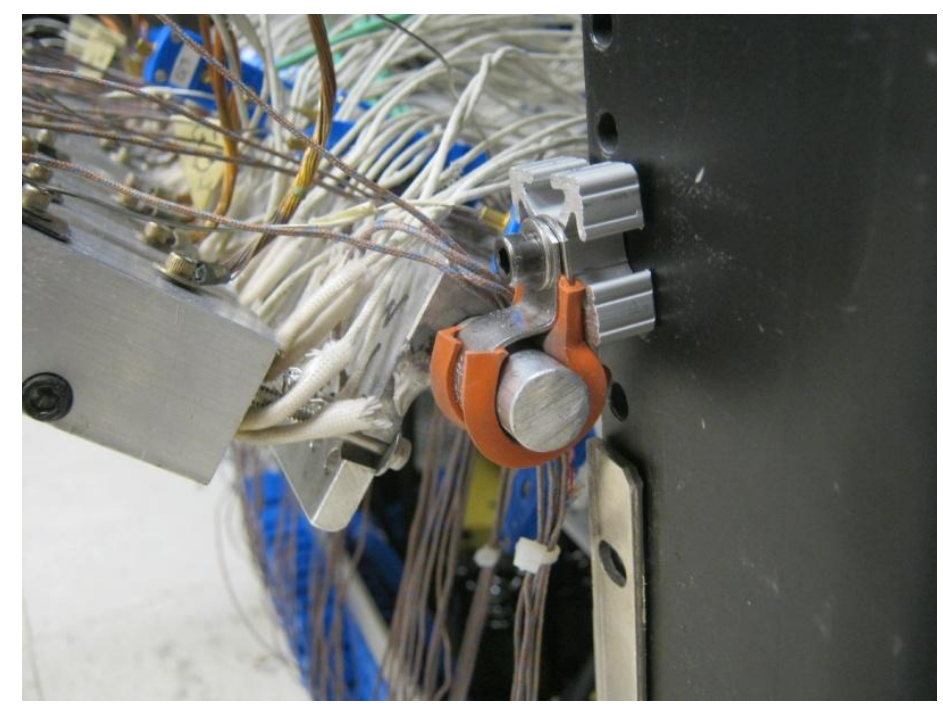

Figure 5a-4: Hinge Assembly at Lower End of Thermosyphon Rack 


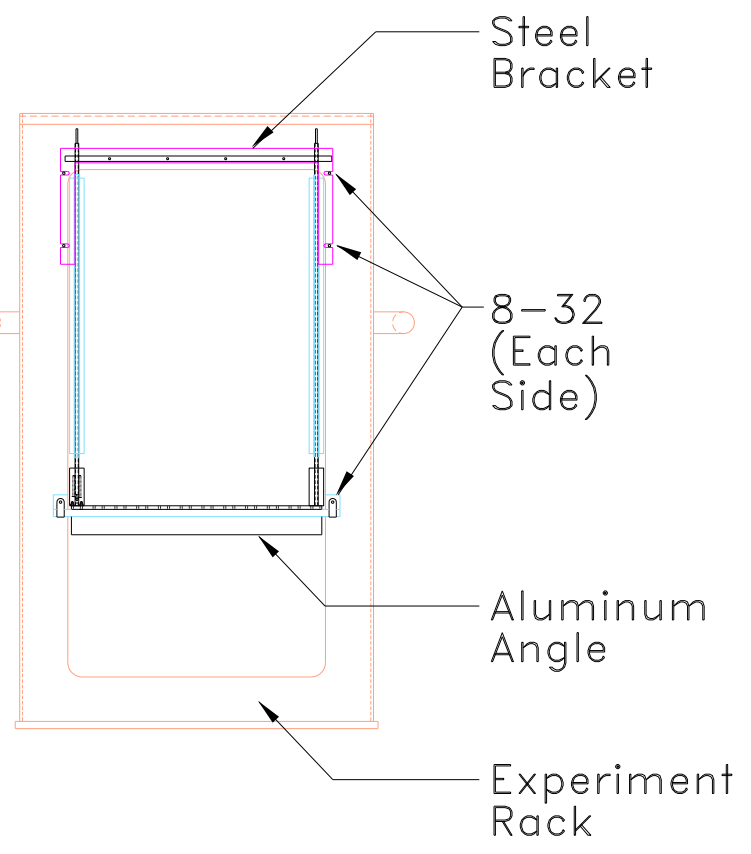

Figure 5a-4: Lateral View of Hinged Thermosyphon Rack on Experiment Rack

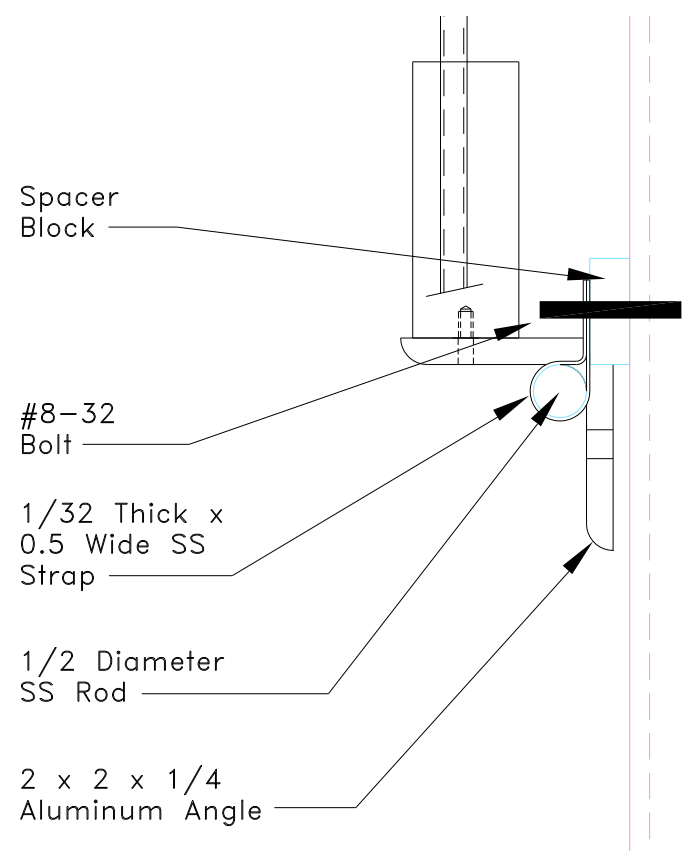


Figure 5a-5: Forward View of Hinged Thermosyphon Rack Hinge Assembly

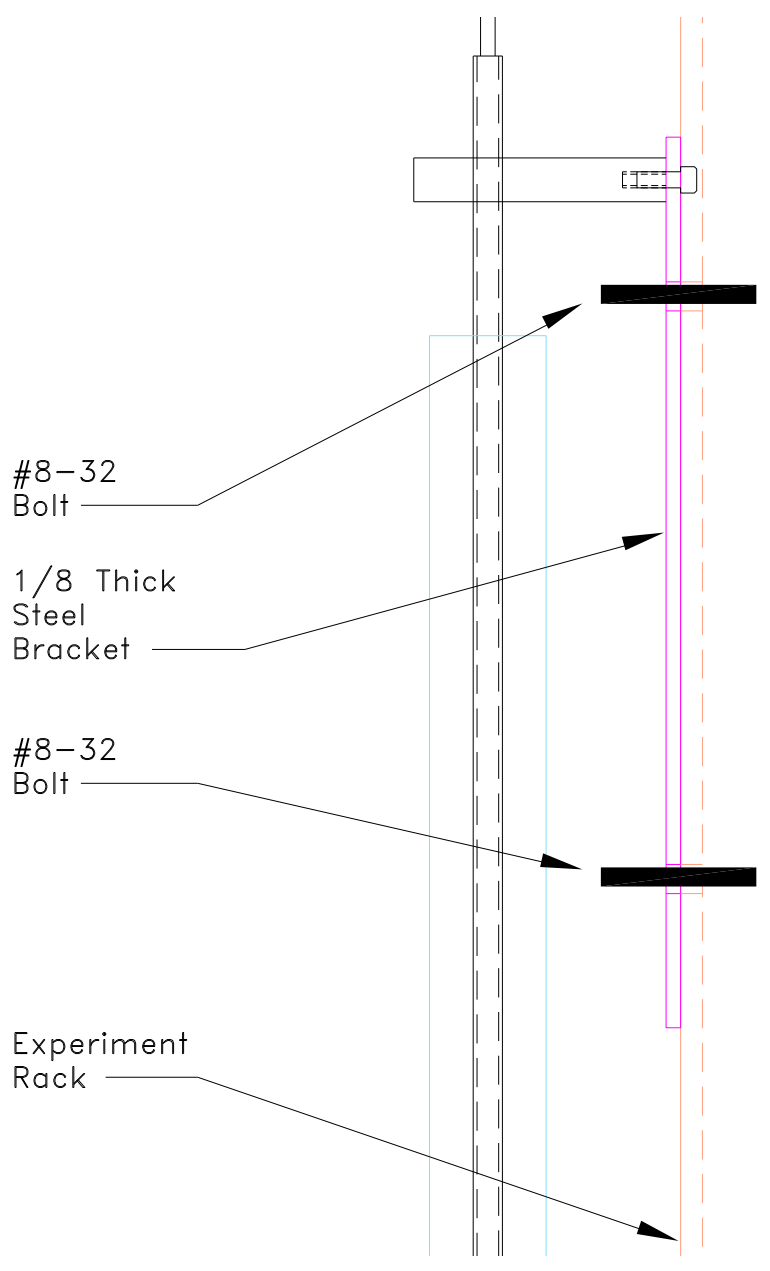

Figure 5a-6: Forward View of Upper Attachment of Hinged Thermosyphon Rack

As listed in Section 5, the Thermosyphon Rack weighs $15 \mathrm{lbs}$. The following table shows the margins of safety for each of the load cases considered. 


\begin{tabular}{|l|c|}
\hline 5a - 1) Hinged Thermosyphon Rack \\
\hline Center of Gravity at mid-height and mid-width of thermosyphon rack & Margin of Safety \\
\hline Case 1: Forward 9g, 6 \#8-32 thermosyphon rack screws in shear & 28 \\
\hline Case 2: Lateral 2g, 6 \#8-32 thermosyphon rack screws in tension & 27 \\
\hline Case 3: Forward 9g, $4 \sim \# 10-32$ bar screws in shear & 185 \\
\hline Case 4: Lateral 2g, $4 \sim \# 10-32$ bar screws in tension & \\
\hline
\end{tabular}




\section{ELECTRICAL ANALYSIS/VERIFICATION}

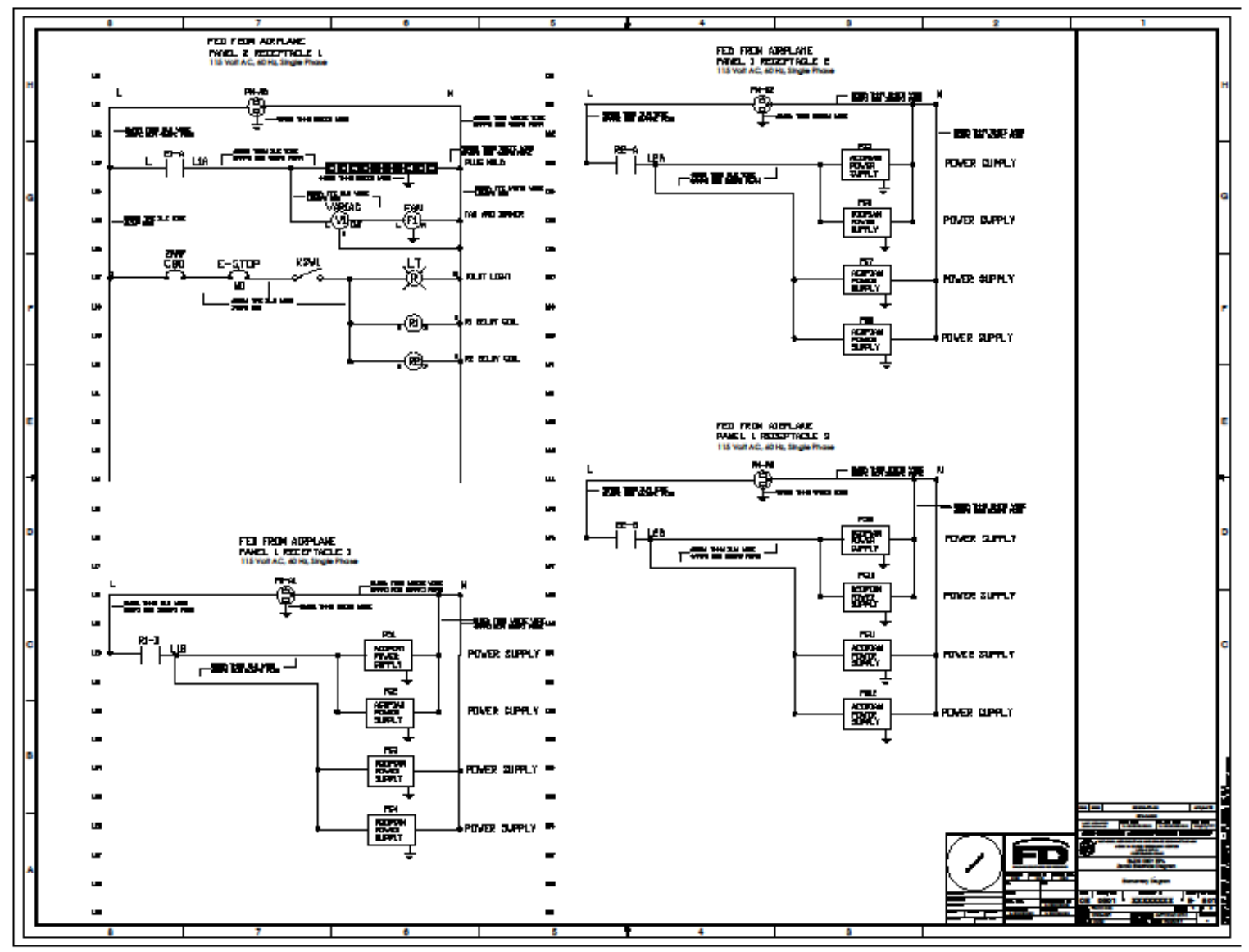




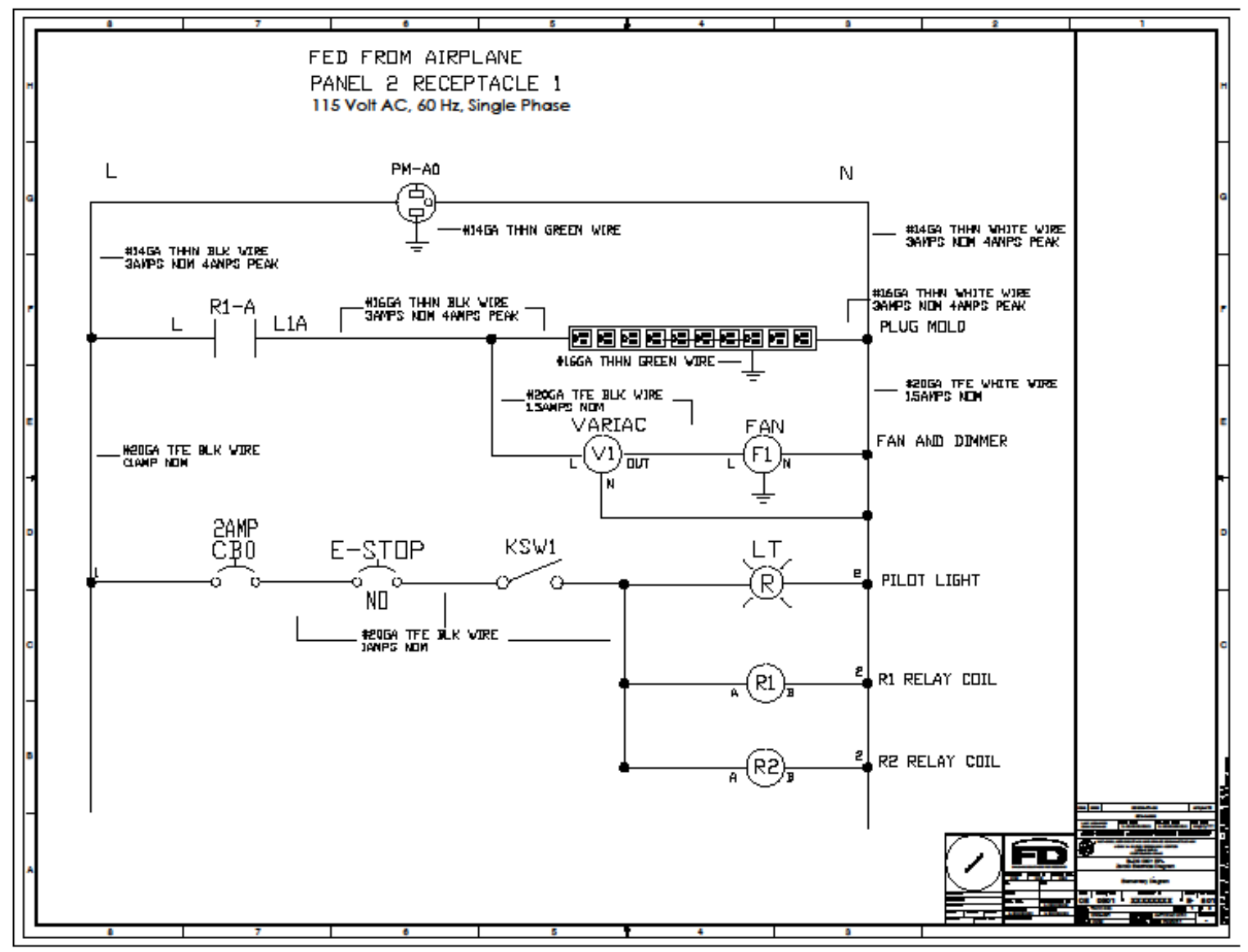




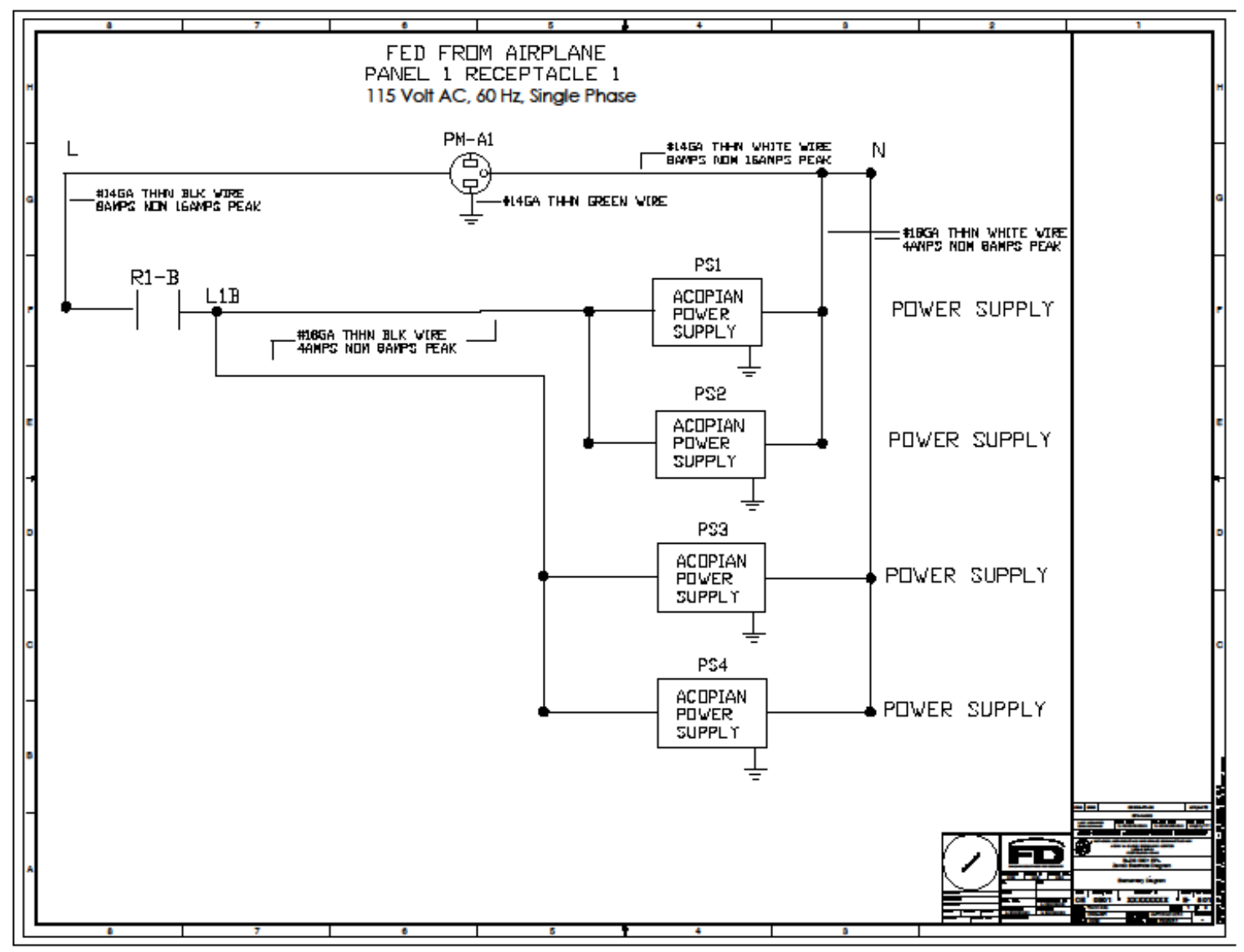




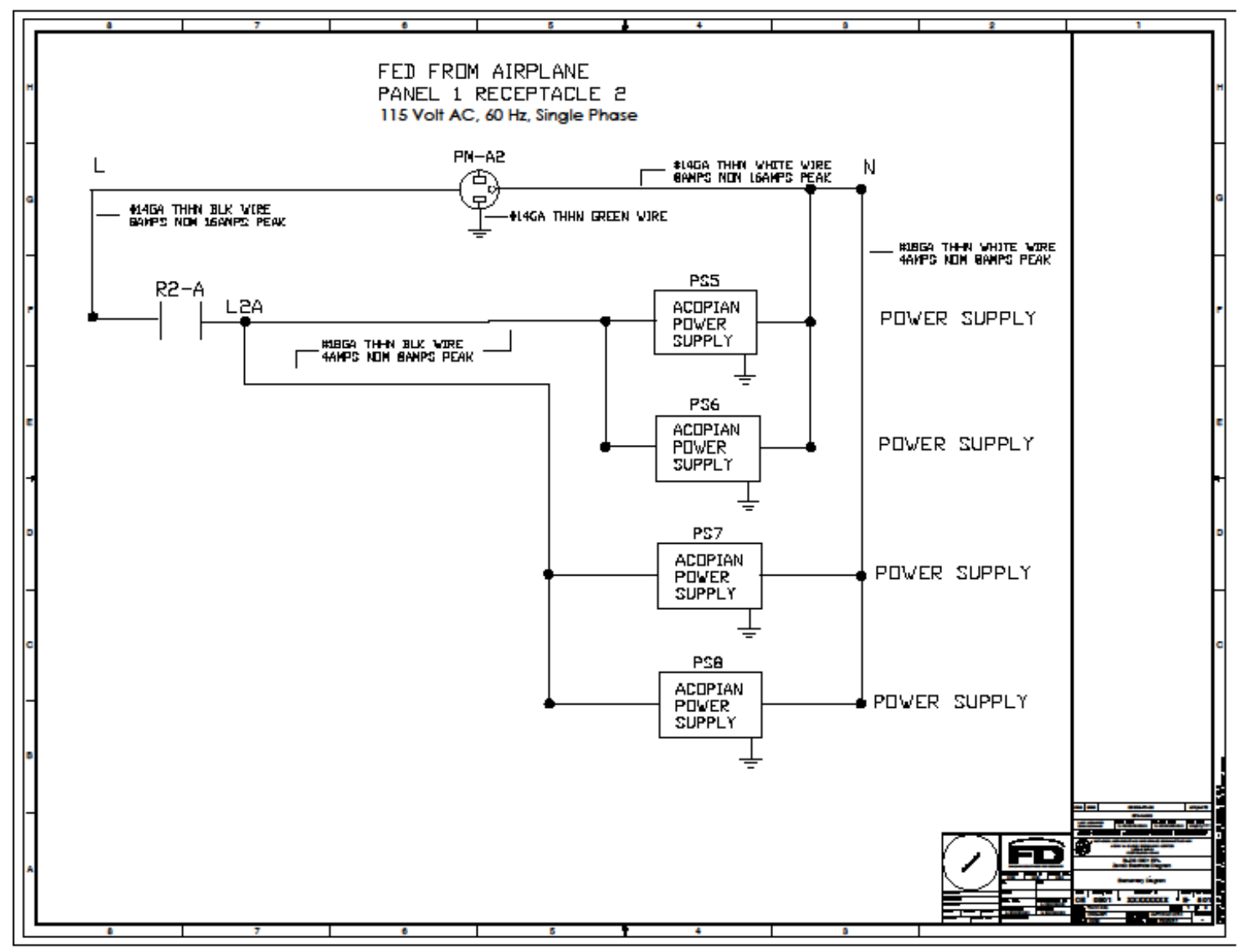




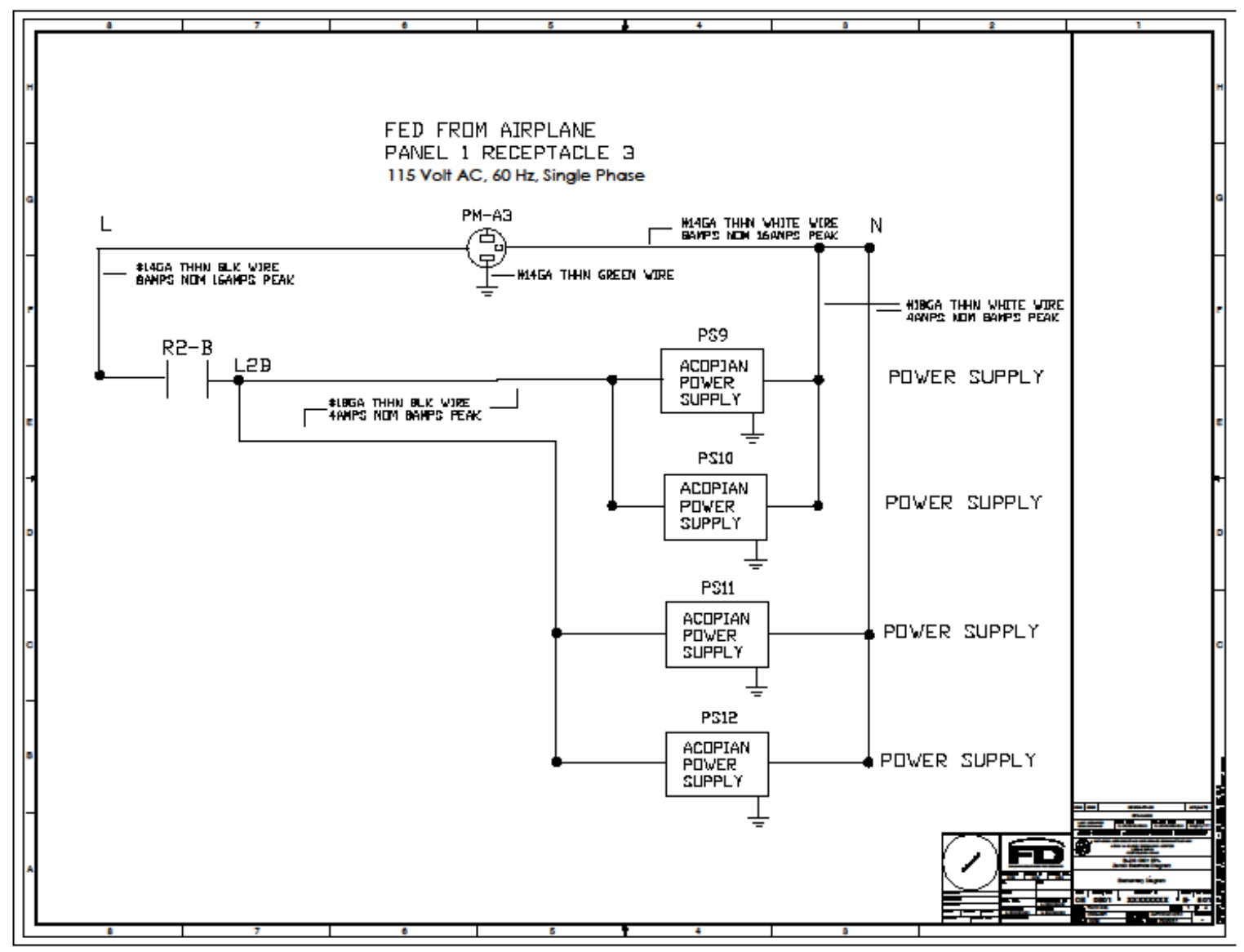




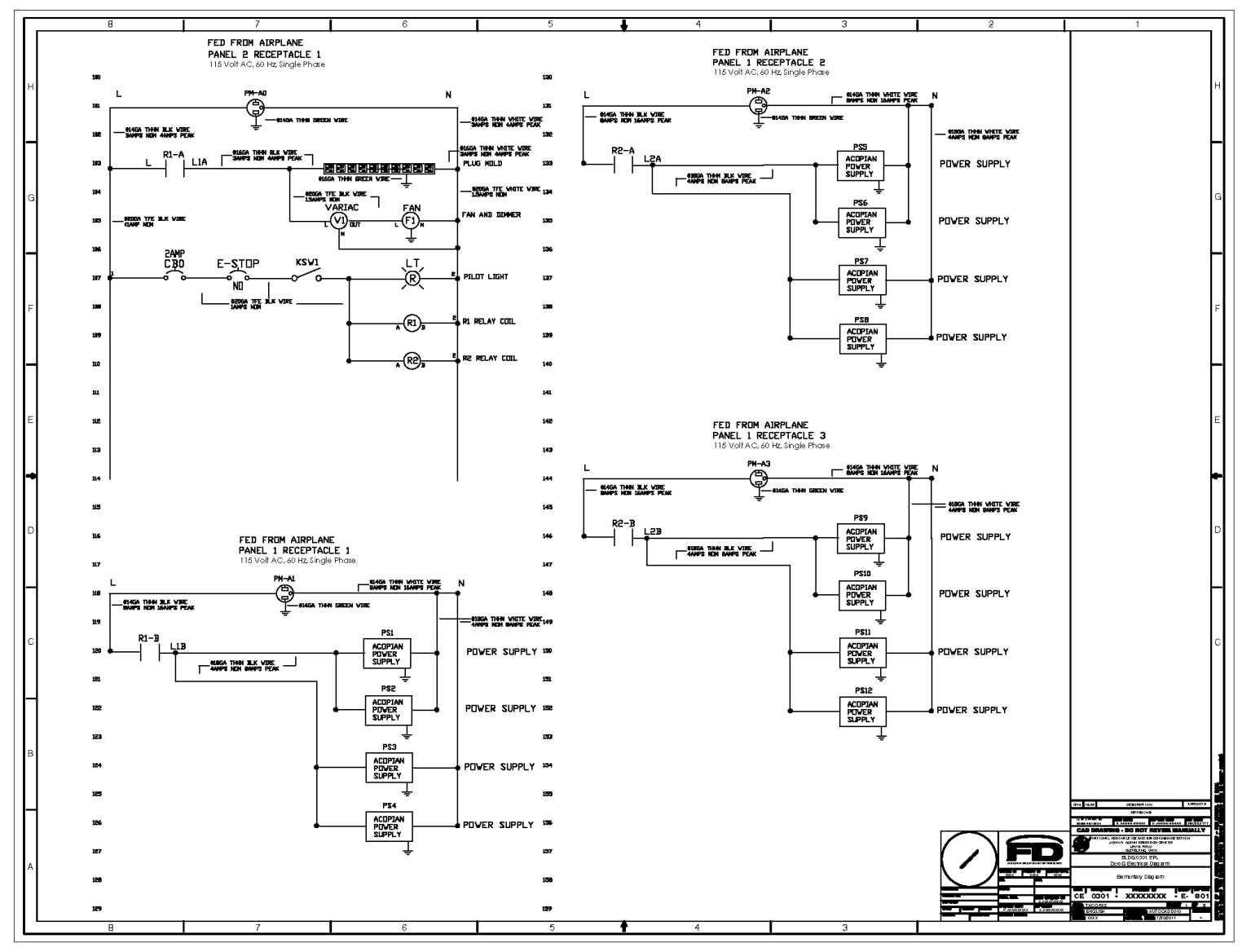




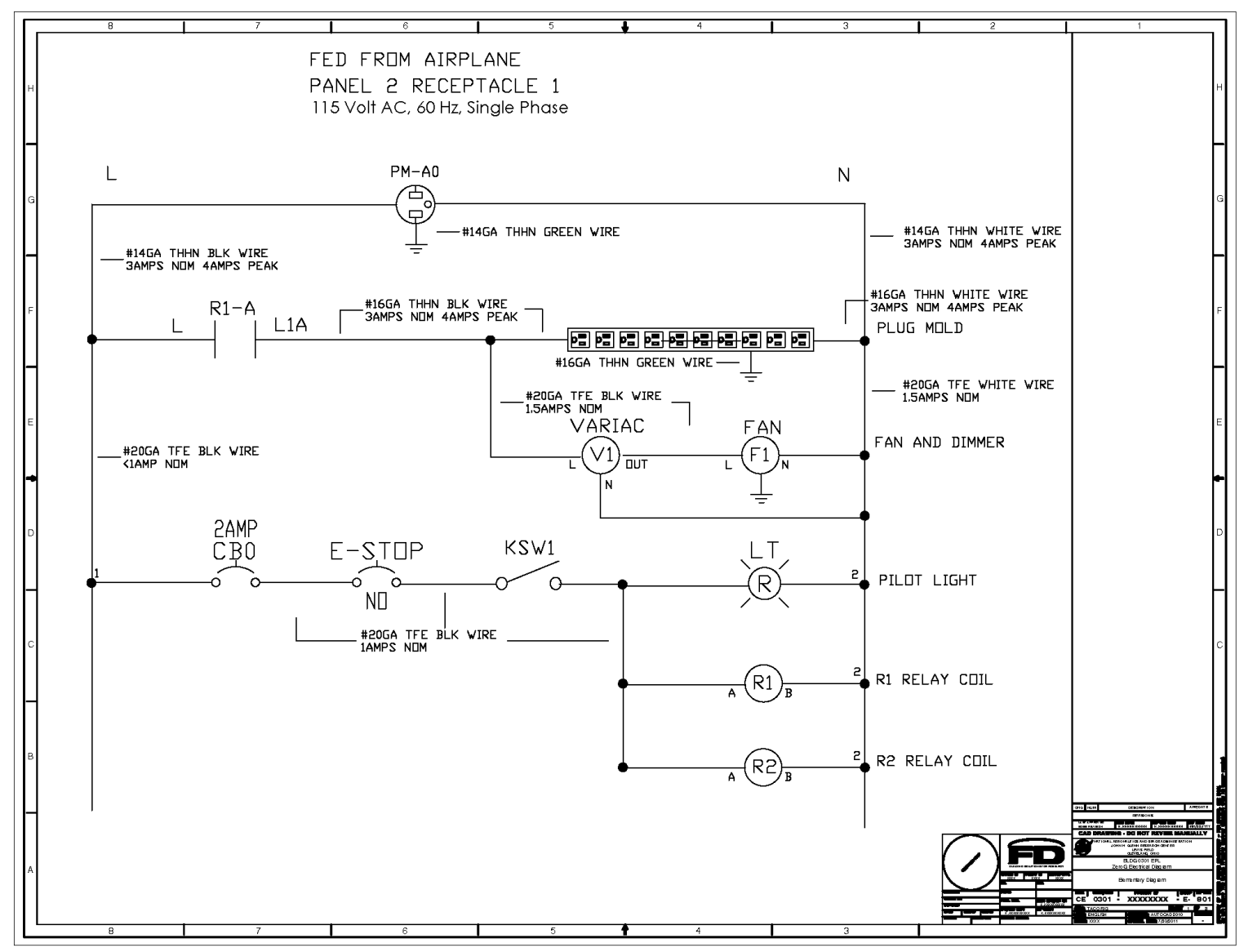




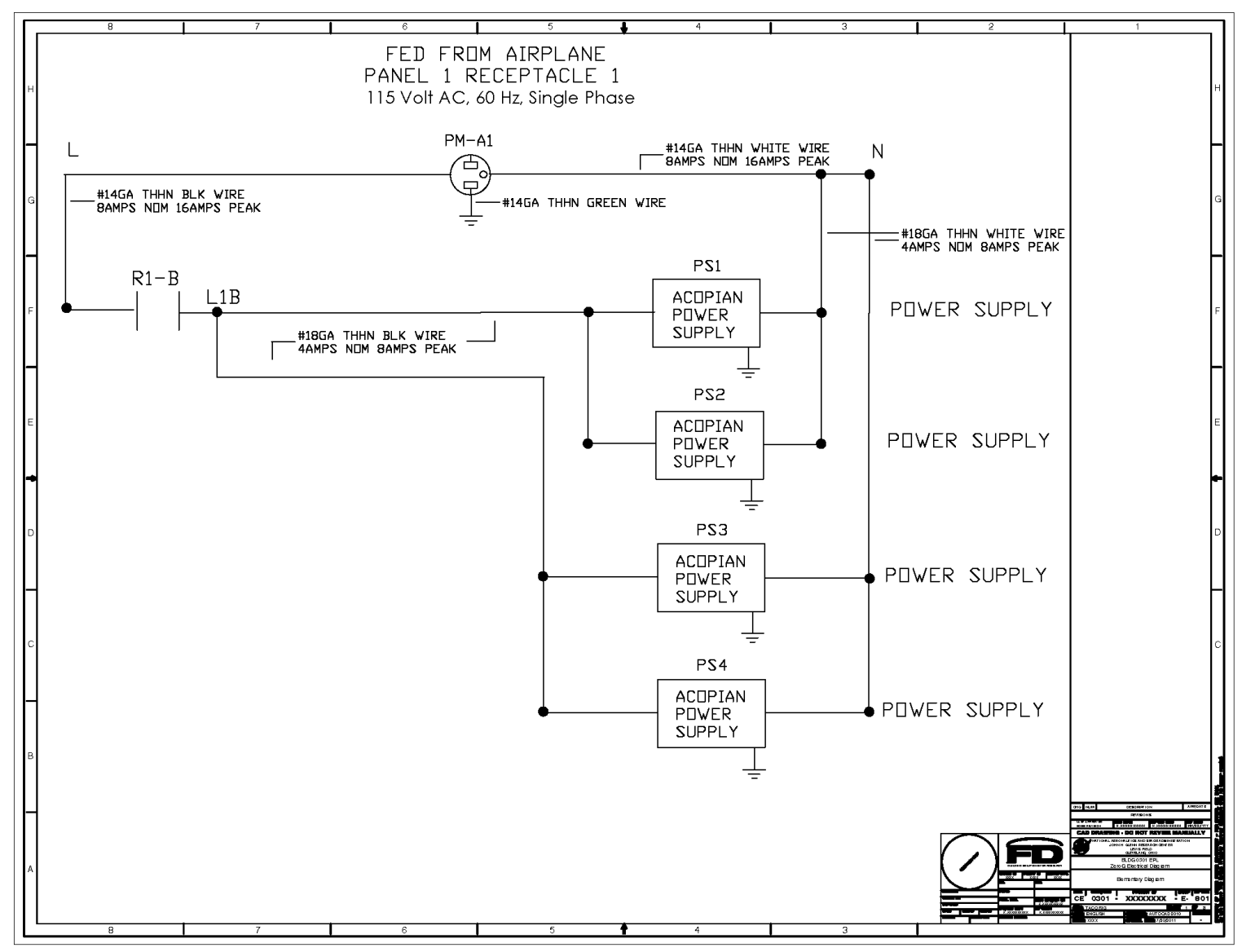




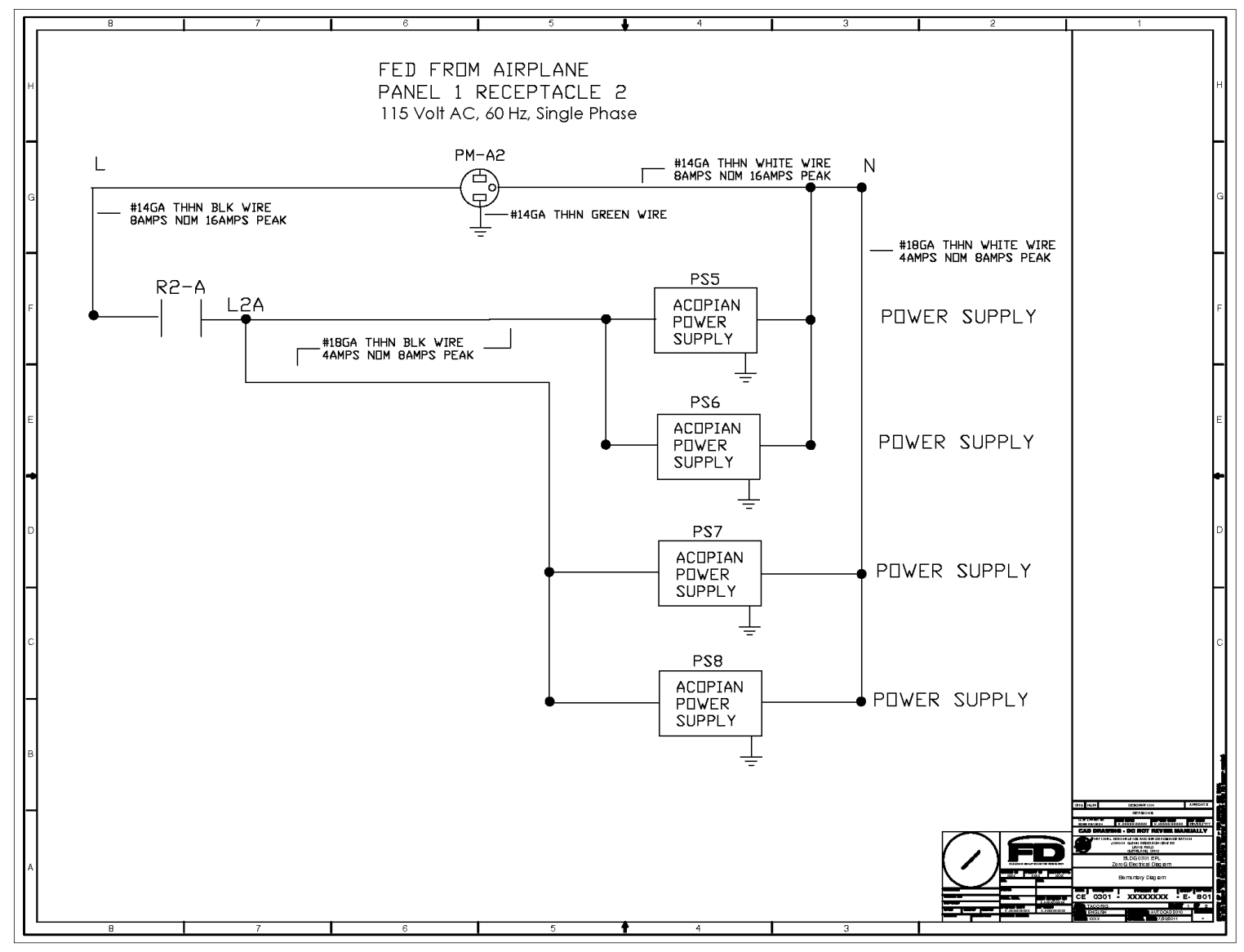




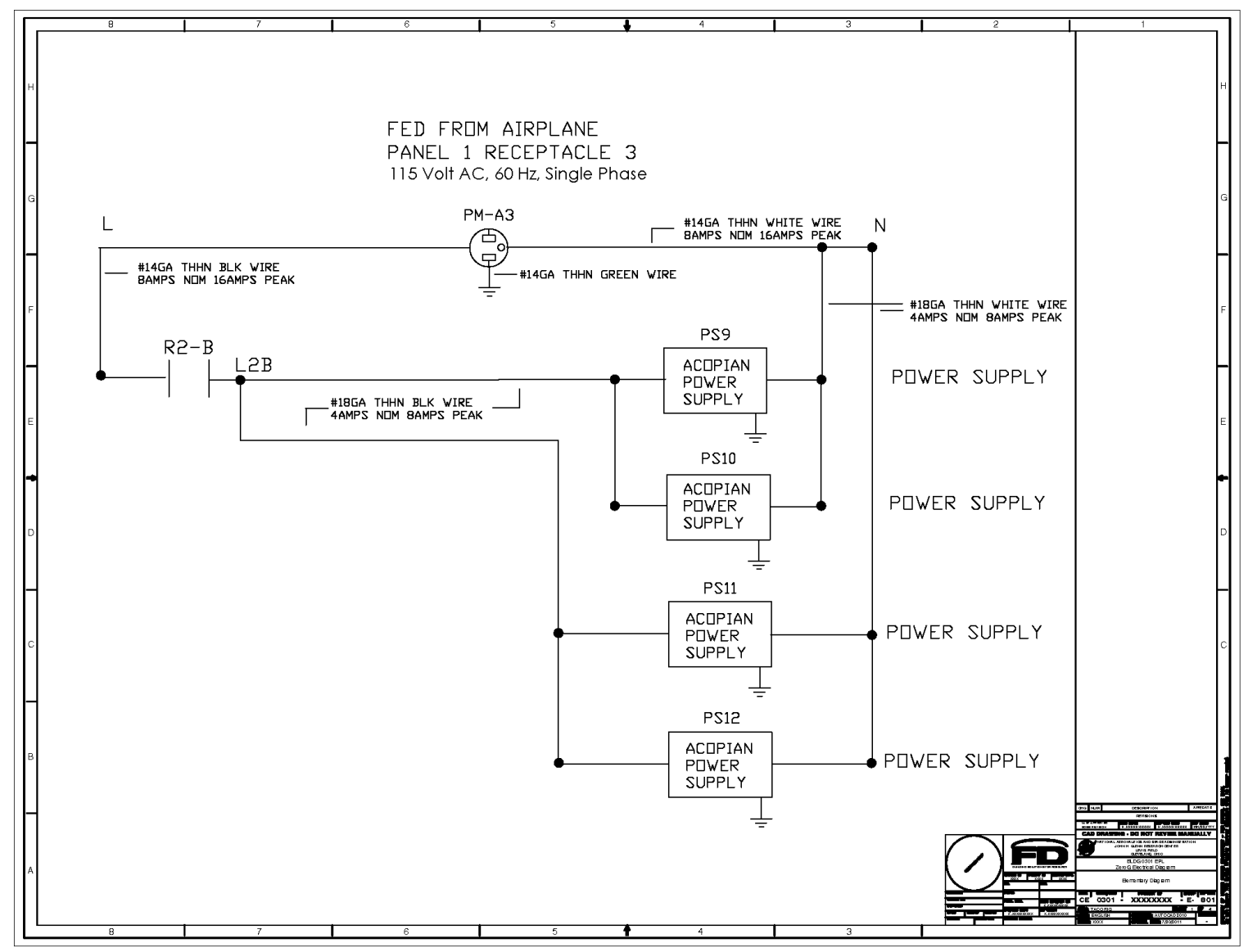

\section{$\underline{\text { LOAD TABLES }}$}

Table 1. Control Load Table

\begin{tabular}{|c|c|c|}
\hline \multicolumn{2}{|c|}{ Power Source Details } & Load Analysis \\
\hline Name & : Power Cord PM-A0 & NI-PXI Chassis \\
\hline Voltage & $: 115 \mathrm{VAC}, 60 \mathrm{~Hz}$ & Laptop Power Supply - 0.3 Amps \\
\hline \multirow[t]{2}{*}{ Wire Gauge } & $: 14$ & - 1.5 Amps \\
\hline & & EPAC Power Supply $\quad-0.2$ Amps \\
\hline Max Outlet C & rrent : $20 \mathrm{Amps}$ & Total Current Draw: 3.0 Amps \\
\hline
\end{tabular}

Table 2. Power Supply Array 1 Load Table 


\begin{tabular}{|c|c|}
\hline Power Source Details & Load Analysis \\
\hline : Power Cord PM-A1 & Acopian Power Supply 1 - 4 Amps \\
\hline$: 115 \mathrm{VAC}, 60 \mathrm{~Hz}$ & Acopian Power Supply $2-4$ Amps \\
\hline Wire Gauge $: 14$ & Acopian Power Supply 3 - 4 Amps \\
\hline & Acopian Power Supply 4 - 4 Amps \\
\hline Max Outlet Current : 20 Amps & Total Current Draw: 16.0 Amps \\
\hline
\end{tabular}

Table 3. Power Supply Array 2 Load Table

\begin{tabular}{|c|c|}
\hline Power Source Details & Load Analysis \\
\hline : Power Cord PM-A2 & Acopian Power Supply 5 - 4 Amps \\
\hline$: 115 \mathrm{VAC}, 60 \mathrm{~Hz}$ & Acopian Power Supply 6 - 4 Amps \\
\hline Wire Gauge $: 14$ & Acopian Power Supply 7 - 4 Amps \\
\hline & Acopian Power Supply 8 - 4 Amps \\
\hline Max Outlet Current : $20 \mathrm{Amps}$ & Total Current Draw: 16.0 Amps \\
\hline
\end{tabular}

Table 4. Power Supply Array 3 Load Table

\begin{tabular}{|c|c|c|}
\hline \multicolumn{2}{|c|}{ Power Source Details } & \multirow{2}{*}{$\begin{array}{l}\text { Load Analysis } \\
\text { Acopian Power Supply } 9 \text { - } 4 \text { Amps }\end{array}$} \\
\hline Name & : Power Cord PM-A3 & \\
\hline Voltage & $: 115 \mathrm{VAC}, 60 \mathrm{~Hz}$ & Acopian Power Supply 10 - 4 Amps \\
\hline \multirow[t]{2}{*}{ Wire Gauge } & $: 14$ & Acopian Power Supply 11 - 4 Amps \\
\hline & & Acopian Power Supply 12 - 4 Amps \\
\hline \multicolumn{2}{|c|}{ Max Outlet Current : 20 Amps } & Total Current Draw: 16.0 Amps \\
\hline
\end{tabular}




\section{$\underline{\text { STORED ENERGY }}$}

No stored electrical energy.

\section{ELECTRICAL KILL SWITCH}

There is an electrical kill switch for our experiment as is outlined in the equipment description.

\section{ELECTRICAL SHUTDOWN PROCEDURE}

Verify that the experiment or test sequence has been completed.

Set all the power supply Voltage Settings to "0" Volts.

Verify on the "Main" Display tab that the voltage, current, and power readings all read " 0 " for each heat pipe.

Verify that all the temperature readings begin to drop in temperature.

To speed up the cooling down procedure, turn the fan control fully clockwise to the full on position.

Verify that all the temperatures drop below 50 Degrees Celsius.

Turn the fan control fully counter-clockwise to the off position and verify the fans turn off.

Turn the key switch counter-clockwise to the off position.

Turn off the laptop computer.

\section{EMERGENCY SHUTDOWN PROCEDURE}

Push the E-STOP "kill switch" button and verify that everything turns off except the computer.

\section{LOSS OF ELECTRICAL POWER}

In the event of electrical power loss (expected, unexpected, or E-STOP), the experiment will fall to a safe position with the electrical power control to the 
heaters set to zero. Upon the return of electrical power, the experiment will be in an idle state with the power to the heaters off.

\section{PRESSURE VESSEL/SYSTEM}

The heat pipes were pressure tested for 490 psi.

Actual pressure anticipated at the $400 \mathrm{~K}$ operating temperature is approximately 60 psi.

\section{Pressure Test Report}

System: Thermo Siphon Array (TACO)

Date: January 13, 2012

The following items were both vacuum leak check and pressure proof tested.

Vacuum leak check was performed to the 8 scale. Pressure test was performed at 490psig.

PN \#

Vacuum Check

Pressure Check

1

2

3

4

5

6

7

8

9

10

11

$$
\text { OK }
$$

OK

OK

OK

OK

OK

OK

OK

OK

OK

OK

OK

$$
\text { OK }
$$

$$
\text { OK }
$$

OK

OK

OK

OK

OK

OK

OK

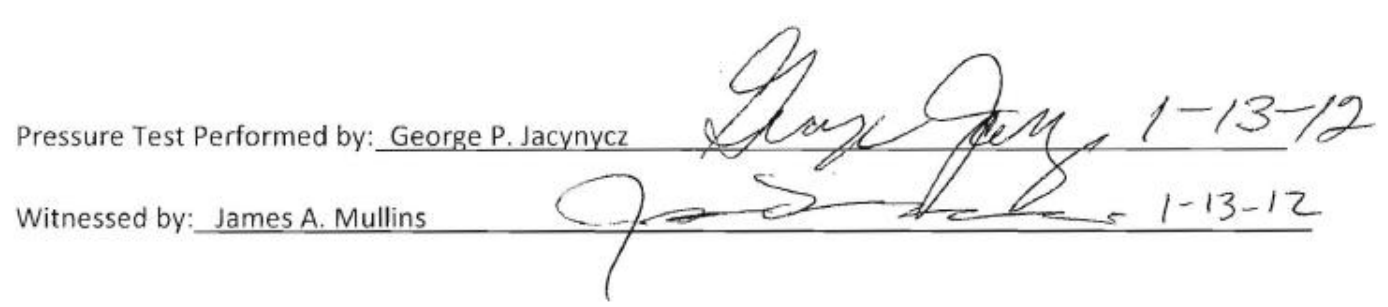




\section{PARABOLA DETAILS AND GROUND CREW ASSITANCE}

This experiment will take place over four flights with a focus on 1/6 $\mathrm{g}$ and zero $\mathrm{g}$ parabolas. Note: We prefer to have the $1 / 6 \mathrm{~g}$ parabolas grouped at the beginning of the flight day and the zero g parabolas grouped at the end of the flight day. It was found from the 2011 flight campaign that 12-15 lunar parabolas were required to get the heat pipe data needed for this research.

Ground Crew Assistance: None Required

In flight crew assistance: None Required

Free floating requirements: None 


\section{HAZARD ANALYSIS}

\begin{tabular}{|c|c|c|c|c|c|c|}
\hline HAZARD & CAUSE & EFFECT & $\begin{array}{c}\text { Sev/Prob } \\
\text { RAC }\end{array}$ & CONTROLS & VERIFICATION & $\begin{array}{l}\text { DISPOSITION } \\
\text { Sev Prob RAC }\end{array}$ \\
\hline $\begin{array}{l}\text { Electrical } \\
\text { Shock }\end{array}$ & $\begin{array}{l}\text { Short circuit } \\
\text { in test } \\
\text { equipment }\end{array}$ & $\begin{array}{l}\text { Burn, } \\
\text { shock } \\
\text { and/or } \\
\text { death }\end{array}$ & $\overline{\text { IA1 }}$ & $\begin{array}{l}\text { System designed } \\
\text { per NASA-STD- } \\
3000 \\
\text { Requirements. } \\
\text { All electrical } \\
\text { circuits } \\
\text { grounded }\end{array}$ & $\begin{array}{l}\text { Review of } \\
\text { Electrical } \\
\text { drawing. } \\
\text { GFCl installed in } \\
\text { electrical } \\
\text { circuitry }\end{array}$ & IE4 \\
\hline $\begin{array}{l}\text { Temperat } \\
\text { ure } \\
\text { Extremes }\end{array}$ & $\begin{array}{l}\text { Heat Pipes } \\
\text { Operate at } \\
400 \mathrm{~K}\end{array}$ & Burn & IIIA2 & $\begin{array}{l}\text { Overtemperatur } \\
\text { e Protection in } \\
\text { controls. } \\
\text { Physical barrier } \\
\text { prevents contact } \\
\text { between heat } \\
\text { pipes and } \\
\text { operators }\end{array}$ & $\begin{array}{l}\text { Review of Test } \\
\text { Equipment. }\end{array}$ & IIID5 \\
\hline Explosion & $\begin{array}{l}\text { Heat Pipe } \\
\text { Rupture } \\
\text { releases } \\
\text { steam. }\end{array}$ & $\begin{array}{l}\text { Burn, } \\
\text { noise }\end{array}$ & IIIA2 & $\begin{array}{l}\text { Temperature } \\
\text { control } \\
\text { prevents } \\
\text { temperature } \\
\text { excursions } \\
\text { which would } \\
\text { cause pressure } \\
\text { inside heat pipe } \\
\text { to exceed } \\
\text { pressure test } \\
\text { psi. }\end{array}$ & $\begin{array}{l}\text { Pressure Testing } \\
\text { Of heat pipes. } \\
\text { Controller } \\
\text { Verification } \\
\text { during ground } \\
\text { testing. }\end{array}$ & IIID5 \\
\hline
\end{tabular}




\section{TOOL REQUIREMENTS}

No special tool requirements.

\section{AIRCRAFT LOADING}

A forklift is preferred for loading/unloading. The unit is equipped with handles, but at $270 \mathrm{lbs}$., it is still heavy to manually carry with four people. The unit is also equipped with pneumatic casters for moving inside the fuselage that will need to be

removed before flight. Caster features are listed below.
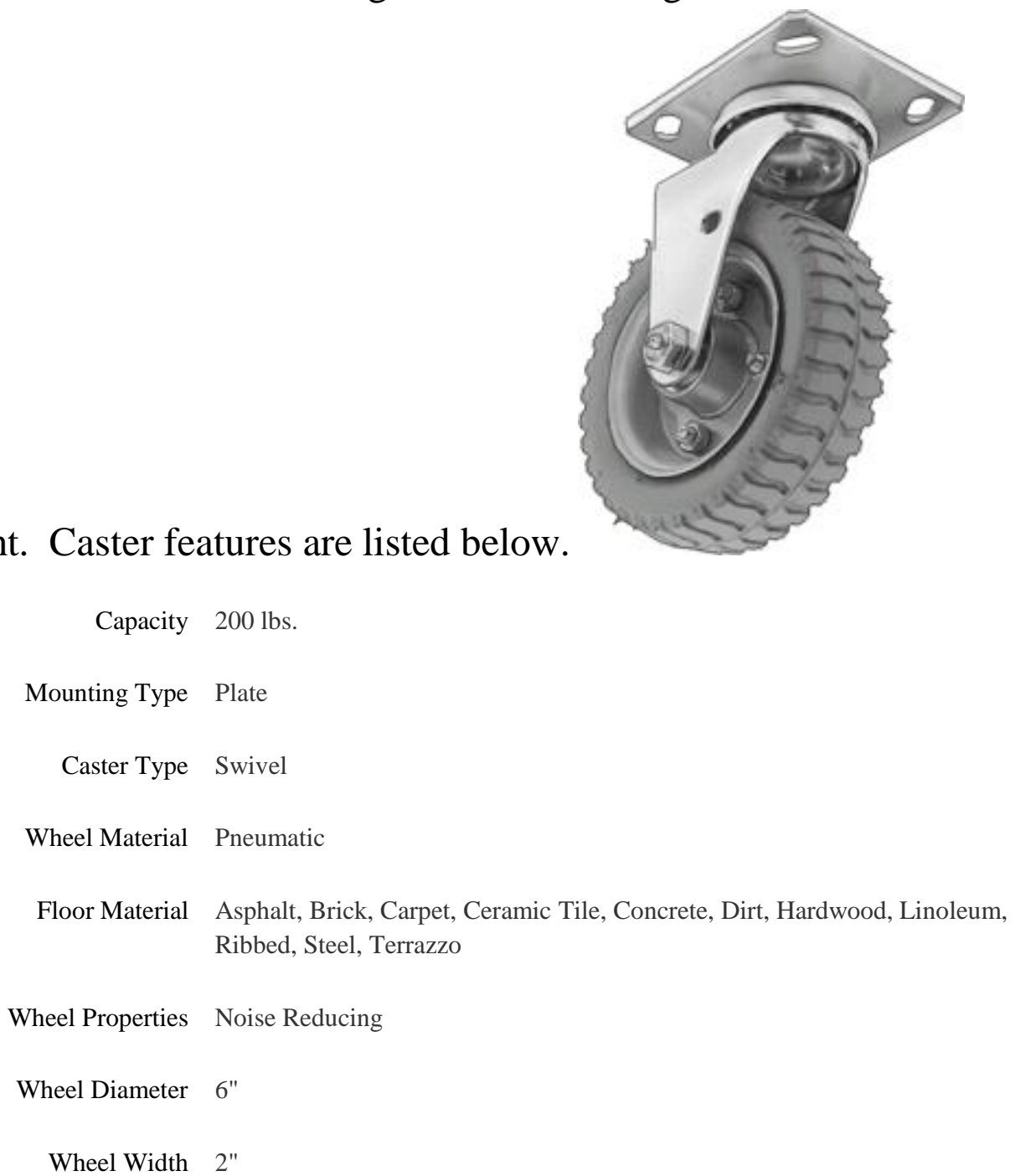


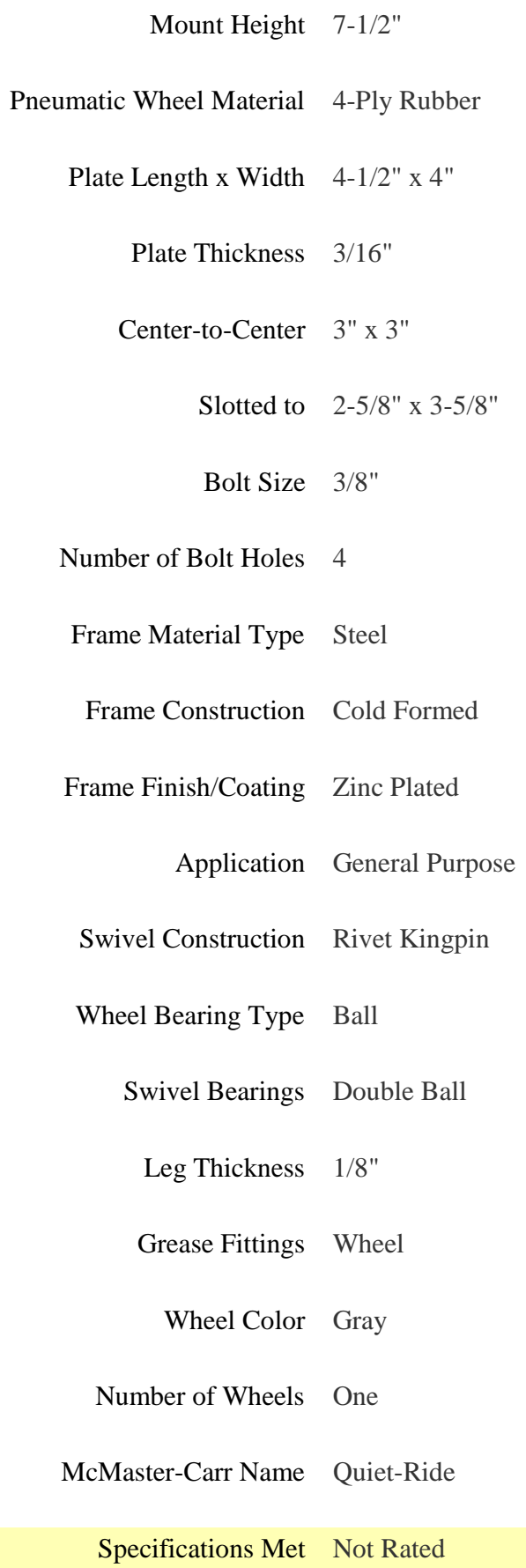

Caster installation will be achieved off of the shipping pallet by sliding the unit to the edge of the pallet and installing two casters, rotating and installing a third caster, and blocking the unit by tilting and inserting $2 \times 4$ and $4 \times 4$ wooden blocks under the unit to install the fourth caster. Caster removal in the fuselage will be 
achieved by tilting and inserting $2 \times 4$ and $4 \times 4$ wooden blocks under the unit with subsequent tilting and removal of the wooden blocks until the unit is at floor level.

\section{GROUND SUPPORT REQUIREMENTS}

Four 120v power outlets will be required on site in order to warm up the heat pipes. During the 2011 flight campaign, we were placed in the high bay were we could use the simulated aircraft power supplies which was needed for our special ground fault interrupter circuits listed above. 


\section{MATERIAL SAFETEY DATA SHEETS}

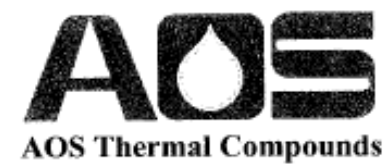

\section{MATERIAL SAFETY DATA SHEET}

SECTION 1: Chemical Product and Company Identification

Aavid VIS \# 000009, 000010

AOS Heat Sink COMnOLnd $000011,000012,022296$.

This is called Sil-Free Grease Series

Manufacturer:

AOS Thermal Compounds

22 Meridian Road, Suite 6

Eatontown, New Jersey 07724

(732) 389-5514
Product Code: 52022

Ref. Aavid p/n 101700F, 101800F, 101900F, 102000F, 101900F,

Emergency Telephone Numbers:

Health: (732) 389-5514 9-5 EST M-F

Flammability: (732) 389-5514 9-5 EST M-F

SECTION 2: Composition, Information on Ingredients

$\begin{array}{ll}\text { Zinc Oxide } & \\ 00840600 & \# 5000 \mathrm{P} \\ 00840600 & \# 5001 \mathrm{P} \\ 00840600 & \# 5002 \mathrm{P}\end{array}$

CAS Registry \#

1314-13-2

(Trade Secret)

(Trade Secret)

00840600 \# $\quad$ (Trade Secret)

- Based on the data available to $\mathrm{AOS}$, this product is not considered a hazard under OSHA Hazard Communication Standard 29 CFR1910.1200.

- The Zinc Oxide in this product is in paste form and will not pose a dust hazard.

\section{SECTION 3: Hazards Identification}

\section{Overview \\ Odorless white paste}

Potential Health Effects

- Eye: May cause irritation

- Skin: Prolonged exposure may cause irritation

- Ingestion: Unknown

- Inhalation: None known

\section{SECTION 4: First Aid Measures}

- Flush eye with water; wash skin. If ingested do not induce vomiting; consult a physician.

AOS Thermal Compounds

Tel. (732)389-5514 22 Meridian Road, Suite 6, Eatontown, NJ 07724 Fax (732)389-6380

$9 / 15 / 20030000$ Page 1 


\section{SECTION 5: Fire Fighting Measures}

- Flashpoint \& Method: $565^{\circ} \mathrm{F} / 296^{\circ} \mathrm{C}(\mathrm{COC})$

- Flammable Limits: LFL: Not determined/UFL: Not determined

- Autoignition Temperature: Not Available

\begin{tabular}{|lc|}
\hline \multicolumn{2}{|c|}{ NFPA } \\
\hline Fire & 0 \\
Health & 1 \\
Reactivity & 0 \\
Spec. Haz. & No \\
\hline
\end{tabular}

\begin{tabular}{|ll|}
\hline \multicolumn{2}{|c|}{ HMIS } \\
\hline Health & 1 \\
Flammability & 0 \\
Reactivity & 0 \\
PPI & \\
\hline
\end{tabular}

- Extinguishing Media: Foam, Carbon Dioxide, Dry Chemical

- Fire Fighting Instructions: Wear self-contained breathing apparatus for enclosed or confined areas

- Unusual Fire \& Explosion Hazards: None known

\section{SECTION 6: Accidental Release Measures}

- Collect product and repackage in a container.

\section{SECTION 7: Handling and Storage}

- Storage temperature: Ambieṇt

- Storage pressure: Atmospheric

- General: Keep container closed

\section{SECTION 8: Exposure Controls, Personal Protection}

- Respiratory Protection: Not necessary.

- Ventilation: Under normal conditions, no special ventilation is needed.

- Skin Protection: Gloves are not necessary.

- Eye Protection: Safety glasses are not necessary.

- Work/Hygienic Practices: Safety glasses \& gloves are recommended.

\section{SECTION 9: Physical and Chemical Properties}

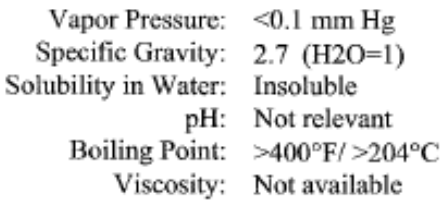

Vapor Pressure: $\quad<0.1 \mathrm{~mm} \mathrm{Hg}$ Specific Gravity: $2.7(\mathrm{H} 2 \mathrm{O}=1)$

Solubility in Water: Insoluble

$\mathrm{pH}$ : Not relevant

Boiling Point: $>400^{\circ} \mathrm{F} />204^{\circ} \mathrm{C}$

Viscosity: Not available

\author{
Vapor Density: Not relevant \\ Evaporation Rate: $<0.01$ (butyl acctate $=1$ ) \\ Freezing Point: Not relevant \\ Odor: Odorless \\ Appearance: White Paste
}

AOS Thermal Compounds

Tel. (732)389-5514 22 Meridian Road, Suite 6, Eatontown, NJ 07724 Fax (732)389-6380

9/15/2003 0000 Page 2 


\section{SECTION 10: Stability and Reactivity}

- General: Product is stable; hazardous polymerization will not occur.

- Materials \& Conditions to Avoid: Strong oxidizing agents.

- Hazardous Decomposition Products: None known.

\section{SECTION 11: Toxicological Information}

- Consult manufacturer for details. (See page 1)

\section{SECTION 12: Ecological Information}

- Consult manufacturer for details. (See page 1)

\section{SECTION 13: Disposal Information}

- Incinerate or dispose of materials in accordance with local, state \& federal regulations.

\section{SECTION 14: Transport Information}

- Not a hazardous material for DOT shipping.

\section{SECTION 15: Regulatory Information}

- All ingredients are on the Toxic Substances Control Act (TSCA) Inventory list or are not required to be listed. If you export this product, please ensure that the ingredients meet the inventory listing requirement of the receiving company.

\section{SECTION 16: Other Information}

- The information herein is presented in good faith and belicved to be accurate as of the revision date shown above. However, no warranty, expressed or implied, is given. It is the buyer's responsibility to ensure that its activities comply with federal, state or provincial, and local laws.

- This MSDS has been updated to conform to standards set forth by the Chemical Manufacturers Association as released through the American National Standard Institute. (See ANSI Z400.1-1993)

AOS Thermal Compounds

Tel. (732)389-5514 22 Meridian Road, Suite 6, Eatontown, NJ 07724 Fax (732)389-6380 9/15/2003 0000 Page 3 


\section{EQUIPMENT PROCEDURE DOCUMENTATION EQUIPMENT SHIPMENT}

Use of commercial transportation vendor (e.g FedEx) to Ellington Field.

\section{GROUND OPERATIONS}

As mentioned in the ground support requirements. We need access to 4, $115 \mathrm{VAC}$ outlets in order to warm-up the experiment before the flight.

\section{$\underline{\text { LOADING/STOWING }}$}

Loading:

A forklift is preferred to load/unload the experiment. The equipment rack is equipped with handle bars and removable pneumatic casters.

Stowing: Laptop Computer.

\section{$\underline{\text { PREFLIGHT }}$}

Preflight operations consist of warming up the heat pipes. 4, $115 \mathrm{VAC}$ outlets are required for preflight and flight operations. Switch from ground support power to aircraft power is acceptable. (Power down during takeoff is acceptable.)

\section{IN-FLIGHT CHECKLIST}

***Note: The entire experiment is contained within the equipment rack. Except for the fan control, it is entirely automated.

Pre-parabola:

- Turn on cooling fans

- Monitor temperatures \& heat pipe functionality

Parabola:

- Adjust cooling fan speed if necessary 
- Adjust heater power if necessary

- When heat pipes flood, turn off heaters via laptop Post-parabola:

- Turn cooling fans up to their maximum speed

- If heat pipes have returned to pre-flooded state, proceed to preparabola checklist.

- If heat pipes have not returned to pre-flooded state, wait for next parabola.

Emergency Procedures:

The heaters for each heat pipe have a circuit breaker that will trip if electrical problems arise. The entire experiment can be shutoff via the emergency stop button, which is located near the fan control and laptop (easily accessible). If the data acquisition system (DAS) detects a temperature that is too high on a specific heat pipe, it will automatically shut the heaters for that heat pipe down. The DAS will continue to function even if the laptop were to freeze up for whatever reason.

\section{POST FLIGHT CHECKLIST}

- Unload experiment from plane

- Download/Analyze data

\section{OFFLOADING OF EXPERIMENT}

The experiment will be removed from the plane using a forklift. As stated in the ground operations section, the experiment is equipped with handles and removable pneumatic casters for movement inside the fuselage. Caster installation will be achieved by tilting and inserting $2 \times 4$ and $4 \times 4$ wooden blocks under the unit. 


\section{EMERGENCY/CONTENGINCY}

Utilize Emergency Stop Button.

\section{Electrical Questionnaire}

For completion by research teams flying on RGO Aircraft through the Flight Opportunities Program

Please answer the following question with verified and measured parameters:

1. Organization Name: NASA GRC FP06

2. Contact Name:_ Marc Gibson Phone: $216-433-5562$

Email:__marc.a.gibson@nasa.gov

3. Aircraft Electrical Power Requirements (actual measured):

a. 115VAC: Normal Current: $16 \mathrm{~A}$ Max Current: $20 \mathrm{~A}$ Phase:__single

b. 28VDC: Normal Current: $\mathrm{N} / \mathrm{A}$ Max Current: $\mathrm{N} / \mathrm{A}$

4. Emergency Shut Down Capability with kill switch in easy access location? YES

5. Grounding: Exposed metal surfaces were adequately grounded to prevent electrical shock. $\mathrm{Y} / \mathrm{N}:$

6. Electromagnetic Compatibility:

a. Wireless device usage $\mathrm{Y} / \mathrm{N}: \mathrm{N}_{-}$; Model: N/A__ Manuf: $\mathrm{N} / \mathrm{A}$

b. Frequency: $\mathrm{N} / \mathrm{A}$ RF Transmit Power: N/A _ FCC approved: $\mathrm{Y} / \mathrm{N}: \mathrm{N}_{\text {_ }} \mathrm{A}_{-}$ 
c. Maximum voltage and current generate if applicable:__ 75VDC_ $3.8 \mathrm{ADC}$

d. Motor usage $\mathrm{Y} / \mathrm{N}$ : _ N/A _ Model: $N / A$ Brushed Motor $\mathrm{Y} / \mathrm{N}: \mathrm{N}_{\mathrm{N}}$ EMI checked $\mathrm{Y} / \mathrm{N}:{ }_{\text {__ _ }} \mathrm{N} / \mathrm{A}$

e. High voltage generator (spark)? Y/N:__ $\mathrm{N} / \mathrm{A}$

f. EMI checked $\mathrm{Y} / \mathrm{N}:[\mathrm{N} / \mathrm{A}$

7. Battery type: N/A Specification: N/A

8. Circuit breaker $\mathrm{Y} / \mathrm{N}: \mathrm{Y}_{\text {__ }}$ Specification:___ 2 and_4ADC_, 20A ELCl

9. Potential liquid in contact with electrical circuitry $\mathrm{Y} / \mathrm{N}:$ $N / A$

10. Identified other potential electrical hazard and safety that was not identified in the TEDP $\mathrm{Y} / \mathrm{N}: \ldots \mathrm{N}$ _ If yes, provide description

If you have questions, please contact: Cap V. Nguyen, cap.nguyen@nasa.gov 
Bibliography

1. Mason, Lee, Poston, David and Qualls, Louis. System Concepts for Affordable Fission Surface Power. Cleveland : NASA/TM, 2008. TM. 2008-215166.

2. Heat Transfer Characteristics in Two-Phase Closed Conventional And Concentric Annular

Thermosyphons. Faghri, A., Chen, M. M. and Morgan, M. Houston : ASME, 1998. 1988 National Heat Transfer Conference. pp. 291-303.

3. Entrainment Limits in Heat Pipes. Tien, C. L. and Chung, K. S. 1979, AIAA, pp. 643-646.

4. Wallis, G. B. One-Dimensional Two-Phase Flow. New York : McGraw-Hill, 1969.

5. Elements of Hydrodynamics of Gas-Liquid Systems. Kutateladze, S. S. 1972, Fluid Mechanics-Soviet Research, pp. 29-50.

6. The Hanging Film Phenomenon in Vertical Annular Two-Phase Flow. Wallis, G. B. and

Makkenchery, S. 1974, J. Fluids Eng., pp. 297-298.

7. Critical heat flux in two phase closed thermosyphons. Imura, H., et al. 1983, J. Heat Mass Transfer, pp. 1181-1188.

8. Dunn, P D and Reay, D A. Heat Pipes. New York : Pergamon Press Inc., 1982.

9. Theory of the Ultimate Heat Transfer Limit of Cylindrical Heat Pipes. Busse, C. A. 1973, Int. J. Heat Mass Transfer, pp. 169-186.

10. Faghri, Amir. Heat Pipe Science and Technololgy. New York, NY 10001 : Taylor and Frances, 1995.

11. Vapor Flow Considerations in Conventional and Gravity-Assisted Heat Pipes. Kemme, J. E.

Bologna : s.n., 1976. Proc. 2cd Intl. Heat Pipe Conf. pp. 11-22.

12. Theorecticl Investigation of Heat Pipes Operating at Low Vapor Pressures. Levy, E. K. 1968, ASME

J. Engineering Industry, Vol. 90, pp. 547-552.

13. A Visualization Study of Flooding and Entrainment in a closed Two-Phase Thermosyphon. Shatto, D.

P., Besly, J. A. and Peterson, G. P. New Orleans, LA : AIAA, 1996. 31st Thermophysics Conference.

14. Performance Limits of Gravity-Assisted HEat Pipes. Prenger, F. C. 1984, Proc. 5th Int. Heat Pipe

Conf. , pp. 1-5.

15. An analytical study on the critical heat flux of countercurrent boiling in a vertical tube with a closed bottom. Katto, Y. and Watanabe, K. 1992, Int. J. Heat Mass Transfer, pp. 3021-3028.

16. Summary of the Manufacture, Testing, and Model Valication of a Full-Scale Radiator for Fission

Surface Power Applications. Ellis, David, Calder, James and Siamidis, John. Albuquerque : s.n., 2011.

Proc. of Nuclear and Emerging Technologies for Space. 